Forsan et haec olim meminisse juvabit

(Vergilius) 

Katholieke Universiteit Leuven

Group Biomedical Sciences

Faculty of Medicine

Center for Molecular and Vascular Biology and

Departement of Plastic Surgery

\title{
INTEGRATION OF BLOOD OUTGROWTH ENDOTHELIAL CELLS IN DERMAL FIBROBLAST SHEETS PROMOTES FULL THICKNESS WOUND HEALING
}

\author{
Benoit Hendrickx
}

Цury:

Chair:

Prof. Dr. B. Topal

Jurymembers:

Prof. Dr. D. McGrouther

Prof. Dr. L. Steinstraesser

Prof. Dr. M. Garmyn

Prof. Dr. M. Dewerchin

Prof. Dr. A. Luttun (promoter)

Prof. Dr. Jan J. Vranckx (co-promoter)

Prof. Dr. P. Broos (co-promoter) 



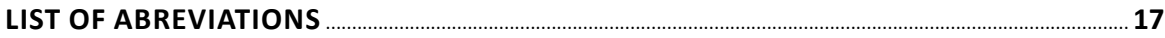

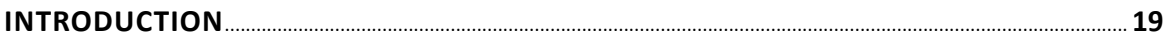

1. SKIN TISSUE ENGINEERING: TIME FOR SOMETHING NEW...................................................................... 21

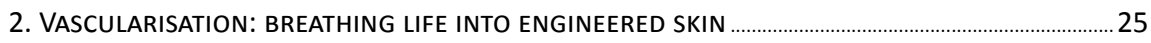

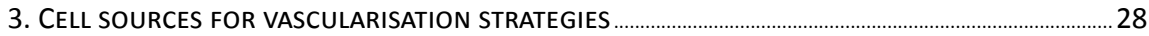

3.1. Mature endothelial cells ............................................................................................................... 29

3.2. Unipotent progenitor cells: Endothelial Progenitor Cells (EPC) ....................................31

3.3. Multipotent progenitor cells .................................................................................................. 33

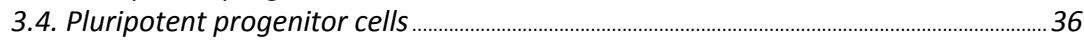

4. IN BETWEEN SAFETY AND AMBITION: BOEC, THE IDEAL SON-IN-LAW? ............................................... 37

5. GROWTH FACTOR CROSS-TALK IN WOUND HEALING: A CONFERENCE CALL BETWEEN WOUND

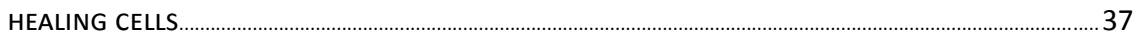

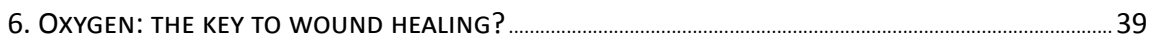

7. FIBROBLASTS: MORE THAN JUST A DERMAL MATRIX FACTORY ………….............................................. 40

8. BOEC AND FIBROBLASTS: DO THEY GO TOGETHER LIKE A HORSE AND CARRIAGE? ........................... 41

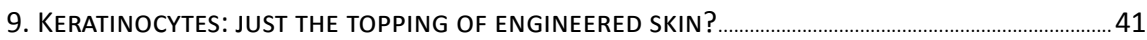

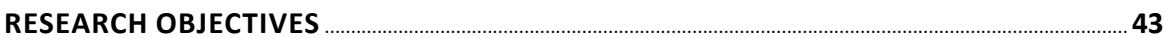

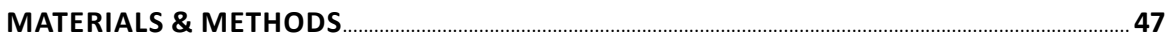

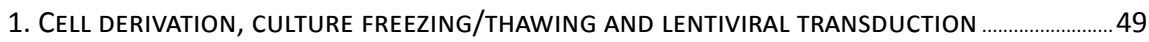

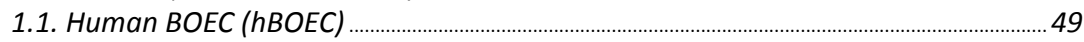

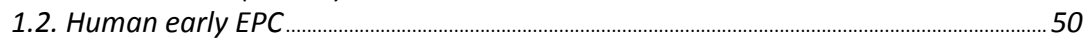

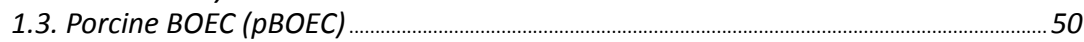

1.4. HUVEC

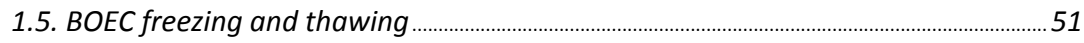

1.6. $h B O E C$ and HUVEC lentiviral transduction .............................................................................. 51

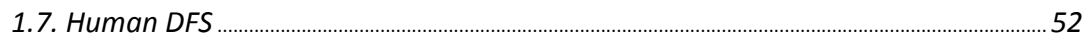

1.8. Human $(h)$ Keratinocytes ................................................................................................................ 53

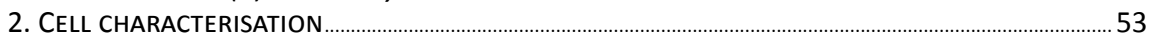

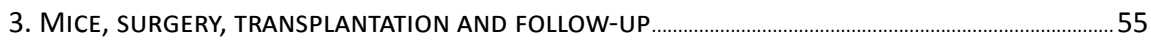

4. LIVE IMAGING AND WOUND MORPHOMETRY ....................................................................................... 56

5. TISSUE PROCESSING, HISTOLOGY AND MICROSCOPY....................................................................... 57

6. VISUALISATION OF BOEC AND HUVEC ENGRAFTMENT ...................................................................... 58

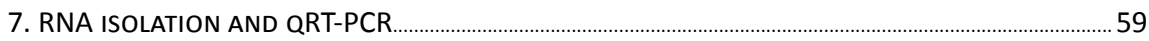

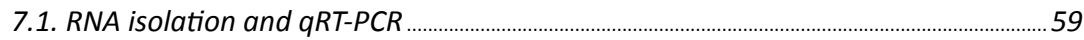

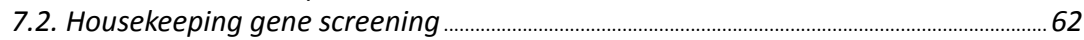

8. CYTOKINE PRODUCTION, CELL PROLIFERATION/MIGRATION ASSAYS .....................................................63

8.1. Cytokine production, zymography and Western blotting ……........................................63

8.2. Cell proliferation/migration ......................................................................................................... 64

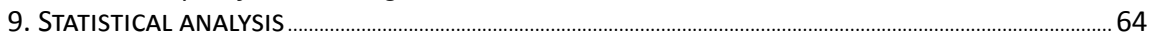

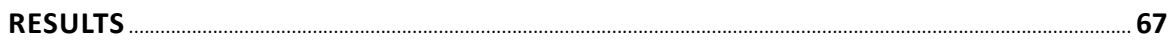

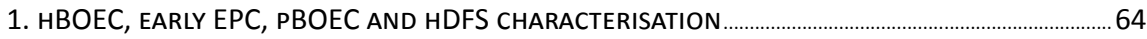

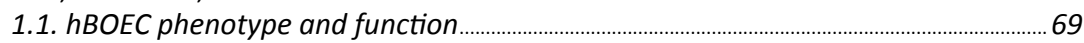

1.2. Early EPC phenotype and function ………............................................................................ 70

1.3. hDFS structure and function ................................................................................................ 72 



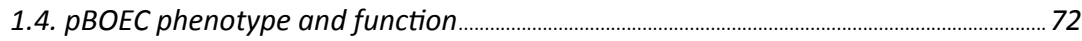

1.5. $h B O E C$, hDFS and $p B O E C$ growth factor production .............................................................. 75

2. HBOEC, UNLIKE HUVEC, INDUCE ROBUST WOUND VASCULARISATION AND RE-OXYGENATION...... 78

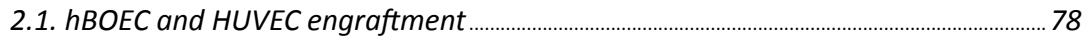

2.2. Effect of $h B O E C$ and HUVEC on vascularisation and re-oxygenation...........................82

2.3. hBOEC, unlike HUVEC, improve dermal matrix organisation and accelerate

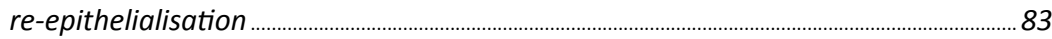

3. HBOEC STIMULATE HEALING BY IMPROVING OXYGENATION AND BY GROWTH FACTOR CROSS-TALK ... 85

3.1. Effect of oxygenation ...................................................................................................................... 85

3.2. Effect of growth factor cross-talk

4. HBOEC IMPROVE MATRIX ORGANISATION AND RE-EPITHELIALISATION OF HDFS IN WOUNDS........88

4.1. Effect of hDFS (+/- hBOEC) on wound contraction and re-epithelialisation .............88

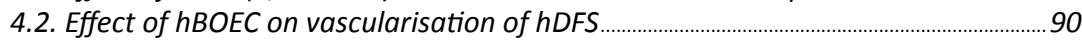

4.3. Effect of $h B O E C$ on matrix organisation in and re-epithelialisation of hDFS...........91

5. EFFECT OF PLGF ON KERATINOCYTES AND HDFS ................................................................................. 92

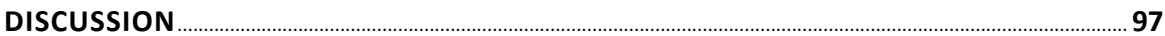

1. BOEC, AN ALL-ROUND PLAYER IN WOUND HEALING ………..................................................................... 97

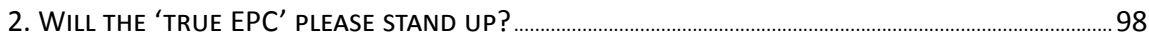

3. ON THE ORIGIN OF 'TRUE EPC'

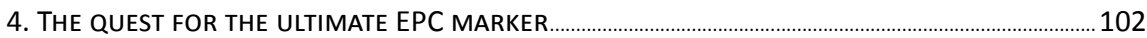

5. BACK TO THE BASICS OF WOUND HEALING: VASCULARISATION AND OXYGENATION.......................104

6. BOEC: CONDUCTOR OF THE WOUND HEALING CYTOKINE ORCHESTRA? ............................................ 104

7. DERMAL MATRIX ORGANISATION AS A BENCHMARK FOR DERMAL MATURATION............................107

8. DFS-BOEC MARRIAGE: WILL IT STAND THE TEST OF TIME? .............................................................. 109

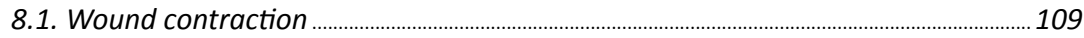

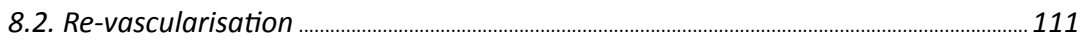

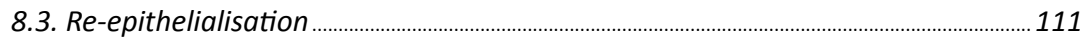

8.4. Dermal matrix deposition and organisation ......................................................................... 112

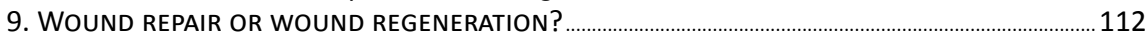

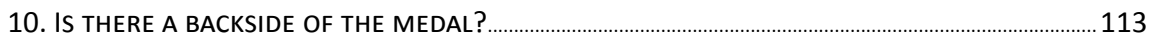

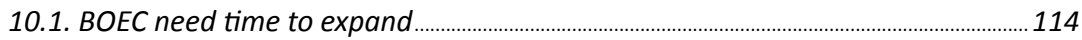

10.2. The need for animal-related ingredients for cell-based tissue engineering?....114

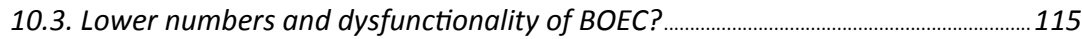

10.4. Off-target vascularisation or tumour formation by BOEC? ..........................................116

CONCLUSIONS \& PERSPECTIVES

1. A VASCULARISED THREE-DIMENSIONAL SKIN SUBSTITUTE FOR CLINICAL USE: ARE WE THERE YET?.120

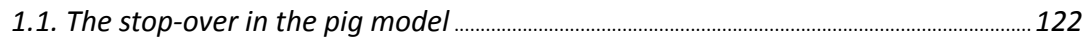

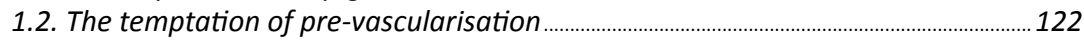

1.3. Digging deeper into engineered skin ........................................................................................... 122

1.4. Lymphatic vessels: the often neglected counterparts of blood vessels ....................123

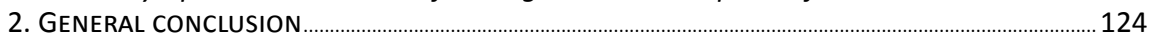

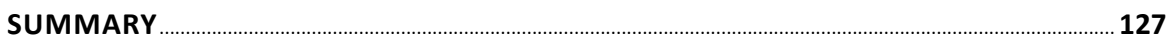

LIST OF REFERENCES

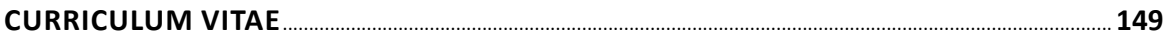





\title{
Think where man's glory most begins and ends And say my glory was I had such friends.
}

\author{
(William B. Yeats)
}



Dit is niet de doctoraatsthesis van Benoit Hendrickx.

Laat $u$ niet misleiden door wat er op de voorpagina staat, dit is niet mijn proefschrift. Het is het verslag van een 4 jaar durende tocht waarin velen hebben meegelopen, soms zelfs het hele parcours. Een parcours met hoogtes en laagtes, zeker, en alle inspanningen die nodig waren om van laag naar hoog te gaan. Een parcours dat je niet alleen loopt. Dat je niet alleen kan lopen. Het is het verhaal van gebundelde kracht, van een gemeenschappelijk project dat uiteindelijk vrucht heeft gedragen en waarvan de naam die op de voorpagina staat eigenlijk niet meer is dan een gemeenschappelijke noemer.

\section{Daarom dank ...}

Dank aan de vertegenwoordigers van onze Alma Mater, Prof. Marc Waer, rector van de KULeuven, Prof. Minne Casteels, vicerector van de groep biomedische wetenschappen en Prof. Bernard Himpens, decaan van de faculteit geneeskunde, om deze doctoraatsthesis voor te dragen. Ik ben ook dank verschuldigd aan het Fonds voor Wetenschappelijk Onderzoek Vlaanderen, voor het toekennen van een aspirantmandaat en op die manier dit doctoraatswerk te ondersteunen. Zoals het in de 16 e eeuw al klonk: 'Gold that buys health can never be ill spent'.

Thanks to the foreign jury members, who both belong to the absolute European top in plastic surgery as well as in research, to come over to Belgium. Prof. McGrouther, it really is an honour to me to have you as a jury member. Thank you for the critical reading of the manuscript and the helpful comments. Lars, thank you for all your support throughout the years, thanks for all the beers, fags and laughs we've shared in so many places on earth, I hope Bochum will only get closer to Leuven in the future! Dank ook aan de andere jurymeden, Prof. Garmyn, Prof. Dewerchin, Prof Van den Oord en Prof. Topal, voor hun constructieve commentaren.

Dank ook aan mij collega-assistenten, Pieter V, Katarina, Rudolf, Wouter, Liesbeth, die in de afgelopen jaren begripvol hebben meegeleefd en van wie ik zoveel klinische en sociale vaardigheden heb geleerd. Biezonder zijn mijn twee runningmates van dit jaar, Pieter $L$ en Stefaan, niet omdat ze fris in mijn geheugen zitten maar omdat zij ervoor gezorgd hebben dat er in dit hectische laatste jaar tijd werd vrijgemaakt om aan dit project te werken en zowel zwijgend als luidop aan deze kar hebben getrokken. Collegae maar toch vrienden, het is soms anders binnen de geneeskunde. Ik wens iedereen collegae toe zoals jullie!

Dank ook aan de stafleden van de dienst plastische heelkunde, Jan, Lloyd, Marc, Gerd, Michel en Katarina, om me de ruimte te geven die nodig was om dit project tot een goed einde te brengen en om me dag in dag uit en met een engelengeduld in te wijden in de geheimen van de plastische heelkunde. De klinische achtergrond die jullie me hebben 
bijgebracht is vruchtbare grond voor het zaaigoed van wetenschappelijk onderzoek. Binnenkort verlaat ik Gasthuisberg voor het Queen Victoria Hospital in East Grinstead en daarna voor het Royal Free Hospital in Londen, met wat ik van jullie meekreeg als bagage kan het niet stuk!

Dank aan de verpleging en medewerkers van de afdelingen en operatiekwartieren, voor het afnemen van de bloedstalen (en zelfs voor het doneren, bij tijd en wijle), voor het verzamelen van de stalen, voor jullie interesse en jullie inzet. De jaren in het labo werden gekleurd door het klinische werk tussendoor, opgevrolijkt door jullie. Mede dankzij jullie ben ik nooit -enfin, zelden- met tegenzin Gasthuisberg opgefietst.

Ik heb niets dan appreciatie, dank en bewondering voor Liesbet, de drijvende kracht achter onze dienst die samen met Evi ons secretariaat en daarmee de dienst draaiend houdt. De stille inzet, efficiëntie en bescheidenheid waarmee je, naast je normale werk, ook dit manuscript en deze dag vorm hebt gegeven zijn onbeschrijfelijk. Je bent, zoals Shakespeare placht te zeggen, "the star to every wandering bark, who's worth's unknown, although his height be taken."

Dank ook aan de medewerkers in het labo. Stijn en Pieter V, bedankt om ons LOPSTERlabo uit de grond te stampen, me al die varkensstreken aan te leren en jullie kennis en kunde over te dragen. Stefaan, mijn buddy tijdens het gros van de voorbije 7 jaar, we vormen een stilaan legendarisch duo zowel in de kliniek als in het labo, maar met jou is het gemakkelijk geschiedenis te schrijven. Alle medewerkers van het dermato-labode-la-peau, Lien, Sofie, Inge, Katrien en alle anderen, bedankt voor jullie hulp en om ons de rust van jullie biotoop te laten verstoren. Kristoff, bedankt om dit project verder uit te bouwen en diepgang te geven. Ik wens je veel succes bij het behalen van jouw doctoraat. Alle medewerkers van de vasculogenese unit: Petra, Tom, Vanessa, Boukje, Tinneke, zonder jullie inzet en vaardigheid was dit project ten dode opgeschreven. Ook al zijn jullie niet altijd even zichtbaar, wat hier bereikt is, is maar mogelijk gemaakt door jullie inzet, nauwkeurigheid en kunde, zoals het onmogelijk is een huis neer te zetten zonder fundamenten.

Seba, David, Bob, Griet en alle andere vrienden van hier in Leuven, aan zee of verspreid over het land, dit thesisavontuur heeft zoveel tijd opgeslorpt dat we mekaar maar weinig zagen. Bedankt voor jullie steun, jullie begrip, jullie interesse, bedankt om er gewoon te zijn. Verschillende van jullie wonen intussen in het buitenland of zelfs in de Vlaanders, maar daar wordt de band niet zwakker door. L'absence est à l'amour ce qu'est le feu au vent: il éteint le petit et allume le grand... Lo'tje, bedankt om -ondanks onze vriendschap- je eraan te wagen dit eigenste boekje te drukken. De gratuite inzet en professionaliteit die je aan de dag legt, vergroten mijn appreciatie voor jou!

Een doctoraat maak je niet in een paar verloren uurtjes vrije tijd. Dit project is voor een deel ten koste gegaan van mijn familie, ergens ver weg aan zee. Ma, zusje, tante Line, 
bedankt voor de steun die ik van jullie kreeg en voor het begrip wanneer ik weer eens een weekend in Leuven bleef werken. Broer, bedankt voor alle ontspannende momenten samen jou en de kinderen, waarin ik energie opdeed om verder te gaan! Valérie en petekind Alec, bedankt om nonkel Benoit met jullie enthousiasme te begeesteren. Jullie allemaal hebben me gemaakt tot wie ik ben, bedankt om er te zijn, ik hoop dat ik er ook voor jullie kan zijn wanneer dat nodig is.

ledereen heeft gidsen nodig op zijn weg. Nomaden in de woestijn vertrouwen op de sterren, ik heb mijn co-promotor Prof. Vranckx om me de weg te wijzen. Jan, je hebt me niet alleen de weg naar de plastische heelkunde getoond, je hebt me ook in dit doctoraatsproject geloodst en daarmee stond je stond je aan de weg van deze thesis. Bedankt voor je nooit aflatende steun, voor je generositeit, voor het vertrouwen en de vriendschap die je me schonk en blijt schenken, zowel in het labo, in de kliniek als daarbuiten. Je weet precies het evenwicht te bewaren tussen leiden en loslaten, je bent zoveel meer dan alleen maar een mentor... Prof. Broos, we hebben de afgelopen jaren wat woelige watertjes doorzwommen, maar met een co-promotor van uw kaliber was het niet moeilijk het hoofd boven water te houden. Bedankt voor uw onvoorwaardelijke steun in dit project!

Ook al hebben velen meegewerkt aan dit project, zonder mijn promotor was het allemaal een maat voor niets. Chef, jouw aanstekelijke passie voor de wetenschap is de rode draad doorheen mijn thesis, jij hebt me het alfabet aangereikt waarmee dit werk is geschreven. Ik ben ervan overtuigd dat een aap een doctoraat kan afleggen, als jij er maar achter staat. Je hebt dat trouwens net een beetje bewezen... Ik bewonder je omwille van je tomeloze wetenschappelijke geestdrift, je eruditie, je vindingrijkheid en je werklust, maar bovenal bewonder ik je als mens. Bedankt voor de vele avonden dat we bij ons thuis van je warme persoonlijkheid hebben mogen genieten en -enigszins gearoseerd- dit werk verder uitbouwden. leder einde is een nieuw begin, het einde van dit doctoraat is het begin van de rest van onze vriendschap!

Liefje, ook al had ik een pro-motor en een koppel co-pro-motoren, jij was de motor van dit project. Je bent van bij het begin de drijvende kracht geweest die mij in alle stilte gesteund heeft en van ons nestje in het Begijnhof een thuis gemaakt heeft waar ik dit doctoraat kon uitbouwen. Bedankt voor de vele keren dat je me -onder zachte dwang- verzocht hebt me achter mijn bureau te zetten en verder te werken, voor je steun wanneer het moeilijk was, voor je warmte, voor je menselijk inzicht. We gaan nu samen een nieuw avontuur tegemoet, ik zie het vol vertrouwen aan!

Leuven, juni 2010

Benoit

Vivez, si m'en croyez, n'attendez à demain

Cueillez dès aujourd'hui les roses de la vie.

(Pierre de Ronsard) 

Les découvertes récentes ont anéanti toutes nos illusions sur la simplicité de la vie.

(Gustave Le Bon)

Ljst of abbreviations 

- aSMA : a smooth muscle actin

- Ang : angiopoietin

- bFGF: basic fibroblast growth factor

- BOEC : blood outgrowth endothelial cells

- CD : cluster of differentiation

- Dil-AcLDL : dioctadecyl tetramethyl indocarbocyanide-acetylated low density lipoprotein

- EC : endothelial cells

- ECM : extracellular matrix

- ELISA : enzyme-linked immuno-sorbent assay

- eNOS : endothelial nitric oxide synthase

- EPC: endothelial progenitor cells

- FACS : fluorescence activated cell sorting

- flt-1 : FMS-like tyrosine kinase-1

- GF: growth factors

- GM-CSF : granulocyte/monocyte-colony stimulating factor

- H\&E : hematoxylin and eosin

- $h(X)$ : human $(X)$

- hDFS: human dermal fibroblast sheets

- IL : interleukin

- KDR : kinase insert domain receptor

- KGF: keratinocyte growth factor

- $m(X)$ : murine $(X)$

- MCP-1 : monocyte/macrophage chemoattractant protein 1

- MMP : matrix metalloproteases

- mRNA : messenger ribonucleic acid

- $p(X)$ : porcine $(X)$

- PDGF : platelet-derived growth factor

- PIGF : placental growth factor

- PIGFKD: PIGF knockdown

- qRT-PCR : quantitative real time polymerase chain reaction

- shRNA : short hairpin ribonucleic acid

- SMC : smooth muscle cells

- STE: skin tissue engineering

- TEM: transmission electron microscopy

- Tie-1 : tyrosine kinase with immunoglobulin-like and EGF-like domains 1

- UEA-lectin : Ulex Europaeus Agglutininlectin

- VE-Cadherin : vascular endothelial cadherin

- VEGF : vascular endothelial growth factor

- vWF : von Willebrand factor 

La science ne sert qu'à vérifier les découvertes de l'instinct.

(Jean Cocteau)

Introduction 



\section{Skin Tissue Engineering: time for something new}

The basis of wound healing is to restore the epidermal layer. However, skin is so much more than just an epidermal barrier. The dermal layer underneath the epidermis provides elasticity and aesthetic appearance to skin, whereas the subcutaneous fat layer accounts for volume and thermoregulation. Normally, wounds tend to heal spontaneously, resulting in scar tissue. The larger the area left to heal, the longer it takes for secondary healing to complete and the worse the outcome in terms of wound contraction and aesthetic appearance. Therefore, even smaller defects in the face need to be reconstructed whereas larger wounds at less visible locations (e.g. the back) can be left to secondary healing. Large skin defects may result from trauma, infections, vascular disease, burns or oncologic surgery. These wounds do not heal properly and need to be reconstructed. Ultimately, reconstructive plastic surgery aims at restoring defects with similar tissue, without creating a burden at the donor site.

Small to very large superficial defects can adequately be covered with skin grafts. Split thickness skin grafts can be harvested in large quantities and expanded by meshing the graft, create minimal donor site morbidity and are quickly re-vascularised. However, the resulting tissue is brittle, unaesthetic and prone to excessive contraction (Fig. 1). 

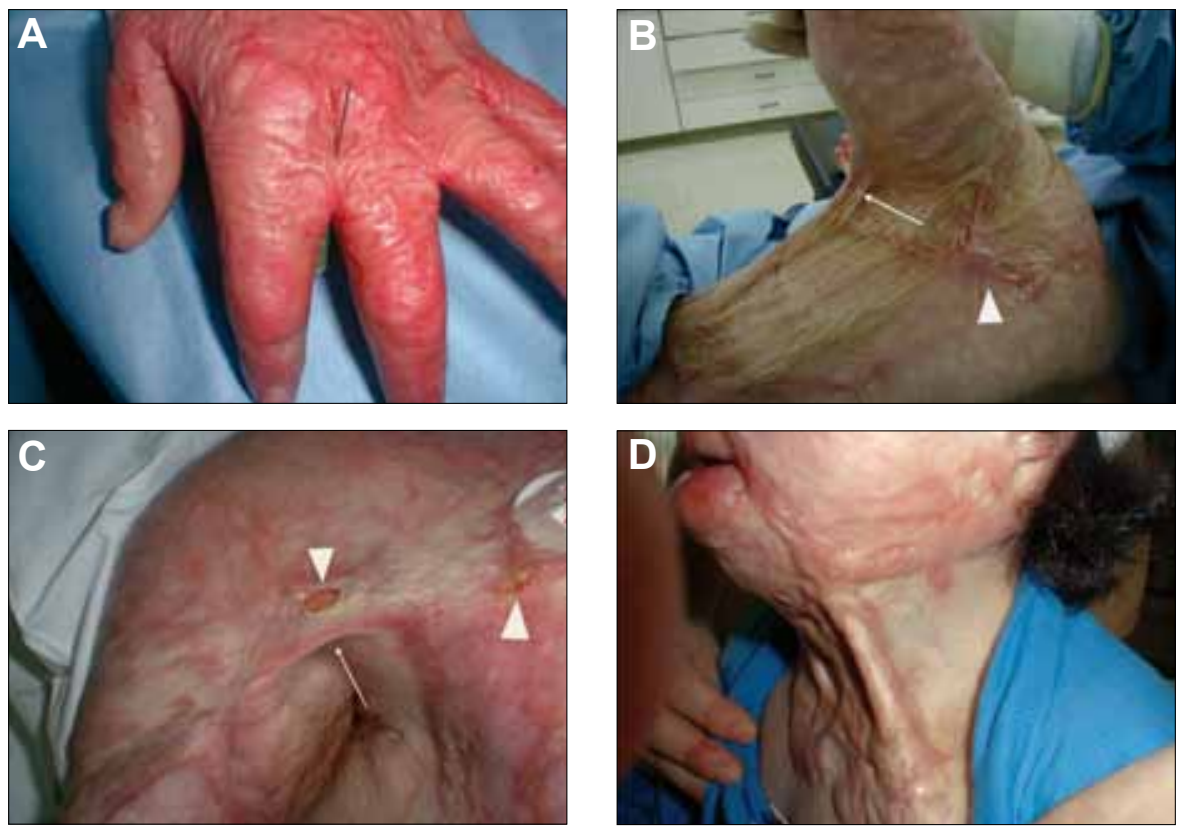

Figure 1. Excessive skin contraction of full thickness burn wounds reconstructed with split thickness skin grafts. A, 'Postburn syndactyly' due to contraction of the web spaces of the fingers. The normal position of the web space is indicated with a needle. $\boldsymbol{B}-\boldsymbol{C}$, Severe contraction of burns in the axillary region reconstructed with split thickness skin grafts. Contractures of the anterior axillary fold (indicated with arrows in $B$ and $C$ ) that impair shoulder abduction. The resulting skin is hypertrophic (arrowhead in $B$ ) or brittle, leading to superficial erosions (arrowheads in $C$ ). $D$, Hypertrophic scarring and wound contraction in the face and anterior neck region, with unsightly appearance and functional impairment of neck mobility. The skin of the neck is especially prone to flexion contracture upon burn wounds. In all cases, scar revision using multiple Z-plasties, full thickness skin grafts and/or flap reconstruction will be mandatory to restore mobility and minimal cosmesis.

Full thickness skin grafts include dermis and epidermis and result therefore in thicker, more elastic scars. However, these grafts initially survive through imbibition, and it takes up to one week before a decent connection is restored between the blood vessels of the wound bed and the vessels in the graft by inosculation ${ }^{1}$. In addition, the donor site generally needs to be closed primarily, limiting the size of those grafts. Moreover, if the wound bed is poorly vascularised or if there is hematoma or seroma between a skin graft and the wound bed, inosculation is prevented, with subsequent graft loss. In an attempt to resore like-with-like tissue, abundant adjacent tissue is often used under the form of local or locoregional flaps (Fig. 2). 

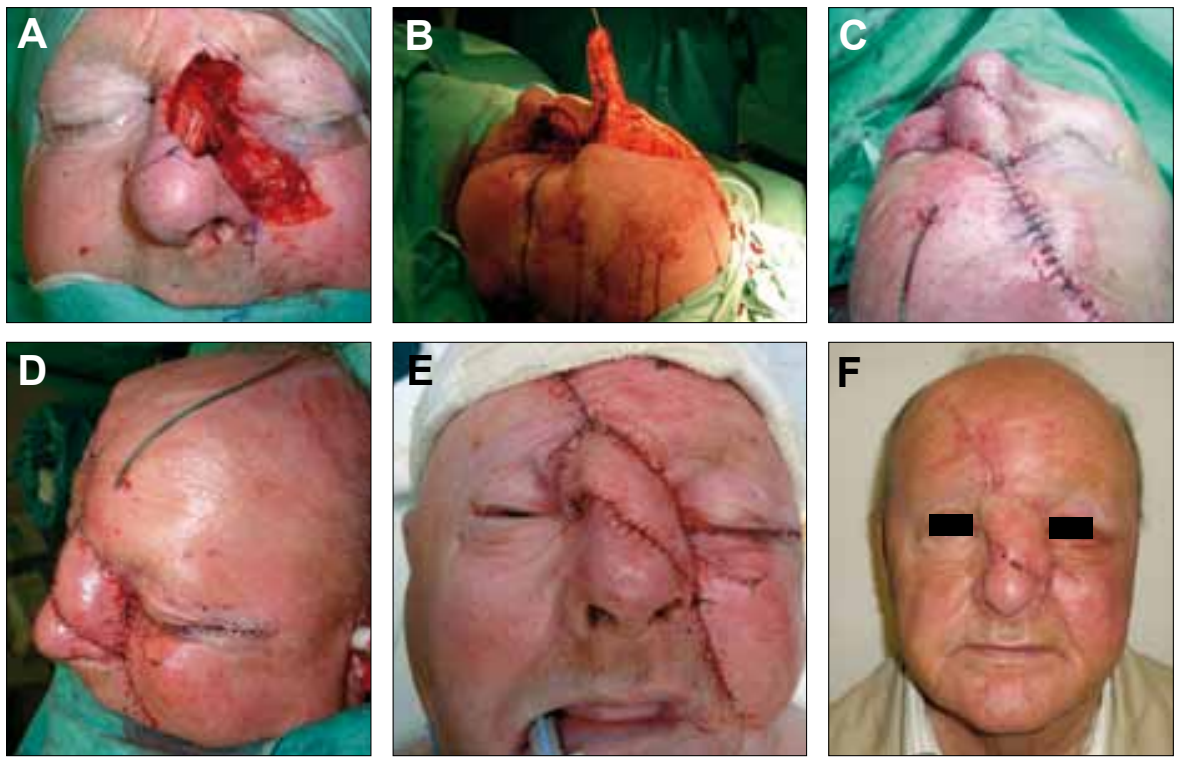

Figure 2. Reconstruction of a full thickness skin defect using a local flap. A spinocellular carcinoma on the left nasal wall and cheek is removed by Moh's surgery, resulting in a large full thickness defect central in the face $(A)$. Merely grafting this defect would result in an unaesthetic, fragile scar with distortion of the lower eyelid and nose. Therefore, a local forehead flap $(B)$ is used to cover the defect and the donor site is closed primarily $(C)$. Colour and texture of the flap match with the surrounding skin $(D)$ and the defect is adequately covered without traction on surrounding structures $(E)$. One month postoperatively, the flap has excellently healed, with acceptable appearance of the scar at the donor site. However, the flap is rather bulky, crosses several aesthetic units and will need surgical correction $(F)$.

Of course, defect size and availability of local tissue are limiting factors for reconstruction with local flaps. If no skin graft can be used and there is no local option for covering the defect, distant tissue needs to be advocated. In that case, distant tissue is harvested on a vascular pedicle, transferred into the defect and the vascular pedicle is connected to the recipient vasculature by microsurgical techniques (Fig. 3). 

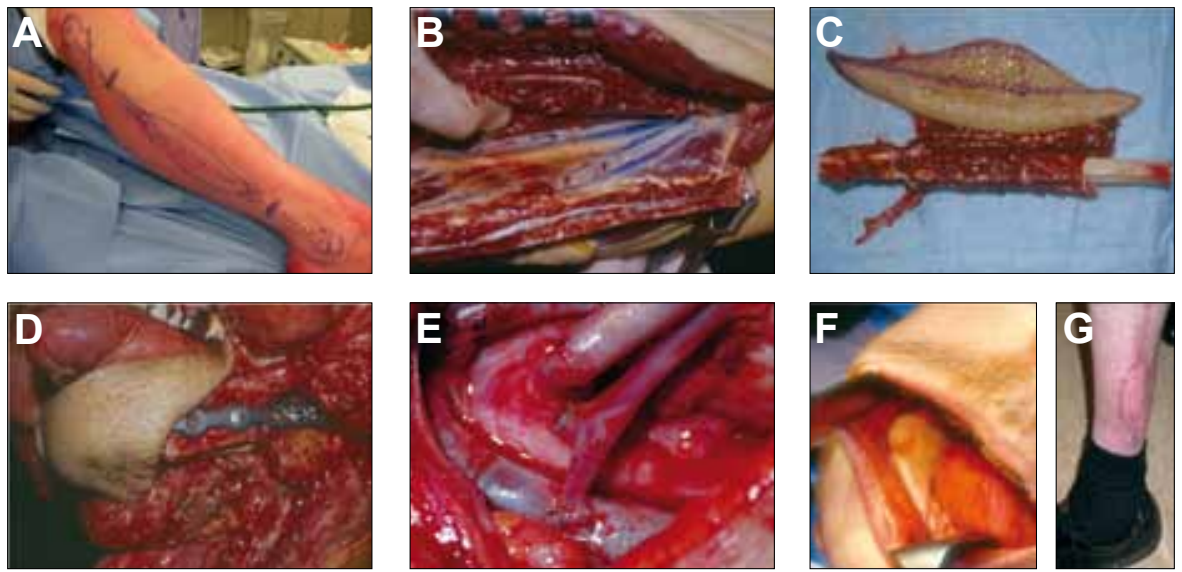

Figure 3. Reconstruction of a defect of the mandibula and oral floor using a free fibula flap. A preoperative drawing indicates the position of the skin paddle and the fibula $(A)$. The osteocutaneus flap is dissected on its vascular pedicle $(B)$ and harvested $(C)$ prior to ex-vivo shaping with osteotomies. Titanium plate and screw fixation reshapes the mandibula $(D)$ and microvascular anastomoses are made on neck vessels to maintain flap viability $(E)$. The skin paddle is used to cover the mucosal defect $(F)$ and the donorsite of the flap is grafted $(G)$.

Essentially, all plastic surgery reconstruction techniques create to some extent nuisance at the site where tissue is removed, ranging from an initially painful and later hyperemic donor site of split thickness skin grafts, to the potential functional impairment at the donor site of composite free flaps such as in the osteocutaneous free fibula flap ${ }^{2}$. To reduce this donor site morbidity, biotechnological advances have been made to introduce artificial components to optimise wound healing with minimal requirements of donor tissue. Already in the ' 80 s, Burke and Yannas applied a matrix consisting of bovine collagen I and chondroitin- 6 sulfate to restore the dermis in full thickness burn wounds ${ }^{3}$, resulting in more elastic scars that tended to contract less (Fig. 4 and 5).
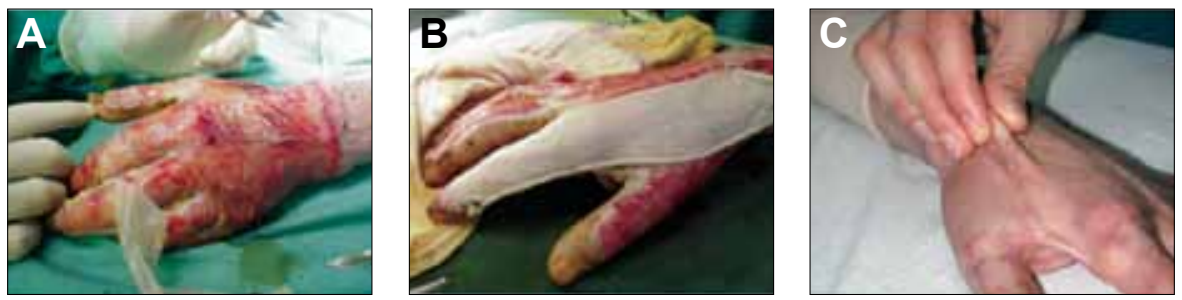

Figure 4. Reconstruction of a full thickness skin defect using a dermal substitute. Full thickness burn wound of the hand, debrided and covered with a commercially available dermal substitute $(A)$ prior to skin grafting $(B)$. The resulting skin is elastic with little tendency to contraction $(C)$. 
A few years later, the Green and colleagues described cultures of autologous keratinocytes for coverage of large burn wounds ${ }^{4}$ (Fig. 5). These landmark papers undoubtedly heralded the era of skin tissue engineering (STE), as for the first time successful efforts were made to use biological scaffolds and cultured cell constructs for skin restoration. STE aims at isolating -with minimal donor site morbidity- skin cells from a patient, ex vivo expansion, integration in a matrix and subsequent transplantation to the wound, so that this skin substitute mimics natural skin in terms of appearance, elasticity, thermoregulation and barrier function. The initial euphoria ebbed away when it became clear that cultured keratinocyte grafts lead to unstable scars. Moreover, it takes weeks before blood vessels grow into artificial dermal substitutes. During this avascular period, the dermal substitute is prone to infection and subsequent loss. More recently, combined approaches tried to restore both dermis and epidermis at once ${ }^{5}$. However, adding layers to engineered skin increases the distance between the host vascular network and the upper layers of the skin construct which results in hypoxia of these upper layers ${ }^{5}$. Cells more than 200 $\mu \mathrm{m}$ away from blood vessels become oxygen-deprived ${ }^{6}$, making STE essentially a matter of rapid and accurate vascularisation of skin substitutes to prevent hypoxiamediated cell death.

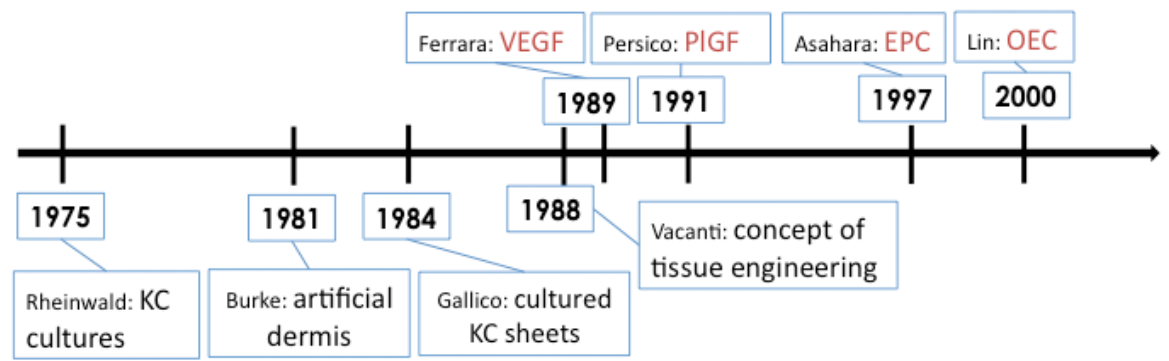

Figure 5. Landmark papers relevant to this project. The first attempts to restore dermis and epidermis were made in the 80's. The major impediment remained however the need for vascularisation. Angiogenic growth factors, discovered in the early 90's, were assumed to solve this problem, but cellbased strategies count for a more stable solution. The identification of different types of EPC in the past decade raises hope for successful vascularisation in skin tissue engineering.

\section{Vascularisation: breathing life into engineered skin}

Several approaches have been tested to vascularise skin substitutes. Apart from surgical prefabrication ${ }^{7}$, skin substitutes have been seeded with angiogenic growth factors ${ }^{8}$, with microspheres loaded with growth factors ${ }^{9}$ or with plasmids encoding growth factors ${ }^{10}$. Since these approaches often require repetitive administration, skin substitutes seeded with cells producing these growth factors on a continuous basis 
provide an attractive alternative. For instance, seeding fibroblasts or keratinocytes results in faster vascularisation, due to the secretion of growth factors ${ }^{11}$. We have used vascular endothelial growth factor (VEGF) over-expression in keratinocytes to augment vascularisation in a porcine wound healing model ${ }^{12}$. However, aside from growth factors supplementation, incorporating cells of endothelial origin in the graft remains the most appealing option, as these cells are predestined to directly contribute to vessel formation. The skin substitute can either be seeded with endothelial cells (EC) to form a vascular network in vitro, prior to application to the wound - the so-called 'pre-vascularisation' technique - or be combined with the skin substitute directly before transfer to the wound. In vitro pre-vascularisation results in faster inosculation to the host vascular network, but raises the problem of unequal cell distribution in the skin substitute, leading to incomplete vascular networks ${ }^{5}$. It therefore seems more feasible to opt for 'in situ' assembly of vascular networks within skin substitutes that have been seeded in vitro with endothelial (precursor) cells that organise themselves in cooperation with endogenous EC into vascular tubes upon implantation. Furthermore, stable and functional vessel networks depend on the recruitment of pericytes (in small vessels) and vascular smooth muscle cells (SMC; in large vessels) around the endothelium, a process that is easier to accomplish in situ ${ }^{13}$.

Formation of an endothelial network can either happen through angiogenesis, i.e. sprouting from existing endothelial tubes, or through vasculogenesis, i.e. the de novo formation and in situ assembly of endothelial-lined vessels. In the context of STE, angiogenesis means ingrowth and sprouting of the host's vascular network into the skin substitute, whereas vasculogenesis is the formation of a tubular network by endothelial (precursor) cells recruited into or exogenously added to the skin substitute and, subsequent connection to and incorporation into the host's vascular network (Fig. 6). 


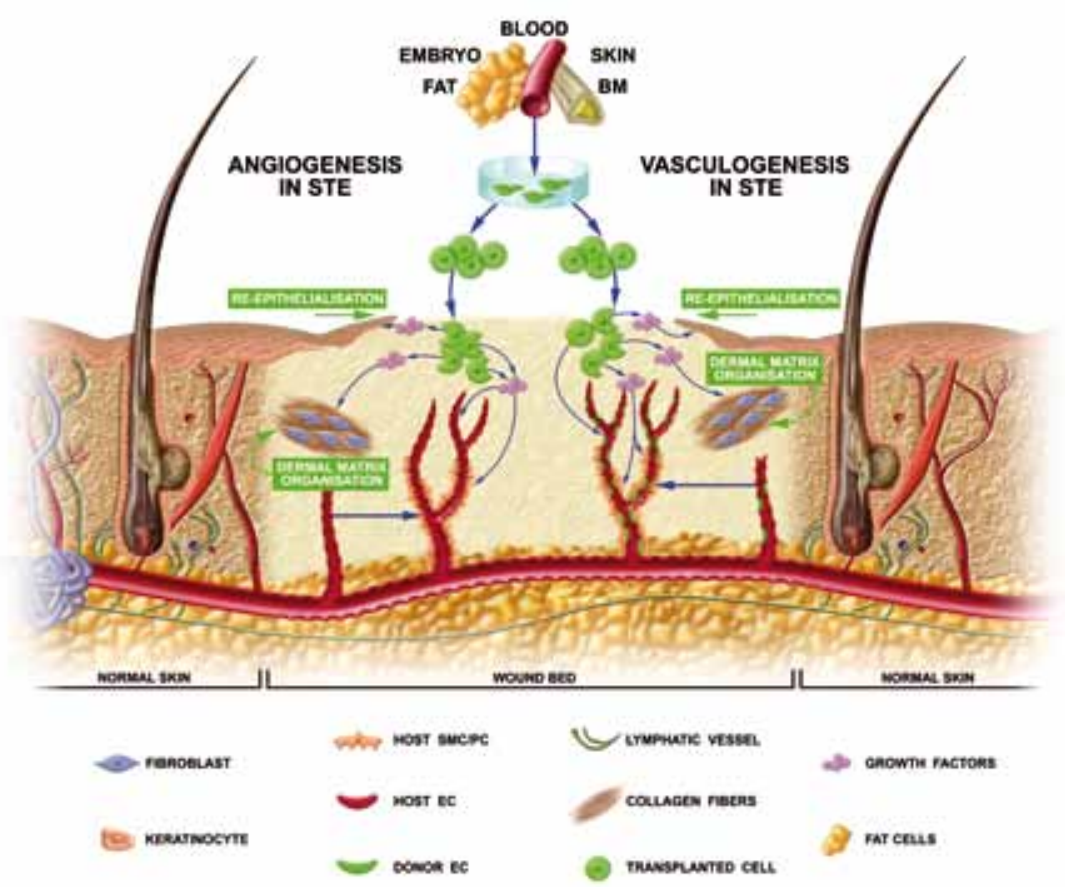

Figure 6. Angiogenesis versus vasculogenesis in STE. Ex vivo expanded cells of different origins are applied to the wound bed and stimulate vessel formation either by secretion of angiogenic factors that communicate with endogenous vascular cells (angiogenesis) or by direct incorporation into nascent vessels (vasculogenesis). Moreover, these cells secrete trophic factors that can stimulate dermal and epidermal healing by communication with fibroblasts and keratinocytes, respectively.

When endothelial (precursor) cells are exogenously added, these can either be allogeneic or autologous (host-derived). Allogeneic cells can be isolated, expanded to obtain the desired amounts, and stored in liquid nitrogen until required in an 'offthe-shelf setting. However, they imply the risk of immunologic rejection ${ }^{14-16}$. While autologous cells are not subject to immunologic rejection, they are often available in only very small amounts, necessitating the need for expansion of these cells to therapeutic amounts. This expansion can either be accomplished endogenously, by stimulating mobilisation of endothelial (precursor) cells by chemokines, and/or exogenously, by in vitro expansion of harvested cells.

Many cell types may contribute to vessel formation in STE through angiogenesis, vasculogenesis or both. Preferably, in addition to stimulating the formation of an endothelial network, the cells may also support vessel stabilisation by pericytes/ 
SMC (Fig. 6). Furthermore, the ideal candidate to allow this in a clinical setting should: (i) be easy to harvest with minimal discomfort to the donor, (ii) be easily and rapidly expandable to amounts sufficient for vascularisation of large skin substitutes, without risk of malignant transformation, (iii) be non-immunogenic (autologous) and (iv) have a trophic effect on wound healing beyond vascularisation, i.e. by communication with other cell types present in the wound bed such as fibroblasts and keratinocytes that together orchestrate the sequential phases of the wound healing process (Fig. 6). In the next chapters we present an overview of a number of candidate cell types for wound vascularisation, discuss their use in STE in vitro and in vivo and their mechanism of action, and score them according to the above-mentioned clinical criteria (Table 1).

\section{Cell sources for vascularisation strategies}

Different (stem/progenitor) cells can be considered for vascularisation of skin substitutes. Hereafter, we give an overview of these thereby using the (endothelial) differentiation potential/status of the cells as a way to categorise them in a hierarchical system (Fig. 7). The zygote on top of this hierarchy has the broadest differentiation potential (i.e. 'totipotent', giving rise to all cell types in an organism, including EC). In the middle, we find 'multipotent progenitor cells' which have the capacity to be coaxed into multiple cell types. For some of these progenitors the differentiation spectrum may contain cells from different embryonic germ layer origin (e.g. EC from the mesoderm and neuronal cells from the ectoderm). A step lower, we find the 'unipotent' progenitors that are committed to a single lineage. Finally, cells at the bottom are terminally differentiated mature EC that cannot give rise to another cell lineage ('nullipotent'). The degree of differentiation is inversely correlated with the expansion capacity of the cells (Fig. 7).

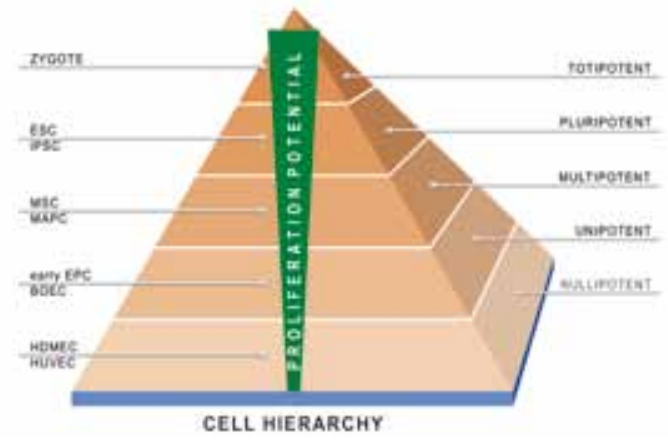

Figure 7. Hierarchy of cell sources that can be used for vascularisation in STE. Candidate cell populations for vascularization can be categorized according to their differentiation potential that inversely correlates with proliferation capacity. Cells with the broadest differentiation potential are on top of the pyramid, while fully differentiated, mature endothelial cells are at the base of the pyramid. ESC: embryonic stem cells; MSC: mesenchymal stem cells; MAPC: multipotent adult progenitor cells; EPC: endothelial progenitor cells; BOEC: blood outgrowth endothelial cells; HDMEC: human dermal microvascular endothelial cells; HUVEC: human umbilical vein endothelial cells. 


\subsection{Mature endothelial cells}

\subsubsection{Human dermal microvascular endothelial cells (HDMEC)}

Microvascular EC can be isolated from skin samples ${ }^{17}$. Further refinement of the culture protocol has led to the development of serum-free culture techniques, making these cells more acceptable for clinical use in STE ${ }^{18}$. HDMEC are commercially available as a standardised EC line that was tested in in vitro wound assays ${ }^{19}$, as well as in in vivo blood vessel formation assays ${ }^{20}$. Even though Nör et al. succeeded in creating functional vessels in a subcutaneous pocket when combining HDMEC with matrigel ${ }^{20}$, Supp et al. were not able to demonstrate the functional connection to the host vasculature in a skin substitute ${ }^{21}$. Commercial HDMEC could theoretically be used for clinical purposes, however, it seems more appealing to use them in an autologous setting ${ }^{21}$. Unfortunately, only relatively small amounts of HDMEC can be harvested and therefore large pieces of donor skin are needed ${ }^{21}$, with increasing donor site morbidity. Combining HDMEC, fibroblasts and keratinocytes in an autologous fashion has been used in a clinical setting, unfortunately with delayed vascularisation and subsequent loss of the constructs in most of the cases ${ }^{22}$. Human fibroblast sheets have been combined with both human umbilical vein endothelial cells (HUVEC) and HDMEC, giving rise to endothelial-lined tube-like structures with apparent lumina in vitro. These endothelialised fibroblast sheets have however not been used in vivo so $\mathrm{far}^{23}$. To the best of our knowledge, no reports have been published about the ability of HDMEC to support vessel stabilisation or trophic communication with wound cells (Table 1). 


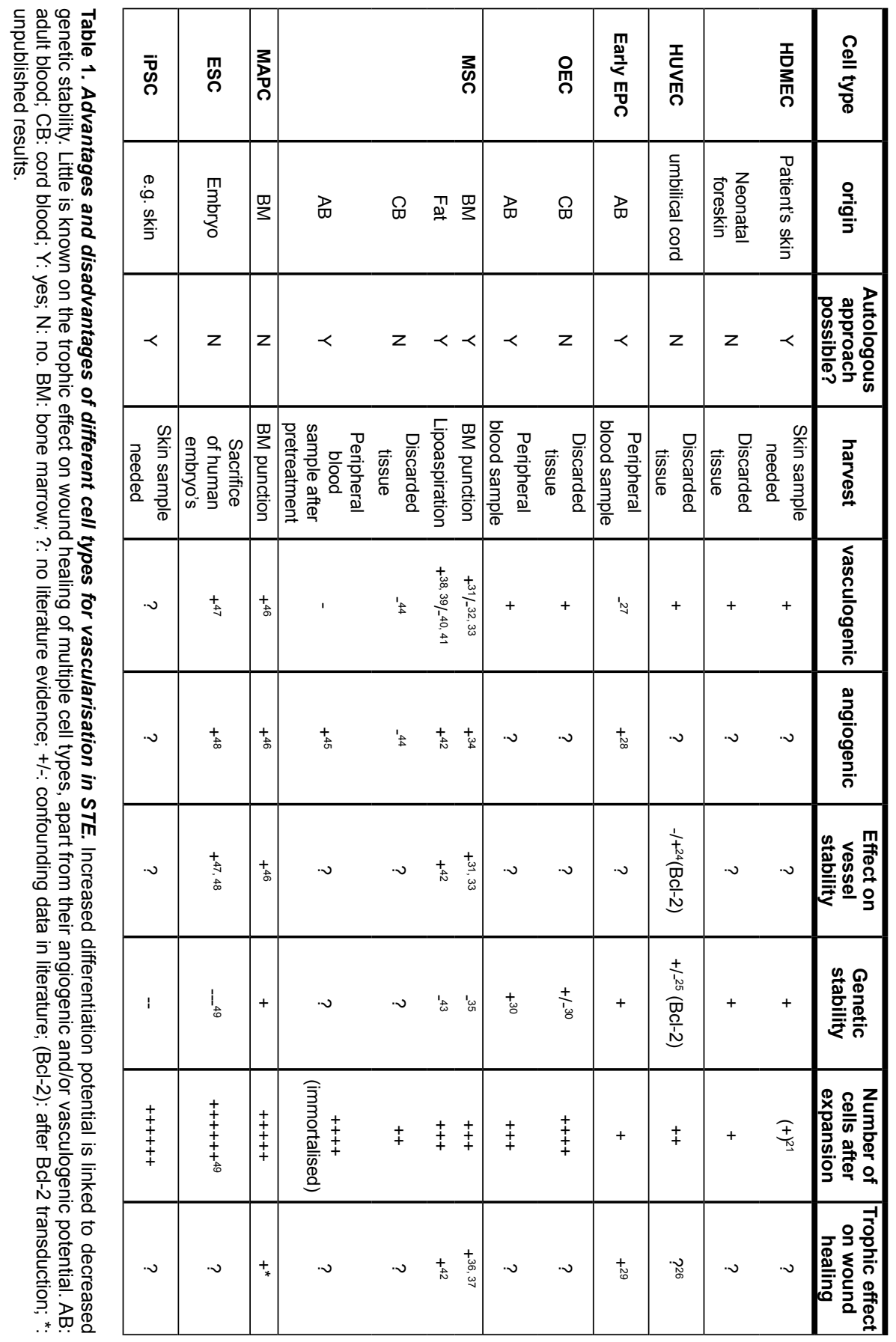




\subsubsection{Human umbilical vein endothelial cells (HUVEC)}

When derived from umbilical cord veins, human EC can be expanded relatively well ${ }^{50}$. HUVEC are the most widely used standardised EC line and serve as a reference in many vascularisation studies (e.g. refs. 34-35). Unfortunately, in the absence of cell banking, these cells can only be used in an allogeneic setting (Table 1). Combination of fibroblasts and HUVEC in a hyaluronic acid scaffold resulted in only very few vascular structures in vitro. ${ }^{51}$ The same combination of cells in a collagen/ glycosaminoglycan matrix in vitro led to the formation of a capillary-like network that could firmly be increased in density by adding VEGF or fibroblast growth factor (FGF) ${ }^{52}$. In combination with fibroblasts and keratinocytes in a collagen matrix in vitro, HUVEC were able to form an organised vascular network. Notwithstanding the presence of collagen, fibroblasts were required to produce extracellular matrix proteins as a guidance grid for migration of HUVEC ${ }^{53}$. Seven years later, the same team was able to demonstrate quick inosculation of this in vitro pre-vascularised skin substitute, resulting in functional hybrid vessels, 4 days after transplantation ${ }^{5}$. To prolong survival, HUVEC have been transduced with a virus encoding the anti-apoptotic protein $\mathrm{Bcl}-2$, leading to a dense and mature (SMC-coated) vascular network in subcutaneously implanted collagen plugs ${ }^{24}$ and in a decellularised dermal matrix ${ }^{54}$. Even though $\mathrm{Bcl}-2$ over-expression on itself did not cause malignant transformation of EC in vitro ${ }^{55}$ or in vivo ${ }^{24}$, the use of retroviral vectors for clinical use has to be considered with caution because of the potential hazards of random viral integration in the genome ${ }^{25,56}$

\subsection{Unipotent progenitor cells: Endothelial Progenitor Cells (EPC)}

It has long been accepted that vasculogenesis involving endothelial precursors only occurred in utero and that post-natal vessel formation was merely the result of angiogenesis. Since the initial description of circulating endothelial progenitors ${ }^{57}$ in 1997 (Fig. 5), there is clear evidence that circulating EPC contribute to adult vasculogenesis. However, different EPC isolation protocols and phenotypes have been described since then, causing a lot of confusion in the field ${ }^{58,59}$. Currently, two major types of EPC are acknowledged, regarding their isolation kinetics and functional characteristics: 'early outgrowth EPC' and 'late outgrowth EPC', of which the latter have the capacity to incorporate into growing vessels.

\subsubsection{Early outgrowth EPC}

Early (outgrowth) EPC are CD $34^{+}$, VEGF-receptor $2^{+}$and $\mathrm{CD} 133^{+}$and are obtained by adherence depletion on fibronectin of the mononuclear fraction of cord or adult blood (Fig. 8). After 4-9 days, colonies of cells with limited proliferation capacity appear that lose CD133 expression but gain mature endothelial marker expression (for review, 
see: ref. 46). Also referred to as 'Colony Forming Unit-EC', early EPC are commonly derived from $\mathrm{CD}_{14}{ }^{+}$(monocytic) cells and form clusters of spindle-shaped cells ${ }^{60}$. They regulate the angiogenic response through secretion of growth factors ${ }^{28,61}$, without becoming part of the endothelial intima ${ }^{27}$ (Table 1). In addition to their trophic effect on angiogenesis, early EPC may facilitate vessel formation by actively drilling tunnels into sites of ischemia, that become lined with true EC ${ }^{62}$. Application of early EPC has proven to increase angiogenesis and epidermal wound healing ${ }^{29,63}$. Overall, regarding their ease of harvest, defined angiogenic potential and trophic effect on wound healing, early EPC can safely be used for STE, even though their limited proliferation capacities may limit their impact. Using cord blood increases yield of cells ${ }^{64}$, but as these cells are allogeneic, they are at risk for immunologic rejection (Table 1).

\subsubsection{Late outgrowth EPC}

The groups of Hebbel and Yoder characterised late outgrowing endothelial-like colonies of collagen-adherent cells that had a much higher proliferation capacity than early EPC. These cells have also been called 'Endothelial Colony Forming Cells' (ECFC) or blood outgrowth endothelial cells (BOEC) ${ }^{60,65,66}$. In contrast to early EPC, BOEC actively incorporate into intimal endothelium and can be expanded to high numbers in vitro. Whether they originate from bone marrow (BM) or from the vessel wall ${ }^{58,65}$, remains a matter of debate. Besides direct incorporation into vessels, BOEC indirectly stimulate host angiogenesis by secreting growth factors ${ }^{67,68}$. Interestingly, early EPC (or the factors they secrete) have a stimulatory effect on tube formation by BOEC ${ }^{69}$, which makes a combination therapy of both cell types attractive. Co-transplantation of early EPC and BOEC had indeed a synergistic effect on revascularisation in an ischemic limb model ${ }^{70}$, but there are no reports so far of this combined approach in STE. BOEC can either be derived from cord or adult blood, with the former showing higher proliferation potential ${ }^{30}$.

\subsubsection{Cord blood BOEC}

Many studies highlight the excellent outgrowth of BOEC from cord blood (CB-BOEC) and suggest them, due to their high expansion and vasculogenic potential, as ideal candidates for (S)TE purposes ${ }^{60,67,71,72}$. Au et al. examined the in vivo vessel formation capacity of CB-BOEC in combination with pericyte-like cells and noted firmly increased survival, vessel formation and vessel stability in comparison with adult blood-derived BOEC (AB-BOEC) ${ }^{71}$. CB-BOEC formed stable vessels in an artificial dermal matrix when co-transplanted with $S M C{ }^{73}$. They also efficiently formed a vascular network when seeded in a decellularised dermal matrix, to a comparable extent as the $\mathrm{Bcl}-2$ transduced HUVEC ${ }^{67}$. However, in contrast to AB-BOEC, CB- 
BOEC are prone to karyotypic aberrations, even though no tumor formation has been reported so far. Therefore, the CB-BOEC may not be free of risk for clinical application ${ }^{30}$. Moreover, autologous CB-BOEC are not available and, as allogeneic cell source, are at risk for immune rejection (Table 1).

\subsubsection{Adult blood BOEC}

Although adult blood samples yield fewer BOEC, there is evidence that this discrepancy can be overcome by VEGF stimulation during culture expansion ${ }^{74}$. Unlike BM-derived stem cells, their harvest creates no donor site morbidity at all. AB-BOEC have successfully been used in endothelialisation of a decellularised aorta in sheep ${ }^{75}$ or in vitro TE vessel constructs ${ }^{76}$, blood vessel growth in tissueengineered bone scaffolds ${ }^{77}$ and for vascularisation of a decellularised dermal skin substitute, in which they remained traceable for more than 4 weeks in vivo, without $\mathrm{Bcl}-2$ transduction ${ }^{78}$. Recently, Reinisch et al. have described a large scale, animal protein-free, humanised expansion strategy for $\mathrm{AB}-\mathrm{BOEC}$ that preserves proliferation and functional characteristics, even after cryopreservation ${ }^{79}$. As serum-free culture protocols for human dermal fibroblasts and keratinocytes are also available ${ }^{80}$, a fully autologous, serum-free, vascularised skin substitute seems to be within reach ${ }^{69}$.

\subsection{Multipotent progenitor cells}

\subsubsection{Mesenchymal stem cells (MSC)}

MSC represent a heterogeneous group of multipotent progenitor cells that can be harvested from several tissues, including BM, skeletal muscle, fat, (umbilical cord) blood, amniotic fluid and different fetal tissues ${ }^{81}$. They act on wound healing through transdifferentiation or cell fusion to wound healing cells ${ }^{82}$, production of cytokines and growth factors ${ }^{83,84}$, maintenance of the extracellular matrix, modulation of the immune system and wound contraction ${ }^{81}$.

There is evidence that adipose-derived MSC and BM-MSC kept in culture for long time become immortalised, undergo spontaneous transformation and form tumours in vivo, which might jeopardize clinical application ${ }^{35,43}$ (Table 1). As the incidence of malignant transformation increases with passage number, it seems safer to consider only cells from initial passages for clinical application. On the other hand, MSC display immunosuppressive characteristics through interactions with Natural Killer cells, B and T lymphocytes and monocytes ${ }^{85}$. Until recently, MSC were considered immunoprivileged and protected against normal alloresponses ${ }^{86}$, making them favourable candidates for allogeneic transplantation. Recent reports however indicate that MSC can engraft in immunocompromised hosts or at 
immunocompromised sites, but may trigger an immune response in hosts with an intact immune system ${ }^{85}$. Nevertheless, taking into account the immunosuppressive features of MSC, Bartholomew et al. found that survival of allogeneic skin transplants was prolonged when combined with BM-MSC, which raises possibilities for STE with allogeneic cells.$^{87}$. Even though most recent TE approaches have chosen to work with MSC, their direct contribution to vessel formation has been controversial. In addition, when considering clinical use in STE, only few sources are possible.

\subsubsection{BM-MSC}

BM-derived MSC are known to differentiate into $\alpha$-smooth muscle cell actin ${ }^{+}$cells, thereby enhancing wound contraction, even in the presence of a dermal scaffold ${ }^{88}$. Markowicz et al. noted increased vascularisation when BM-derived MSC were seeded in a collagen spounge in vivo, as well as enhanced collagen production ${ }^{89}$. There are only few reports of endothelial differentiation of BM-MSC in vivo ${ }^{31}$ and their contribution to neo-vascularisation is most likely related to their trophic effect on host vessels ${ }^{34}$. BM-MSC also stimulate vessel maturation, through differentiation into perivascular cells ${ }^{31}$ and increased angiopoietin (Ang)1/Ang2 secretion ratio ${ }^{32}$. Combination of BM-MSC with BM-derived hematopoietic cells with EPC-like characteristics seems to have a synergistic effect on vascularisation in vivo ${ }^{90}$. There is also evidence that BM-MSC can differentiate into epidermal cells, albeit in very small amounts ${ }^{31}$. BMMSC were shown to augment vascularisation in a dermal scaffold in a pig model ${ }^{91}$ and to induce healing of burns and chronic wounds when combined with an artificial dermis in preliminary clinical trials ${ }^{36,92}$ or acute wounds when sprayed in a fibrin glue ${ }^{93}$. None of these clinical trials, however, used a control population, making the results difficult to interpret. Standard MSC culture protocols include the use of foetal calf serum, possibly leading to zoonoses or immune reactions in the host. Platelet lysate has been advocated as a surrogate for foetal calf serum in isolation of BM-MSC, but it is not clear yet whether this isolation procedure gives rise to cells with identical properties as BM-MSC obtained through the standard isolation protocol ${ }^{94,95}$.

\subsubsection{Adipose-derived MSC}

In contrast to BM-MSC, there is more evidence of differentiation of adiposederived MSC into EC ${ }^{38,39,96}$, even though some authors are unable to prove direct incorporation ${ }^{40,41}$. Most authors use (a modification of) the isolation protocol as initially described by Zuk and coworkers ${ }^{97}$, that consists of enzymatic digestion of a lipo-aspirate and centrifugation to obtain the stromal vascular fraction (SVF). Adherence depletion on plastic sorts out the cell fraction that is referred to as processed lipo-aspirate (PLA) cells ${ }^{98}$, adipose derived stromal cells ${ }^{99}$, adipose derived stem cells ${ }^{42}$, or adipose-derived $\mathrm{MSC}^{40}$, and that consists of a heterogeneous 
population that contains vascular (pericytes and endothelial progenitor) cells, besides multipotent mesenchymal stem cells ${ }^{100}$. However, as adipose tissue is highly vascular ${ }^{101}$ and other authors have shown the presence of EC with high proliferative capacity in the vessel wall ${ }^{102}$, it might be possible that $\mathrm{EC}$ contamination accounts for the vasculogenic effect of adipose-derived MSC. Adipose-derived MSC can also differentiate towards perivascular cells, thereby increasing vessel stability ${ }^{99,103}$. They can easily be harvested and applied in an autologous manner. Moreover, they appear to have a high expansion capacity in vitro ${ }^{104}$ and are successfully used in STE, leading to increased vascularisation and wound closure ${ }^{42}$.

\subsubsection{3. $C B-M S C$}

MSC can also be grown from cord blood and can be differentiated in vitro towards cells of all three germ layers ${ }^{105}$, including cells with endothelial characteristics ${ }^{106}$. Application in a hind limbischemia model did not result in increased angiogenesis, but rather myogenesis ${ }^{44}$. They have therefore been used in a clinical setting where myogenesis might be beneficial, such as in dilated cardiomyopathy ${ }^{107}$ and Buerger's disease ${ }^{108}$, but not yet for STE vascularisation purposes.

\subsubsection{PB-MSC}

After BM stimulation, MSC can even be isolated from peripheral blood ${ }^{109}$. These cells have been used to induce angiogenesis in a dermal scaffold, but there is no evidence of direct incorporation of these cells in a vascular network ${ }^{45}$.

Concerning the choice of tissue source for clinical use of MSC for STE, harvesting $\mathrm{BM}$ represents a rather invasive and painful procedure that gives rise to a limited number of MSC ${ }^{104}$. It would therefore be preferable to opt for adipose-derived MSC, as they can easily be derived from even rather skinny patients, are easy to expand and contribute both directly and indirectly to vascularisation ${ }^{39,98,104}$. Moreover, BMMSC are believed to undergo quicker senescence than adipose-MSC, which makes the former somehow less favourable candidates for STE ${ }^{104}$. However, for this comparative study, BM samples were taken from patients undergoing hip surgery, a much older population than in the adipose-derived MSC group that consisted of younger patients undergoing liposuction ${ }^{104}$.

\subsubsection{Multipotent adult progenitor cells (MAPC)}

Other investigators report the isolation of a different BM-derived multipotent cell type that displays a vast expansion capacity combined with a broad differentiation potential that encompasses cells from the three embryonic germ layers ${ }^{110}$. These MAPC are morphologically, molecularly and functionally different from BM-MSC and can in 
vitro differentiate into EC that contribute to vasculogenesis in vivo ${ }^{46,111-113}$ (Table 1). While MAPC represent an almost inexhaustible source of cells that can be used in STE vascularisation, the long-term procedure required to derive MAPC makes an autologous approach not feasible. Nevertheless, similar to MSC, MAPC also seem to have immunosuppressive capacity, which may be favourable in an allogeneic setting ${ }^{114,115}$. Despite their large expansion capacity, no karyotypic instabilities have been reported for human MAPC. Our recent data reveal that MAPC transplantation improves wound vascularisation as well as re-epithelialisation in a full thickness wound model in immunodeficient mice (unpublished results) (Table 1).

\subsection{Pluripotent progenitor cells}

\subsubsection{Embryonic Stem Cells (ESC)}

ESC are derived from the inner cell mass of the blastocyst-stage embryo which puts some ethical restraints on their (clinical) use. Addition of VEGF can differentiate these cells towards EC that have been used for therapeutic re-vascularisation of ischemic limbs where they were shown to directly contribute to vessels ${ }^{48}$. ESC have a selfrenewal capacity and represent therefore an inexhaustible source of EC (Table 1). They are however, due to this vast proliferative potential, prone to teratoma formation ${ }^{49}$ (Table 1). Transplantation of selected endothelial-predifferentiated ESC can prevent teratoma, however the presence of residual undifferentiated ESC remains a concern. Immortalised ESC-derived EC have been used for tissue-engineering of blood vessels ${ }^{116}$, but we have no record of ESC studies on STE so far.

\subsubsection{Induced pluripotent stem cells (iPSC)}

As first described by Takahashi et al. in mice, these ESC-like cells are obtained through reprogramming of skin fibroblasts (or other somatic cells) by transduction with a combination of only 4 genes (Oct4, Sox2, c-Myc and Klf4) ${ }^{117}$. In 2007, iPSC were also successfully derived from human fibroblasts, by using a combination of different genes (Oct3/4, Lin28, nanog and Sox2) ${ }^{118}$. As this avoids the destruction of embryos, the use of iPSC is not linked to ethical issues. Moreover, unlike ESC, they can be derived from the patient, making an autologous approach feasible (Table 1). The CD34+, CD31+, CD43- fraction gives rise to vascular structures in vitro ${ }^{119-121}$, but has never been used for vasculogenic purposes in vivo so far. While iPSC are not entirely similar to ESC, they also carry the risk of teratoma formation and genetic instability ${ }^{122,123}$. Moreover, the need for genetic manipulation through viral integration renders an additional risk for transformation. Therefore, clinical use of IPSC awaits the design of new selection procedures and reprogramming protocols to avoid tumorigenicity. 


\section{In between safety and ambition: BOEC, the ideal son-in-law?}

Mature EC are no doubt safe from tumour formation and are ready to form vessels in vivo. They are however difficult to obtain in an autologous fashion from a patient and hard to expand in culture. On the other side of the spectrum (Fig. 7), pluripotent stem cells have high expansion capacity but are at risk for tumour formation and therefore expelled from clinical application in wound healing. Within the multipotent group, fat-derived MSC appear to be very promising, regarding their ease of harvest, effect on vascularisation and expansion capacity. They carry however the theoretical risk of malignant transformation, which implicates they should be applied with caution. In our research, we focused on BOEC because they can be harvested with minimal donor site morbidity from any patient and can constitutively be expanded without risk of tumour formation. Whether they are able to intervene in other processes of wound healing is still largely unknown (Table 1).

\section{Growth factor cross-talk in wound healing: a conference call between wound} healing cells

How do wounds heal exactly? What makes fibroblasts produce organised collagen matrices and who tells keratinocytes to migrate over wound edges? There is no clear neuronal axis that tells the brain that tissue is damaged somewhere and that sends healing signals back from the brain to the wound. However, the wound healing process needs to be orchestrated and therefore, communication between cells in the healing wound is essential. Wound cells communicate with each other through special signalling peptides, cytokines, that exert their effects on other cells that have receptors for these cytokines ${ }^{124}$. Growth factors are an interesting group of cytokines. Besides acting as mitogens, they modulate cellular behaviour, matrix production and degradation, migration and attraction of cells. Many growth factors and cytokines are involved in wound healing, where they act as signals to coordinate the healing process. Here, we focus on some of these factors that are of particular interest in wound healing in general and in this project in particular.

The Fibroblast Growth Factor (FGF) family consists of over 20 members. FGF-2 or basic FGF stimulates angiogenesis, granulation tissue formation, fibroblast migration and proliferation, re-epithelialisation and synthesis of various extracellular matrix proteins ${ }^{125}$. Another member of this family, FGF-7 or Keratinocyte Growth Factor (KGF) specifically stimulates migration and proliferation of keratinocytes ${ }^{126}$.

Macrophage/monocyte Chemo-attractant Protein-1 (MCP-1) is a chemokine that attracts monocytes and macrophages. Even though exogenous addition of MCP1 yielded only moderate improvements in wound healing, mice lacking MCP-1 
had delayed wound healing with reduced re-epithelialisation, angiogenesis and hydroxylated collagen fibres ${ }^{127} 128$.

Hepatocyte Growth Factor (HGF), also known as Scatter Factor, stimulates the motility, migration, and morphological changes of a number of cell types, including EC and epithelial cells. HGF appears to be a potent stimulator of angiogenesis and modulator of proteolytic enzymes. Keratinocytes are known to highly express the HGF receptor and have been shown, in response to HGF, to rapidly increase their migration speed, which indicates its potential role in re-epithilialisation during the healing process ${ }^{129}$.

Granulocyte Macrophage-Colony Stimulating Factor (GM-CSF) and inflammatory cytokines as Interleukin-6 (IL-6) both induce keratinocyte proliferation. It has been suggested that GM-CSF works directly on keratinocytes, but also indirectly by upregulating IL-6. A role of GM-CSF in angiogenesis has also been suggested ${ }^{128 .}$

Platelet Derived Growth Factor (PDGF) is one of the earlier growth factors described in wound healing ${ }^{130}$. It stimulates proliferation of fibroblasts and production of dermal matrix as well as matrix remodelling by secretion of matrix metalloproteinases (MMP). Although less potent than VEGF or FGF, PDGF stimulates angiogenesis but has a particular role in vessel maturation by recruitment of pericytes. PDGF also plays a role in re-epithelialisation by upregulating the production of insulin growth factor-1 (IGF-1) and thrombospondin-1 ${ }^{128}$. Being involved in each stage of healing, being decreased in chronic wounds and being effective in clinical wound healing trials, it is the only growth factor currently approved by FDA in chronic wound treatment ${ }^{131}$.

Other factors act more on vessel formation and stability. Both Angiopoietins- 1 and -2 (Ang-1 and Ang-2) bind the Tie-2 receptor, Ang-1 being agonistic and Ang-2 being agonistic or antagonistic, depending on the context. It has been shown that Ang-1 can also activate Tie- 1 and its signal is amplified through heterodimeric interaction with Tie-2. Whereas Ang- 1 is involved in vessel maturation, attraction of pericytes and adhesion of mural cells to the endothelium, Ang-2 seems to be involved in vascular remodelling ${ }^{132}$.

Vascular Endothelial Growth Factor-A (VEGF-A) is a factor that is very well known for its effects on angiogenesis. It acts mainly through two receptors, VEGFR1 or fms-like tyrosine kinase-1 (FIt-1) and VEGFR2 or kinase domain receptor (KDR; fetal-liver kinase-1 or Flk-1 in mice). Whereas activation of Flt-1 leads to induced vascular permeability, stimulation of MMP-expression by vascular SMC and the induction of anti-apoptotic proteins, activation of Flk1 /KDR results in chemotaxis and proliferation of $\mathrm{EC}^{133}$. The angiogenic effect of VEGF-A is meditated through increased vascular permeability, degradation of the basement membrane by MMP- 
1, MMP-2 and stimulation of vascular SMC to express MMP-1, MMP-3 and MMP-9, and EC migration and proliferation ${ }^{12,133 .} \mathrm{We}^{12}$ and others ${ }^{128}$ have previously shown that VEGF-A expression enhances besides angiogenesis also granulation tissue formation and re-epithelialisation.

Another member of the VEGF family, Placental Growth Factor (PIGF), is a mediator of angiogenesis, by binding selectively to Flt-1. Interestingly, this factor is specifically involved in pathological angiogenesis by amplifying the effect of VEGF, in part by cross-talk between FIt-1 and Flk-1 ${ }^{134,135}$. PIGF overexpression in mouse skin was shown to firmly increase density, branching and SMC coating of blood vessels ${ }^{136}$, whereas PIGF-null mice display decreased SMC coating of blood vessels and delayed wound healing ${ }^{134}$. During wound healing, PIGF is expressed by migrating keratinocytes and EC, acting in a paracrine and autocrine way as both these cell types express FIt-1. PIGF is however in some cases also suggested as an angiogenesis inhibitor by forming PIGF/VEGF heterodimers which are up to 50 times less potent than VEGF homodimers ${ }^{137}$.

How these growth factors and cytokines exert their effects on wound healing is still largely unknown, but little by little the communication code of wound healing is unravelled. As growth factors are so important in wound healing, many attempts to improve wound healing are based on growth factor supplementation.

\section{Oxygen: the key to wound healing?}

Even though the importance of appropriate delivery of nutrients is obvious, the role of oxygen in wound healing remains controversial. Studies on wound healing ${ }^{138}$ demonstrate that oxygen tension in the wound centre is as low as $1 \%{ }^{139}$, which is consistent with our current measurements by electron paramagnetic resonance $(2.1 \pm 0.5 \%$ at day 5$)$ in our mouse model of wound healing. This hypoxic situation is not compatible with the high metabolic demands of the cells involved in the repair process ${ }^{140}$. Although inflammatory cells tend to use little oxygen as they produce energy for respiration via the hexose-monophosphate-shunt, oxidant production (for bacterial killing), collagen synthesis, angiogenesis and re-epithelialisation require oxygen in a high concentration ${ }^{141 .}$

On the other hand, acute hypoxia is a necessary trigger to initiate many aspects of the healing process. Tissue hypoxia activates the HIF1a-SDF-1 cascade in attraction of angiogenic cells ${ }^{140,142}$. The constitutive (aerobic) production of lactate by inflammatory cells and fibroblasts is an additional and sufficient angiogenic trigger ${ }^{141}$. The initial wound bed hypoxia further triggers keratinocytes to migrate over the wound edges ${ }^{143}$. On the contrary, sustained hypoxia on the contrary leads to tissue loss ${ }^{140}$ and therefore restoration of oxygen levels is mandatory for proper wound healing. 
The importance of oxygen in collagen synthesis has been well documented. An important step in the development of the final helical structure of collagen is the hydroxylation of the proline residues, which is oxygen dependent ${ }^{144}$. Hypoxia leads to the formation of an unstable triple helix that cannot be used for the assembly of neatly organised collagen fibrils ${ }^{145}$. The underlying molecular mechanisms by which oxygen tension regulates matrix organisation are incompletely understood. Siddiqui et al. ${ }^{146}$ noted an initially increased fibroblast replication and adequately hydroxylated collagen synthesis in response to hypoxia, likely through an autocrine mechanism via hypoxiainduced up-regulation of TGF $\beta 1$. This effect disappeared promptly after 3 days, leading to reduced fibroblast proliferation and collagen synthesis. Accordingly, Steinbrech et al. ${ }^{147}$ described increased collagen type I mRNA expression by fibroblasts upon hypoxia in vitro, an effect that is however abruptly down-regulated after 48 hours. Unfortunately, the latter authors only measured collagen-mRNA expression and did not look for protein expression.

\section{Fibroblasts: more than just a dermal matrix factory}

Dermal substitutes have been used since decades to obtain a more elastic, natural skin that is less prone to contraction ${ }^{148,149}$ (Fig. 4). Whereas acellular dermal substitutes have been used experimentally and clinically to reduce wound contraction, true regeneration of the dermis was never achieved ${ }^{150}$. Dermal substitutes seeded with autologous dermal fibroblasts have proven to be far superior in restoring a properly organised dermal matrix, compared to acellular matrices ${ }^{151}$. Several fibroblast-containing dermal substitutes, with or without keratinocytes, have been approved for clinical use (e.g. Dermagraft $^{\circledR}$, Apligraf $^{\circledR}$, Orcel $\left.^{\circledR}\right)^{152}$ and all of them rely on an artificial matrix to deliver the fibroblasts. These cellular matrices are dependent on quick and decent vascularisation for the survival of the dermal and epidermal cells ${ }^{153}$, as cells more than $200 \mu \mathrm{m}$ away from blood vessels become oxygen-deprived ${ }^{6}$ and in skin grafts thicker than $400 \mu \mathrm{m}$, blood vessels cannot penetrate quickly enough to feed the epidermal layer ${ }^{154}$. It has been shown that inclusion of fibroblasts in a decellularised dermal matrix also reduces wound contraction ${ }^{155,156}$. Indeed, administration of dermal fibroblasts to the wound decreases fibroblast invasion from the wound edges ${ }^{151}$ and these invading fibroblasts are prone to differentiate into protomyofibroblasts that become myofibroblasts, probably upon TGF $\beta 1$ stimulation. Besides, fibroblasts produce numerous growth factors and other cytokines that are involved in wound healing ${ }^{128}$. It is beyond doubt that fibroblasts play an essential role in wound healing, hence their popularity in STE. 


\section{BOEC and fibroblasts: do they go together like a horse and carriage?}

Fibroblasts are indispensable in dermal healing and are valuable candidates for implementation in STE. To function properly in a dermal substitute, fibroblasts need oxygen and nutrient delivery for proliferation and decent matrix production. Thus, survival of cell-seeded constructs depends on quick vascularisation. It therefore seems logical to combine fibroblasts with endothelial-like cells. Indeed, previous publications report on the fruitful combination of fibroblasts with HUVEC ${ }^{5}$ or HDMEC ${ }^{21}$. As BOEC can be harvested with minimal donor site morbidity, can be expanded ex vivo and are readily predestined to form vessels in vivo, a combined approach of BOEC and fibroblasts was most appealing to us. As the role of fibroblasts in wound healing is rather well described, we especially focused our work here on the role of BOEC in wound healing and in STE, and investigated the strategy of combining them with a dermal substitute consisting of multilayered dermal fibroblast sheets.

\section{Keratinocytes: just the topping of engineered skin?}

Wound closure essentially means restoration of the epidermal layer. In large defects, this is achieved by skin grafting or application of cultured keratinocytes, whereas small defects tend to re-epithelialise spontaneously. Since re-epithelialisation is impaired in chronic wounds ${ }^{157}$, many wound healing strategies focus on improved keratinocyte migration, proliferation and differentiation. Importantly, keratinocytes do not act on their own, but closely interact with the other cells involved in the healing process. They produce IL-1, a factor that stimulates fibroblasts to produce important keratinocyte mitogens in return ${ }^{158}$, such as IL-6, GM-CSF and KGF. A decently formed basement membrane is important for dermal-epidermal adhesion. Laminin 5 is one of the major components of the basement membrane and is exclusively produced by keratinocytes ${ }^{159}$, whereas other components are both fibroblast- and keratinocyte-derived. Also, keratinocytes produce growth factors that modulate fibroblast behaviour, such as TGF- $\alpha$, EGF and PDGF, and proteinases that modulate the newly formed dermal matrix to expose appropriate epitopes for their own migration ${ }^{160}$. Keratinocyte-derived TGF- $\beta$ is a trigger for fibroblasts to differentiate towards myofibroblasts ${ }^{157}$, in an attempt to reduce the non-epithelialised wound surface by wound contraction. On the other hand, fibroblasts provide a matrix that serves as a guidance grid for migration of keratinocytes and produce cytokines that modulate keratinocyte behaviour ${ }^{128}$. Keratinocytes should thus not be regarded as merely coverage of wounds, but as active mediators of the healing process. Therefore, they are included in many engineered skin constructs. Already in the 1980's, fibroblast-seeded dermal matrices were used clinically in combination with keratinocytes for coverage of burn wounds (Fig. 5). Besides, both cells produce angiogenic growth factors ${ }^{128}$ to insure appropriate delivery of oxygen and nutrients. Considering the principal role both fibroblasts and keratinocytes play in wound healing, we intended to examine the possible interaction of BOEC with both key players. 

La clef de toutes les sciences est sans contredit le point d'interrogation; nous devons la plupart des grandes découvertes au comment?

Et la sagesse dans la vie consiste peut-être à se demander, à tout propos, pourquoi?

(Honoré de Balzac)

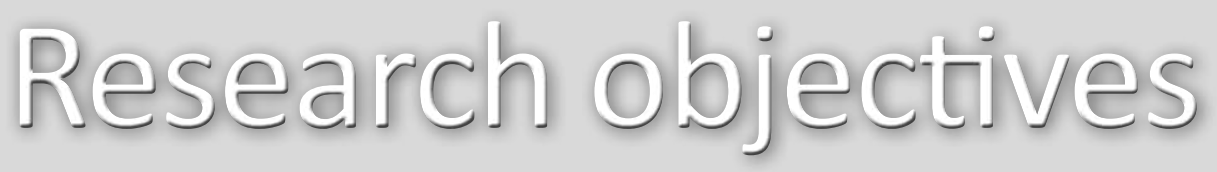



In the introduction we made the argument that vascularisation as a route to deliver oxygen is the cornerstone of the wound healing process and that BOEC have very promising features for re-vascularisation strategies. We further emphasised the importance of growth factors to orchestrate cellular communication during wound healing and the essential role of fibroblasts in STE approaches. Therefore, in this doctoral thesis the overall aim was to explore in a preclinical mouse model the potential of BOEC for improving wound healing, singly or in combination with a selfassembled dermal substitute, consisting of human dermal fibroblast sheets (hDFS).

The specific objectives of this work were to:

1. obtain a reproducible isolation protocol for BOEC from humans (hBOEC; to be tested in immunedeficient mice) and pigs (pBOEC; for future testing in an immunecompetent larger animal model prior to clinical use);

2. fully characterise $B O E C$ in terms of gene/protein expression, in vitro functionality and growth factor expression and compare these characteristics with other cells used for vascularisation purposes such as HUVEC and early EPC in order to accurately position them in the endothelial (progenitor) cell hierarchy;

3. apply hBOEC, hDFS or a combination of both in a full thickness wound healing model, to analyse the effects on vascularisation/oxygenation, dermal and epidermal healing and wound contraction;

4. compare the latter effects on wound healing with that of mature $E C$ that have previously been used in STE, such as HUVEC;

5. dissect out the mechanisms by which hBOEC and hDFS exert their effect on dermal and epidermal wound healing.

The main clinical finality of our current work was to explore the feasibility of using a fully autologous approach to make a vascularised dermal equivalent for reconstruction of large skin defects, such as in patients with burns or large surgical wounds.

If a man will begin with certainties, he shall end in doubts, but if he will be content to begin with doubts, he shall end in certainties. 

Peu lire, beaucoup voir, beaucoup faire.

(Baron Guillaume Dupuytren)

Materials \& Methods 



\section{Cell derivation, culture freezing/thawing and lentiviral transduction}

\subsection{Human BOEC (hBOEC)}

Venous blood samples $(40 \mathrm{ml})$ were obtained from healthy human donors volunteers age 28-35 and anticoagulated with $100 \mathrm{IU} / \mathrm{ml}$ heparin. The mononuclear cell fraction was isolated by density centrifugation using a slightly modified protocol as described by Yoder et al ${ }^{66}$. Briefly, blood was diluted $1: 1$ in PBS, containing $2 \%$ foetal bovine serum (FBS) and $1 \%$ penicillin/streptomycin/amphotericin (PSA). This mixture was layered onto $25 \mathrm{ml}$ Ficoll-Paque (GE Healthcare, Diegem, Belgium) and centrifuged at $750 \mathrm{~g}$ for 30 minutes. The buffy coat was aspirated, washed 3 times in PBS and cells were resuspended in EBM-2 supplemented with bullet kit (Lonza, Verviers, Belgium) and $1 \%$ additional PSA, and plated on collagen type I-coated dishes (Greiner Bio One $\mathrm{GmBH}$, Frickenhausen, Germany). During the first week, media was changed daily and afterwards every other day. Colonies with typical cobble-stone morphology started to appear from day 11 onwards (Fig. 8). Mycoplasma contamination was excluded, using the MycoalertMycoplasma Detection kit (Cambrex, Milan, Italy), following the manufacturer's instructions. hBOEC from passage 2 to 4 were used for animal experiments.

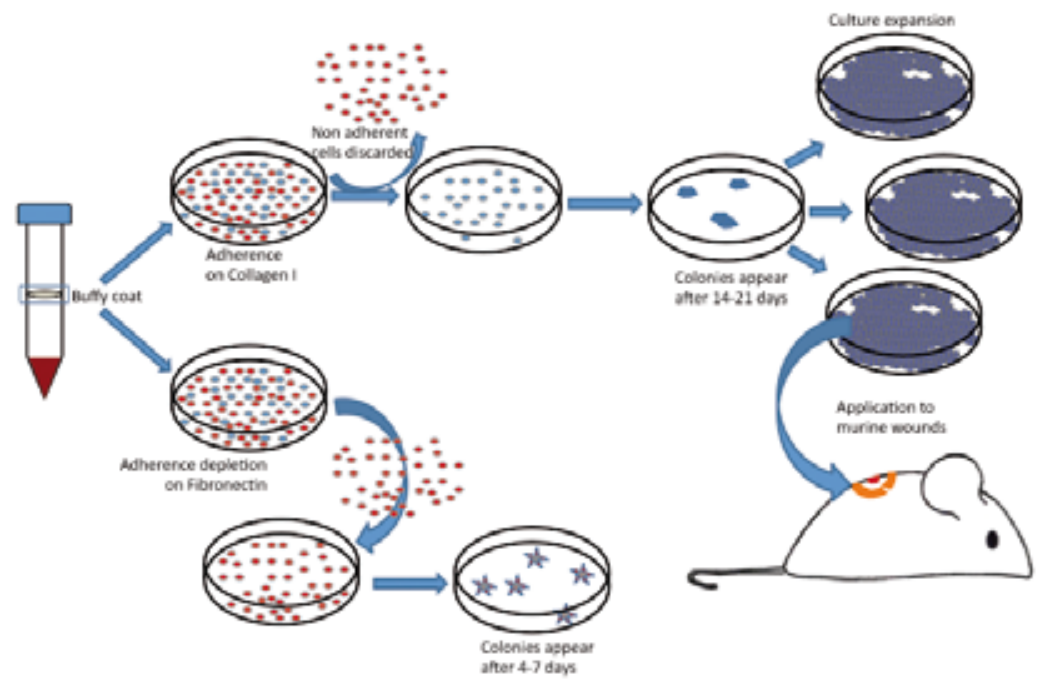

Figure 8. Isolation of $h B O E C$ and early EPC. Mononuclear cells were obtained from peripheral blood after density centrifugation and the buffy coat was plated onto collagen type l-coated dishes (for $B O E C$ isolation) or fibronectin-coated dishes (for early EPC isolation). Medium was changed regularly in collagen-coated plates, to remove non-adherent cells. BOEC colonies appeared after 2-3 weeks and could be expanded prior to use in our wound healing model. After 48 hours, non-adherent cells from the fibronectin-coated dishes were replated and colonies of early EPC were visible after 4-7 days. 


\subsection{Human early EPC}

Mononuclear cell fractions were obtained from peripheral blood of healthy volunteers by density centrifugation as described above and plated at $5 \times 10^{6}$ cells/6-well onto fibronectin-coated dishes in Dulbecco's Modified Eagle Medium (DMEM; high glucose) supplemented with $10 \%$ FBS and antibiotics. Forty-eight hours later, the non-adherent cells were transferred to fibronectin-coated 24-well plates and seeded at $1 \times 10^{6}$ cells per well. Colonies with rounded cells in the centre and larger flat cells radiating from the centre appeared after 4-7 days (Fig. 8).

\subsection{Porcine BOEC (pBOEC)}

One year old female Yorkshire pigs were anesthetised with $5 \mathrm{ml}$ i.m. zolazepam/ tiletamine (Zoletil 100; Vibrac, Carros, France) and 2ml xylazine (Xyl-M 2\%; VMD, Arendonk, Belgium). Pigs were intubated with a $7.5 \mathrm{~mm}$ endotracheal tube and anesthesia was maintained with 0.7-1.5 \% isoflurane (ISOBA, Abott Laboratories, Shering-Plough, Heist-op-den-Berg, Belgium). If possible, venous blood samples were obtained by catheterisation of the ear veins; otherwise, a transverse incision was made in the groin region, the femoral vein was dissected and catheterised. Fifty $\mathrm{ml}$ venous blood was aspirated, supplemented with $600 \mathrm{mg}$ clindamycin (Dalacin Pharmacia, Puurs, Belgium), and anticoagulated with $100 \mathrm{lU}$ heparin/ml (Leo Pharma NV, Wilrijk, Belgium). Blood samples were diluted 1:1 using PBS containing $2 \%$ FBS and $1 \%$ penicillin/streptomycin/amphotericin (PSA). This mixture was layered onto $25 \mathrm{ml}$ Histopaque 1083 (Sigma Aldrich, Bornem, Belgium) and centrifuged at $550 \mathrm{~g}$ for 20 minutes. The buffy coat was aspirated, washed 3 times in PBS and cells were resuspended in EBM-2 supplemented with bullet kit without hydrocortisone (Lonza, Verviers, Belgium) and $1 \%$ additional PSA, and plated on collagen type I-coated dishes (Greiner Bio One $\mathrm{GmBH}$, Frickenhausen, Germany). During the first week, media was changed daily and afterwards every other day. Colonies appeared as soon as after 5-6 days. All animals received human care in compliance with the principles of laboratory animal care (Royal Decree of 14 November 1993, Belgium) and the European Directive 86/609/EEC.

\subsection{HUVEC}

Umbilical cords were stored in isotonic buffer supplemented with antibiotics until the start of the isolation procedure. To obtain HUVEC, the umbilical vein was cannulated, rinsed with PBS to get rid of blood clots, injected with collagenase type I $(7.5 \mathrm{mg} /$ $\mathrm{ml}$; Gibco) and incubated for 20 minutes at $37^{\circ} \mathrm{C}$. Detached HUVEC were collected, washed with PBS and plated on gelatin-coated flasks ( $0.1 \%$ gelatin) in IMDM with $20 \%$ foetal calf serum and $1 \%$ penicillin/streptomycin. After 24 hours cells were washed 
twice with PBS to remove non-adherent hematopoietic cells. Cells were maintained in culture until $75-80 \%$ confluence and were replated to a confluence around $20-25 \%$. From passage 1, HUVEC were cultured in EBM-2 supplemented with EGM-2-MV bulletkit (Lonza, Verviers, Belgium). Cells used for in vitro and in vivo experiments were between passage 5 and 7 .

\subsection{BOEC freezing and thawing}

hBOEC or pBOEC were divided up in aliquots of $2 \times 10^{6}$ cells and resuspended in $1 \mathrm{ml}$ freezing medium containing 70\% EGM-2, 20\% FBS and 10\% DMSO. Samples were stored in isopropanol-buffered freezing boxes in $-80^{\circ} \mathrm{C}$ for 48 hours, before being transferred to liquid nitrogen storage tanks. Cells were thawed rapidly by putting the freezing vials at $37^{\circ} \mathrm{C}$ in a water bath. The content of each freezing vial was aspirated into $9 \mathrm{ml}$ of fresh growth media, taking care to gently mix the DMSO-containing freezing media with the fresh media by air-aspiration. DMSO was removed by centrifugation and cells were plated in collagen type l-coated $10 \mathrm{~cm}$ dishes (Greiner Bio One $\mathrm{GmBH}$, Frickenhausen, Germany). The day after, medium was replaced to remove dead cells.

\section{6. hBOEC and HUVEC lentiviral transduction}

hBOEC at passage 1 or HUVEC at passage 5 were plated at $75-80 \%$ confluence in collagen type I-coated plates in complete growth media. Cells were incubated with lentivirus (Multiplicity of infection or MOI 100) overnight, after which media was changed to complete growth media. Cells were expanded as described above. Transduction efficiency was monitored by FACS and was $\sim 100 \%$ for all viruses (data not shown). Virus constructs used were: PGK-GFP (hBOEC; Fig. 9A), pTripMR1-CMVDsRedscrambled_shRNA (hBOEC and HUVEC; control virus; Fig. 9B) and pTripMR1CMVDsRed-shPIGF1 (hBOEC; Fig. 9C). PIGF ${ }^{K D}$ virus-knockdown efficiency by the latter virus was monitored by ELISA (R\&DSystems) on supernatant and by qRT-PCR on RNA from the transduced cells compared to cells that were treated with control virus. Target sequences used in the pTripMR1-CMVDsRed-scrambled_shRNA virus and the pTripMR1-CMVDsRed-shPIGF1 virus were 5' GGTATCTACTAGATGTACT 3' and 5' AAGCCAGATTCTCTTGAAT 3', respectively. 

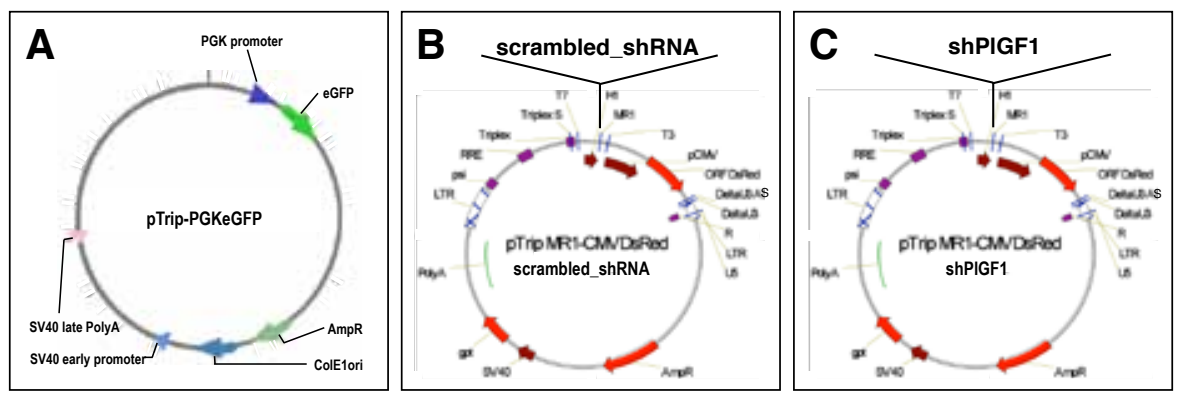

Figure 9. Vector maps of the lentiviral constructs for hBOEC transduction. A, PGK-GFP vector, used for scoring of hBOEC engraftment. $B, C$, PIGF transcription was knocked down using a short hairpin construct against PIGF $(C)$. A scrambled shRNA vector $(B)$ served as negative control. Note the presence of CMV-promoted DsRed in both vectors, providing an additional tool to trace transduced cells in vivo.

\subsection{Human DFS}

Dermal fibroblasts were isolated out of human skin samples, incubated with dispase II (Roche Diagnostics, Vilvoorde, Belgium) overnight at $4^{\circ} \mathrm{C}$ and afterwards for 3 hours at $37^{\circ} \mathrm{C}$ to remove the epidermis. The dermal component was finely minced and then incubated at $37^{\circ} \mathrm{C}$ for 3 hours with collagenase type IA (Sigma Aldrich, Bornem, Belgium). The digested dermal fragments were then gently scraped using a skin scraper, and the resulting suspension filtered through a $100 \mu \mathrm{m}$ cell strainer (BD Biosciences, Erembodegem, Belgium). The filtrate was spun at $400 \mathrm{~g}$ for 7 minutes, the pellet resuspended and the cells plated on plastic, non-coated Petri dishes in media consisting of 3:1 DMEM:Ham's F12, supplemented with $1 \%$ PSA, $10 \%$ FBS, $4.2 \times 10^{-4} \mathrm{mg} / \mathrm{ml}$ hydrocortisone, $0.021 \mathrm{mg} / \mathrm{ml}$ adenine, $2.1 \times 10^{-5} \mathrm{mg} / \mathrm{ml}$ epidermal growth factor (EGF), $5 \times 10^{-3} \mathrm{mg} / \mathrm{ml}$ transferrin, $1.4 \times 10^{-6} \mathrm{mg} / \mathrm{ml}$ tri-iodothyronine, $5.3 \times 10^{-3} \mathrm{mg} / \mathrm{ml}$ insulin and $5.3 \times 10^{-5} \mathrm{mg} / \mathrm{ml}$ ascorbate. The fibroblasts were expanded up to the third passage and then grown into multilayered lawns, changing the media every third day. After 2-3 weeks, the fibroblast layers were thick enough to be manipulated using fine forceps for engineering them into a three-dimensional fibroblast sheet with the use of a carrier membrane (N-Terface, Delasco, Council Bluffs, USA) (Fig. 10). 

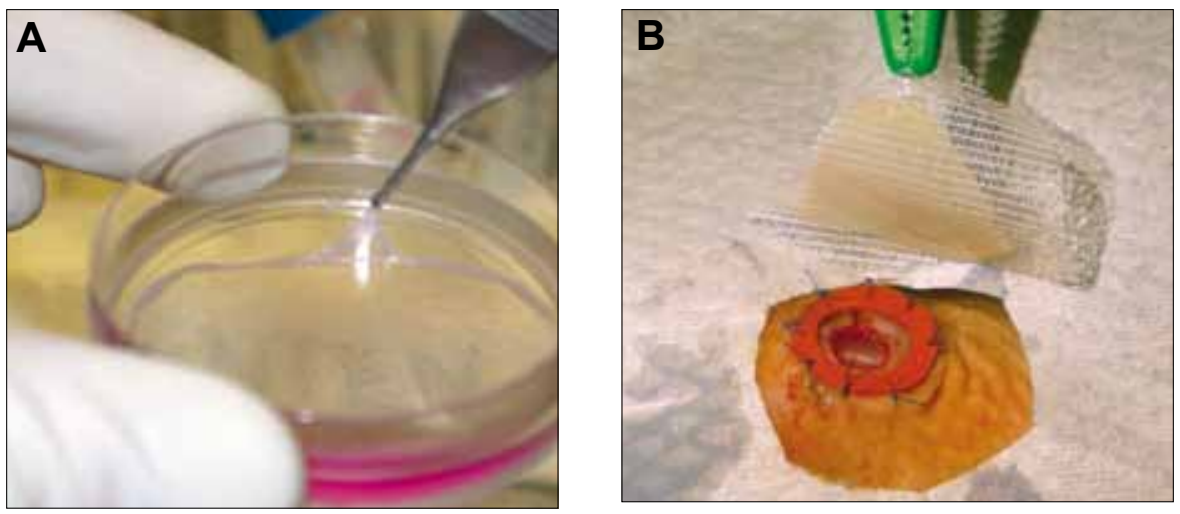

Figure 10. Dermal fibroblast sheets serve as a dermal substitute. Dermal fibroblasts were grown in multilayered sheets that could be handled with a forceps $(A)$. A commercially available carrier membrane facilitated DFS application in our wound healing model $(B)$.

\subsection{Human (h)Keratinocytes}

Primary keratinocytes were isolated and pooled from foreskins of five different donors (less than 6 years old) as described ${ }^{162}$. Third to fifth passage cells were used in experiments. Keratinocytes were cultured in serum-free media (Keratinocyte-SFM; Invitrogen, Belgium), which harbours several growth factors $(5 \mathrm{mg} / \mathrm{ml}$ insulin, $74 \mathrm{ng} /$ $\mathrm{ml}$ hydrocortisone, $6.7 \mathrm{ng} / \mathrm{ml}$ triiodo-L-thyronine, $50 \mathrm{mg} / \mathrm{ml}$ bovine pituitary extract, and $5 \mathrm{ng} / \mathrm{ml}$ human recombinant EGF).

\section{Cell characterisation}

hBOEC, early EPC, HUVEC, hDFS and hKeratinocyte cultures were analysed under various conditions for their expression profile by quantitative (q)RT-PCR. hBOEC and early EPC were phenotyped by FACS and/or immunofluorescence (a list of FACS and immunofluorescence antibodies is provided in Table 2) and were functionally evaluated by the Dil-acetylated LDL (Dil-AcLDL) uptake assay, UEA-lectin binding and by tube formation onto matrigel, as described ${ }^{111}$. hDFS incubated either in normoxic $\left(20 \% \mathrm{O}_{2}\right)$ or hypoxic $\left(1 \% \mathrm{O}_{2}\right)$ conditions, were characterised following fixation, paraffin embedding and sectioning. Sirius red-stained $7 \mu \mathrm{m}$ sections were used for analysing matrix organisation (polarised light). Some of the hDFS were fixed in $2.5 \%$ glutaraldehyde for transmission electron microscopy (TEM). All experiments involving human cell/tissue donors were performed with approval of the Ethical Committee of the University Hospital, UZLeuven. 


\begin{tabular}{|c|c|c|c|c|}
\hline Antigen & Target species & Supplier, catalog $\mathrm{N}^{\circ}$ & Dilution & $\begin{array}{c}\text { Label/ } \\
\text { Application }\end{array}$ \\
\hline vWF & Human & $\begin{array}{l}\text { Santa Cruz, } \\
\text { Sc-14014 }\end{array}$ & $1: 20$ & None/IF \\
\hline CD31 & Human & DAKO M0823 & $1: 25$ & None/IF \\
\hline CD31 & Human & $\begin{array}{l}\text { BD Pharmingen } \\
555445\end{array}$ & $1: 20$ & FITC/FACS \\
\hline$\alpha-S M A$ & human/mouse & Sigma C-6198 & $1: 200$ & Су-3/IF \\
\hline CD31 & Mouse & $\begin{array}{c}\text { BD Pharmingen } \\
557355\end{array}$ & $1: 500$ & None/IF or IHC \\
\hline CD45 & Human & $\begin{array}{c}\text { BD Pharmingen } \\
345808\end{array}$ & $1: 20$ & FITC/FACS \\
\hline UEA lectin & Human & Sigma L9006 & $1: 50$ & FITC/IF \\
\hline KDR & Human & $\begin{array}{c}\text { ReliatechGmBH } \\
\text { 101-MBi32 }\end{array}$ & $1: 10$ & biotin/FACS \\
\hline Tie-2 & Human & $\begin{array}{c}\text { ReliatechGmBH } \\
\text { 101-MBi54 }\end{array}$ & $1: 10$ & biotin/FACS \\
\hline VE-cadherin & Human & Cayman 160840 & $1: 40$ & None/IF in vitro \\
\hline AcLDL & & $\begin{array}{l}\text { Biomedical } \\
\text { Technical Inc. }\end{array}$ & $1: 20$ & Dil/FACS \\
\hline Pancytokeratin & Mouse & Sigma C2562 & $1: 1000$ & None/IHC \\
\hline Connexin43 & human/mouse & $\begin{array}{l}\text { Santa Cruz } \\
\text { sc-9059 }\end{array}$ & $1: 50$ & None/IF \\
\hline $\begin{array}{l}\text { Hypoxyprobe-1- } \\
\text { Mab }\end{array}$ & Mouse & $\begin{array}{c}\text { Chemicon clone } \\
4.3 .11 .3\end{array}$ & $1: 50$ & None/IHC \\
\hline $\lg G 1 k$ & & $\begin{array}{l}\text { BD Pharmingen } \\
555909\end{array}$ & $1: 20$ & $\begin{array}{l}\text { FITC/FACS } \\
\text { isotype }\end{array}$ \\
\hline $\lg G 1 k$ & & $\begin{array}{c}\text { BD Pharmingen } \\
555747\end{array}$ & $1: 10$ & $\begin{array}{l}\text { biotin/FACS } \\
\text { isotype }\end{array}$ \\
\hline Flt-1 (VEGFR1) & Human & Sigma V4262 & $1: 500$ & Western blot \\
\hline$\alpha$-tubulin & Human & Sigma T6199 & $1: 1000$ & Western blot \\
\hline
\end{tabular}

Table 2. Antibodies used for FACS, immunohistology and Western blot. 


\section{Mice, surgery, transplantation and follow-up}

In this study, we chose to use male mice in order to eliminate the confounding effect of female hormones on wound healing ${ }^{163}$. Athymic nude Foxn1 males (age 9-12 weeks) were anesthetised with an i.p. injection of ketamine $(100 \mathrm{mg} / \mathrm{kg})$ and xylazine $(10 \mathrm{mg} / \mathrm{kg})$. Atropine $(0.01 \mathrm{mg} / \mathrm{kg})$ was administered i.p. as premedication. Under sterile and temperature-controlled $\left(37^{\circ} \mathrm{C}\right)$ conditions, standardised full thickness wounds were made with a $0.5 \mathrm{~cm}$ biopsy puncher (Stiefel Laboratories, Offenbach am Main, Germany) on the back of the mouse in the mid-dorsal region. A silicone ring was fixed (using Histoacryl tissue adhesive, Braun, Diegem, Belgium) and sutured around the wound (Fig. 11) and wounds were treated with saline, $5 \times 10^{5} \mathrm{hBOEC}, 5 \times 10^{5}$ HUVEC, hDFS or hDFS seeded with $5 \times 10^{5} \mathrm{hBOEC}$. For doseresponse studies, some mice were transplanted with $1 \times 10^{6}$ or $1.5 \times 10^{6} \mathrm{hBOEC}$. An occlusive dressing (Tegaderm ${ }^{\circledast}, 3 \mathrm{M}$, Diegem, Belgium) was used to keep the wound moist.
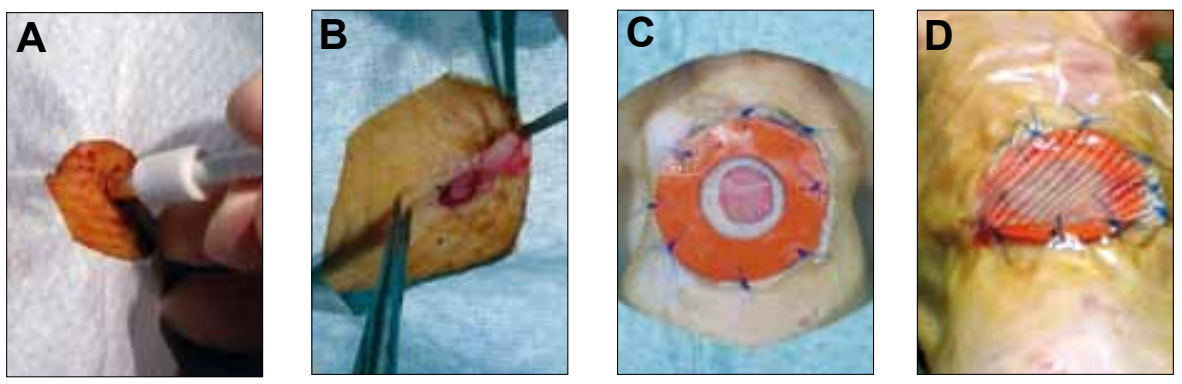

Figure 11. Wound healing model. Using a skin biopsy puncher $(A)$, full thickness wounds $(B)$ were made on the back of athymic nude mice. A silicone ring was glued and sutured to splint the wound $(C)$ and after application of HUVEC, hBOEC and/or hDFS, the wound was covered with a semi-occlusive dressing $(D)$.

In addition, all wounded mice were housed individually to avoid fighting and to prevent removal of the occlusive wound dressing. Postoperative analgesia was achieved by a subcutaneous injection of buprenorphin $(0.1 \mathrm{mg} / \mathrm{kg})$. Every other day, digital pictures were taken (using a NikonD1 camera and Camera Control Pro software, Nikon, Brussels, Belgium) of the wounds, under isofluorane anaesthesia, at which time the occlusive dressing was renewed. In some mice, wound blood flow was monitored every other day by scanning the area including the entire ring with a Lisca PIM II (Gambro, Breda, The Netherlands; Fig. 12) under temperature-controlled conditions, using the normal skin region under the processus xyphoideus for normalisation. Vascularisation was peaking at day 4 and day 8 in hBOEC-treated wounds, which made us decide to examine the wounds histologically at time points following the two peaks, i.e. at day 5 and day 10 (Fig. 12). 
Electron paramagnetic resonance (EPR) oximetry was performed under isoflurane anaesthesia and temperature-controlled conditions $\left(37^{\circ} \mathrm{C}\right)$ using an EPR spectrometer (Magnettech, Berlin, Germany) operating at $1.2 \mathrm{GHz}$ with an extended loop resonator placed over the head of the mice, 24 hours after implantation of Lithium-Phtallocyanin crystals in the wound bed ${ }^{164}$. Mice were housed in specific pathogen-free conditions and procedures involving animals were performed according to the guidelines of the Institutional Animal Care and Use Committee of KULeuven.
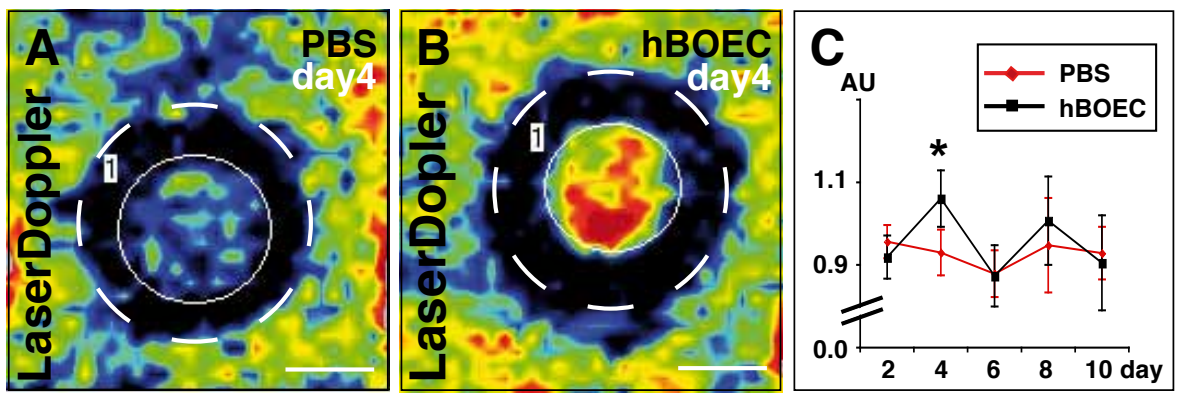

Figure 12. Laser doppler analysis. Representative laser doppler scans of a wound treated with PBS $(A)$ or hBOEC $(B)$ at day 4 , revealing more perfusional activity in the latter. When flow patterns were followed-up every other day after wound surgery, two peaks of increased blood flow could be detected in the hBOEC-treated wounds (black line in $C$ ), which were not observed in PBS-treated wounds (red line in $C$ ). Data in $C$ are expressed as arbitrary units (AU) representing an average of 5 scans for each wound relative to an average of 5 scans of normal skin. Scale bars: $3 \mathrm{~mm}$ in $A, B$.

\section{Live imaging and wound morphometry}

Live imaging of cell engraftment was performed under anaesthesia $(100 \mathrm{mg} / \mathrm{kg}$ ketamine $+10 \mathrm{mg} / \mathrm{kg}$ xylazine) using a Zeiss Lumar dissection microscope (Zeiss, Zaventem, Belgium). Wound contraction was evaluated by comparing relative wound area (RWA) over time. On a two-daily basis, digital pictures were taken of the wound and RWA was calculated using ImageJ software (NIH, Baltimore, Maryland) by dividing the healing wound area by the fixed reference area inside the silicone ring and expressing it as a percentage. To account for small inter-animal variations, for each time point, relative wound area of each individual animal was expressed as percentage compared to the relative wound area at day 0

$$
\left[\mathrm{RWA}_{\text {corrected }}=\left(\mathrm{RWA}_{\text {dayx }} / \mathrm{RWA}_{\text {day }}\right) \times 100\right] \text {. }
$$

Wound contraction \% was calculated as the complement of relative wound area

$$
\text { [100-RWA } \text { corrected }_{\text {. }} \text {. }
$$




\section{Tissue processing, histology and microscopy}

At two time points (day 5 and 10) after wounding, mice were sacrificed and square skin fragments including the circular wound area and a rim of normal skin were dissected out, rinsed in PBS and post-fixed overnight at $4^{\circ} \mathrm{C}$ using zinc-paraformaldehyde. Following fixation, the skin fragments were separated in two equal pieces at the midline of the wound and processed for paraffin or optimal cutting temperature (OCT) embedding.

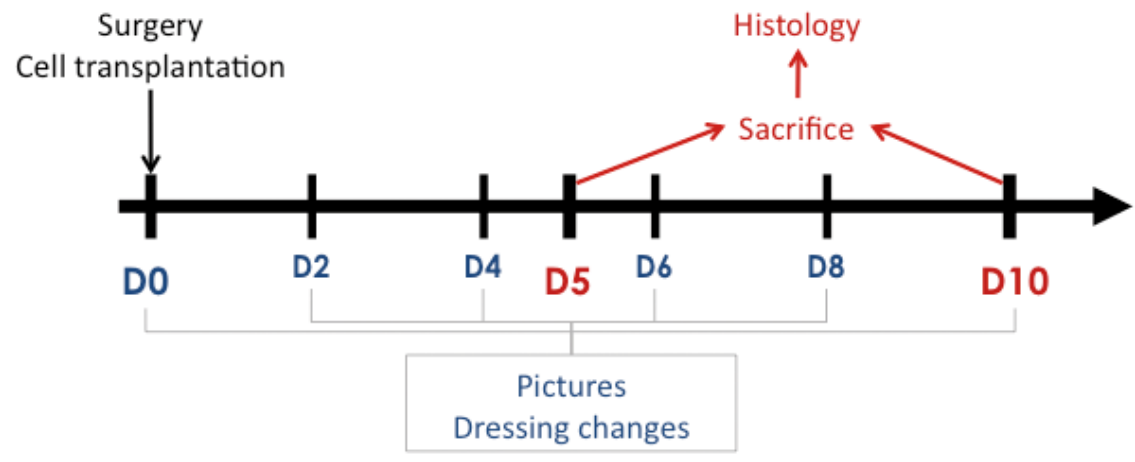

Figure 13. Chronologic presentation of the wound healing experiment. Cells were transplanted immediately after wounding. On a two-daily basis, dressings were changed and pictures were taken. According to the blood flow peaks on laser doppler examination, mice were sacrificed at day (D)5 and D10 for histological evaluation.

In some mice, half of the tissue was fixed with glutaraldehyde $(2.5 \%$ in $0.1 \mathrm{M} \mathrm{Na}$ cacodylate buffer, $\mathrm{pH} 7.3$ ) followed by post-fixation with $2 \%$ osmiumtretroxide and embedding in EPON 812 resin. From the polymerised resin blocks, semi-thin sections of $0.5-1 \mu \mathrm{m}$ were made and stained with $1 \%$ toluidin blue in $1 \%$ borax for light microscopic observation. Ultra-thin sections $(70 \mathrm{~nm})$ were placed on copper grids and contrasted with $4 \%$ uranyl acetate. For TEM, a JEM2100 microscope (JEOL, Zaventem, Belgium) at $200 \mathrm{kV}$ was used to record images of collagen bundles. For all stainings and analyses, 7 or $8 \mu \mathrm{m}$ sections were used spanning a representative area of $\sim 0.7-1.4 \mathrm{~mm}$ wide. Hematoxylin\&eosin (H\&E) and Sirius red stainings were performed as described ${ }^{165}$. Sirius red is an azo-dye that interacts with positively charged groups on collagen and the resulting parallel orientation with the long axes of the collagen fibres results in enhanced birefringency under polarised light ${ }^{166}$. The birefringency colour further changes as a function of collagen organisation, more specifically, the diameter and packaging of the collagen fibres ${ }^{167}$ : thick, closely packed collagen appears as red-orange birefringent, whereas loosely packed, thin collagen is yellow-greenish birefringent. 
Detection of hypoxic cells was done using Hypoxyprobe ${ }^{\mathrm{TM}}$ (pimonidazole hydrochloride, which specifically binds to cells that have $\mathrm{O}_{2}$ concentrations of less than $14 \mu \mathrm{M}$ and are therefore hypoxic), according to the manufacturer's instructions (Millipore, Brussels, Belgium), as described ${ }^{168}$. Briefly, 60 minutes before sacrifice at day 5 after wounding, mice were i.p. injected with $60 \mu \mathrm{g} / \mathrm{g}$ Hypoxyprobe $^{\mathrm{TM}}$. After perfusion-fixation, wounds were dissected out, post-fixed, dehydrated and embedded in paraffin. Seven $\mu \mathrm{m}$ sections were stained with a mAb against Hypoxyprobe ${ }^{\mathrm{TM}}$, provided in the kit. Serial sections were stained for mouse and human-cell-derived blood vessels to allow for correlation studies between re-vascularisation and hypoxia. For immunohistochemistry and immunofluorescence, a list of primary antibodies and corresponding working dilutions is provided in Table 2. To rule out cross-reactivity of human- or mouse-specific antibodies or lectins, they were tested on sections of both human and mouse skin samples (Fig. 14). Pictures for morphometric analysis were taken using a Zeiss Axio Imager connected to an Axiocam MRc5 camera (Zeiss) and analysis/image recording was performed using Axiovision (Zeiss), Image $\mathrm{J}(\mathrm{NIH})$ or KS300 (Leica) software.
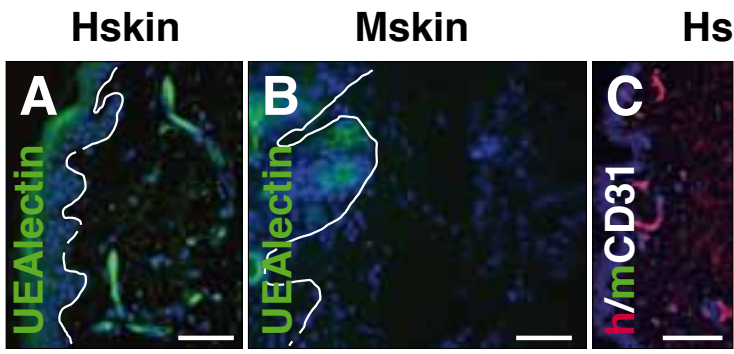

Hskin

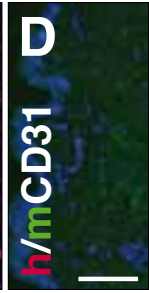

Mskin

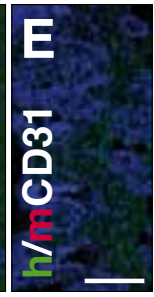

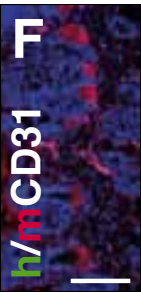

Figure 14. Species-selectivity of antibodies. $A, B$, Cross-sections of human skin (Hskin in $A$ ) and mouse skin (Mskin in $B$ ) with Ulex Europaeus Agglutinin (UEA)-lectin in green revealing the specific binding of this lectin to human endothelium. $\boldsymbol{C}-\boldsymbol{F}$, Cross-sections of human skin (Hskin in $C, D)$ and mouse skin (Mskin in in E,F) double-stained with human-specific CD31 in red and mouse-specific CD31 in green $(C, D)$ or double-stained with human-specific CD31 in green and mouse-specific CD31 in red $(E, F)$ revealing the species specificity of both antibodies. DAPI (blue) was used as nuclear counterstain in $A-F$. Scale bars: $100 \mu \mathrm{m}$ in $A, B, 150 \mu \mathrm{m}$ in $C-F$.

\section{Visualisation of BOEC and HUVEC engraftment}

To visualise the cells using fluorescence microscopy, some animals were transplanted with hBOEC labelled with Dil-AcLDL (Fig. 23B-D) immediately before transplantation or transduced with a lentiviral construct expressing GFP (PGK-GFP; Fig. 15A,B). For some animals, HUVEC were labelled with a lentiviral construct expressing DsRed (CMV-DsRed; Fig. 15C,D and Fig. 23H). Briefly, hBOEC were incubated for 4 hours with $10 \mu \mathrm{g} / \mathrm{ml}$ Dil-AcLDL in EGM-2 at $37^{\circ} \mathrm{C}$, and washed 3 times with PBS, prior to transplantation in the wounds. Lentiviral transduction of hBOEC or HUVEC was performed as described above (see 1.6.). 

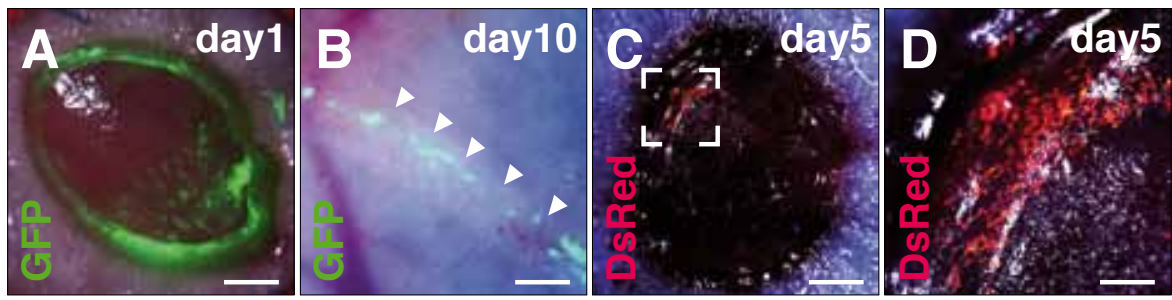

Figure 15. Engraftment of $h B O E C$ and HUVEC. $A, B$, GFP-transduced hBOEC are visible upon transplantation in vivo $(A)$ and located in the vicinity of capillaries, organised in a vessel-like structure (indicated by white arrowheads in $B$ ) after 10 days. $\boldsymbol{C , D}$, DsRed-transduced HUVEC are detected in the wound at day $5(C)$ in a more scattered pattern ( $D$; represents inset indicated in $C)$. Scale bars: 60 $\mu \mathrm{m}$ in $D$ and $200 \mu \mathrm{m}$ in $A-C$.

\section{RNA isolation and qRT-PCR}

\subsection{RNA isolation and qRT-PCR}

Total RNA from cell lysates was extracted using the RNeasy minikit (Qiagen, Valencia, CA). mRNA was reverse transcribed using Superscript II Reverse Transcriptase (Invitrogen, Carlsbad, CA) and cDNA underwent 50 amplification rounds (ABI PRISM 7700, Perkin Elmer/Applied Biosystems, Foster City, CA) as follows: 50 cycles of a 2 step PCR $\left(95^{\circ} \mathrm{C}\right.$ for 15 seconds, $60^{\circ} \mathrm{C}$ for 45 seconds) after initial denaturation $\left(95^{\circ} \mathrm{C}\right.$ for 10 minutes) with $1 \mathrm{ml}$ of $\mathrm{CDNA}$ template, $1 \mathrm{ml}$ of primer mix and $1 \mathrm{x}$ TaqMan SYBR Green Universal Mix PCR reaction buffer (Applied Biosystems, Lennik, Belgium). Primers used for amplification are shown in Table 3A-D. mRNA levels were normalised using GAPDH or b-actin as housekeeping gene. For comparative qRTPCR on samples in $1 \%$ or $20 \%$ O2, hypoxanthine-phosphoribosyl-transferase-1 (HPRT1) was used as housekeeping gene (see 7.2.). 


\section{hBOEC CHARACTERISATION}

\begin{tabular}{lcc}
\hline $\begin{array}{c}\text { Gene/protein } \\
\text { name }\end{array}$ & Forward primer sequence (5'-3') & Reverse primer sequence (5'-3') \\
\hline Flt-1 (VEGFR1) & GGACTGACAGCAAACCCAAG & CAGCCCCGACTCCTTACTTT \\
\hline PECAM (CD31) & ACTGCACAGCCTTCAACAGA & TTTCTTCCATGGGGCAAG \\
\hline VE-cadherin & GTTCACGCATCGGTTGTTC & TCTGCATCCACTGCTGTCA \\
\hline KDR (VEGFR2) & TCCTGTATGGAGGAGGAGGA & CGGCTCTTTCGCTTACTGTT \\
\hline Tie-1 & AGTGTACGAGCTGATGCGTCA & AATGCCCGCGTAAGTGAAGT \\
\hline Tie-2 & TGCCCAGATATTGGTGTCCT & CTCATAAAGCGTGGTATTCACGTA \\
\hline vWF & GTCGAGCTGCACAGTGACAT & CCACGTAAGGAACAGAGACCA \\
\hline CD34 & TGCAACATCTCCCACTAAACCC & CTTAAACTCCGCACAGCTGGA \\
\hline AC133 & TCCTGGGGCTGCTGTTTATT & ACGCCTTGTCCTTGGTAGTGTT \\
\hline eN0S & GTGGACGCACAGTAACATGG & ACCTCCCAGTTCTTCACACG \\
\hline CXCR4 & TGAGAAGCATGACGGACAAG & GACGCCAACATAGACCACCT \\
\hline CD45 & TGATAAGACAACAGTGGAGAAAGGA & GTGTTGGGCTTTGCCCTG \\
\hline CD18 & TTCGCGGTGACCAGTAGGAT & CCAGGAAGACCCTGGAGGAG \\
\hline BMP-2 & CCCAGCGTGAAAAGAGAGAC & GGAAGCAGCAACGCTAGAAG \\
\hline BMP-4 & GCTTCCACCACGAAGAACAT & TCACATTGTGGTGGACCAGT \\
\hline MMP-2 & CACTTTCCTGGGCAACAAAT & TGATGTCATCCTGGGACAGA \\
\hline MMP-9 & TGGATCCAAAACTACTCGGAAGA & ACACCAAACTGGATGACGATGTC \\
\hline & & \\
\hline
\end{tabular}

Table 3A. PCR primers for hBOEC characterisation.

\section{GROWTH FACTOR PROFILE ANALYSIS}

\begin{tabular}{lcc}
\hline $\begin{array}{c}\text { Gene/protein } \\
\text { name }\end{array}$ & Forward primer sequence (5'-3') & Reverse primer sequence (5'-3') \\
\hline Ang-1 & TCCAAAGAGGCTGGAAGGAA & CTGCCTCTGACTGGTAATGGC \\
\hline Ang-2 & ACACACCACAAATGGCATCTACA & TAATTGTCCACCCGCCTCC \\
\hline VEGF-A & ACCAAGGCCAGCACATAGGA & AGGCCCACAGGGATTTTCTT \\
\hline PIGF & GCGATGAGAATCTGCACTGTGT & GAACGTCAGCTCCACGTAGGA \\
\hline PDGF-B & CATTCCCGAGGAGCTTTATGAG & CTCCAGCTCGCCTCCAGAG \\
\hline MCP-1 & GCCTCCAGCATGAAAGTCTC & CAGATCTCCTTGGCCACAAT \\
\hline TGF-11 & TGAGTGGCTGTCTTTTGACG & TCTCTGTGGAGCTGAAGCAA \\
\hline bFGF & GCGCATCCACCCCGA & CCAGTAATCTTC- \\
\hline KGF & ATGAACACCCGGAGCACTAC & GGGCTGGAACAGTTCACATT \\
\hline IL-6 & TACCCCCAGGAGAAGATTCC & TTTTCTGCCAGTGCCTCTTT \\
\hline HGF & ACACCCGCTGGGAGTACTGT & TCCTTGACCTTGGATGCATTC \\
\hline GM-CSF & ATGTGAATGCCATCCAGGAG & AATCTGGGTTGCACAGGAAG \\
\hline MMP-14 & GAGCTCAGGGCAGTGGATAG & GGTAGCCCGGTTCTACCTTC \\
\hline MMP-1 & CACAACTGCCAAATGGGCTT & CCCTTTGAAAAACCGGACTTC \\
\hline
\end{tabular}

Table 3B. PCR primers for analysis of $h B O E C$ and hDFS growth factor profile. 
HOUSE KEEPING GENES/KERATINOCYTE MIGRATION

\begin{tabular}{llc}
\hline $\begin{array}{c}\text { Gene/protein } \\
\text { name }\end{array}$ & Forward primer sequence (5'-3') & Reverse primer sequence (5'-3') \\
\hline GAPDH & TGGTATCGTGGAAGGACTCATGAC & ATGCCAGTGAGCTTCCCGTTCAGC \\
\hline -actin & TGGCACCACACCTTCTACAAT & TAGCAACGTACATGGCTGGG \\
\hline HPRT1 & ACCCCACGAAGTGTTGGATA & AAGCAGATGGCCACAGAACT \\
\hline B2M & TCTCTCTTTCTGGCCTGGAG & TCTTTTTCAGTGGGGGTGAA \\
\hline GUSB & AGCCTGTGACCTTTGTGACC & AAGCGTTTCCACTCCATACG \\
\hline YWHAZ & TGAAGCCATTGCTGAACTTG & TATTTGTGGGACAGCATGGA \\
\hline IPO8 & AACCTATGCAGTGGGCATTC & GGATCTTCTTGCCACAGCTC \\
\hline POLR2A & CATCATCCGAGACAATGGTG & CATCTCATCCCCGTCAAAGT \\
\hline RPLPO & TCGACAATGGCAGCATCTAC & GCCTTGACCTTTTCAGCAAG \\
\hline TBP & CGGCTGTTTAACTTCGCTTC & CAGGCTGTTGTTCTGATCCA \\
\hline Connexin43 & GGCGTGAGGAAAGTACCAAA & GCAGGATTCGGAAAATGAAA \\
\hline
\end{tabular}

Table 3C. PCR primers for housekeeping gene screening and keratinocyte migration.

PBOEC CHARACTERISATION

\begin{tabular}{lll}
\hline $\begin{array}{c}\text { Gene/protein } \\
\text { name }\end{array}$ & Forward primer sequence (5'-3') & Reverse primer sequence (5'-3') \\
\hline PECAM (CD31) & AGAAGACGACTGCGGAGTACA & ACGACTCCACCTTCGATCAC \\
\hline VE-cadherin & CAGCAACGGCTACTCACAAA & ATTCTTCCCCATGAGGCTCT \\
\hline KDR (VEGFR-2) & CTCAATGTGTCCCTTTGTGC & GCTGTCCCAGGAAATTCTGT \\
\hline Tie-2 & TGAGCCTTACTTTGGGGATG & TGCACGCAGAGCTCATATTC \\
\hline vWF & CACCCCTCAAAACAACGAGT & CTGGACCATCGTCTTCCAGT \\
\hline CD34 & GGAAACCACACCAGATGCTT & AGGTCTGAGGCTGGACAGAA \\
\hline eNOS & CCAGCTCGACCATCTCTACC & CTCAGGATGTCCTGCACGTA \\
\hline CD18 & GGAGGTCTCCAGGACATCAA & CCTTGCCCAGAGAAGTTCAG \\
\hline CD11b & AGAAGGAGACACCCAGAGCA & GTAGGACAATGGGCGTCACT \\
\hline MMP-2 & AGGGCATCCAGGAGCTCTAT & GATGAACCGGTCCTTGAAGA \\
\hline MMP-9 & GCCGACATCGTTATCCAGTT & CCTTTTGCGTTTCCGAAGTA \\
\hline MMP-14 & TGCAGCAGTATGGCTACCTG & TAGCGCTTCCTTCGAACATT \\
\hline KGF & TGACCTAGGAGCAACGATCA & GGGCTGGAACAGTTCACATT \\
\hline PIGF & GGCTCTTCACTTGCTTCCTG & CACACAGTGCAGGTTCTCGT \\
\hline Ang1 & ATCTTAATGGGGGAGGTTGG & GCTCTGTTTTCCTGCTGTCC \\
\hline Ang2 & AACACTGGCTGGGAAATGAG & AGCCTCCTGTGAGCATCTGT \\
\hline MCP-1 & CCGAAGCTTGAATCCTCATC & TCCAGGTGGCTTATGGAGTC \\
\hline TGF $\mathbf{1} 1$ & TGCTGTTCAACACGTCGGAG & CTGAGGTAGCGCCAGGAATC \\
\hline GAPDH & ACCCAGAAGACTGTGGATGG & AGATCCACAACCGACACGTT \\
\hline
\end{tabular}

Table 3D. PCR primers for pBOEC characterisation. 


\subsection{Housekeeping gene screening}

We intended to perform comparative qRT-PCR under different oxygen conditions in vitro. Since variation in oxygen levels may change the expression of routinely used housekeeping genes (e.g. GAPDH or $\beta$-actin) and the appropriate housekeeping gene may be different for different cell types ${ }^{169,170}$, the choice of an appropriate alternative housekeeping gene is necessary. Therefore, we performed a separate screening of a panel of housekeeping genes (Table $3 \mathrm{C}$ ) in order to find an appropriate candidate for hKeratinocytes and hDFS (Fig. 16) by measuring the expression of these genes in high $(20 \%)$ and low $(1 \%)$ oxygen conditions using samples with identical amounts of RNA. For an ideal housekeeping gene, the $\Delta \mathrm{C}_{\mathrm{T}}$ between high and low oxygen should be close to 0 and there should be the lowest possible variation between replicates of the same oxygen condition (estimated by calculating the standard error of the mean: SEM). We indeed detected that GAPDH and $\beta$-actin expression was altered by oxygen conditions, and that HPRT1 was the most stable gene under variable oxygen conditions for hKeratinocytes and hDFS. We therefore chose for HPRT1 as housekeeping gene in PCR-experiments with varying oxygen levels (Fig. 16).

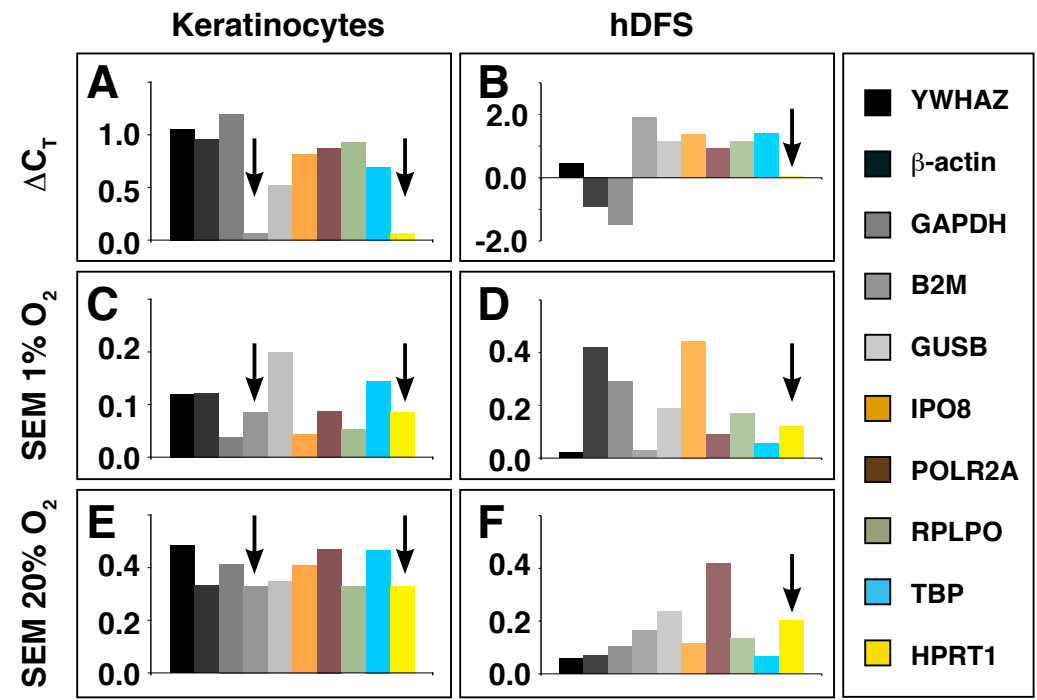

Figure 16. Housekeeping gene screening. $A, B$, Diagram showing the difference in threshold cycle $\left(\Delta \mathrm{C}_{\mathrm{T}}\right)$ between hypoxia $\left(1 \% \mathrm{O}_{2}\right)$ and normoxia $\left(20 \% \mathrm{O}_{2}\right)$ for each of the genes tested by qRT-PCR on RNA isolated from keratinocytes $(A)$ or hDFS $(B)$, revealing that only two genes (indicated with arrows) are suitable as housekeeping gene (i.e. having a very low $\Delta C_{T}$ ) for keratinocytes $(A)$ and only one gene (indicated with arrow) in hDFS $(B)$. C - F, To choose between the two housekeeping genes for keratinocytes, the standard error of the mean (SEM) for each of the $\mathrm{O}_{2}$ conditions was determined. The diagrams in $C-F$ show the SEM for triplicates run for each gene under hypoxic $(C, D)$ or normoxic $(E, F)$ conditions, revealing that SEM were low and that there were no significant differences between the two genes (indicated with arrows) for keratinocytes, meaning that both genes were equally suited as housekeeping gene. 


\section{Cytokine production, cell proliferation/migration assays}

\subsection{Cytokine production, zymography and Western blotting}

To assess cytokine production, hBOEC, HUVEC, or hDFS were plated/incubated at high confluence in triplicate or quadruplicate in the appropriate media and supernatant was collected, in some cases concentrated 10x using Microcon filter units (Millipore, Brussels, Belgium), and frozen. Protein concentration was determined by the Bradford assay. ELISA kits were from R\&D Systems and the procedure was performed according to the manufacturer's recommendations.

Zymography was performed as previously described ${ }^{165}$. Briefly, $75 \mathrm{mg}$ of total protein was diluted in sampling buffer $(0.04 \mathrm{M}$ Tris- $\mathrm{HCl}, \mathrm{pH} 6.8,5 \% \mathrm{v} / \mathrm{v}$ glycerol, $16.6 \mathrm{mg} /$ $\mathrm{ml} \mathrm{SDS}$ en $0.02 \mathrm{mg} / \mathrm{ml}$ bromophenol blue) and loaded on a Novex $10 \%$ Zymogram gelatin gel (Invitrogen, Carlsbad, CA). The gel was run in electrophoresis buffer (24 $\mathrm{mM}$ Tris, $\mathrm{pH} 8.3,192 \mathrm{mM}$ glycine and $0.1 \%$ SDS) for about two hours at $126 \mathrm{~V}$ and $40 \mathrm{~mA} / \mathrm{gel}$.

After a 30 minute incubation in renaturing buffer $(2.5 \% \mathrm{v} / \mathrm{v}$ Triton $\mathrm{X}-100)$ and overnight incubation in developing buffer (10 mMTris, $40 \mathrm{mMTris} . \mathrm{HCl}, 0.2 \mathrm{mMNaCl}$, $6.67 \mathrm{mM} \mathrm{CaCl} 2,0.01 \% \mathrm{v} / \mathrm{v}$ Triton X-100), gels were stained for 3 hours in $0.5 \%$ $\mathrm{wt} / \mathrm{v}$ Coomassie Blue R250 in $45 \% \mathrm{EtOH}$ v/v, $10 \%$ v/v acetic acid and destained by repeated stirring in destaining buffer ( $45 \% \mathrm{EtOH}$ v/v and $10 \%$ acetic acid). Gels were transferred to storage buffer ( $7 \%$ acetic acidv/v, $25 \% \mathrm{MeOH}$ v/v and $2 \%$ glycerol $\mathrm{v} / \mathrm{v}$ ) and dried between cellofan membranes. Gelatinase activity was visible as clear white bands in the blue gel.

For Western blot analysis, samples were collected in RIPA buffer $(150 \mathrm{mM} \mathrm{NaCl}$, $1.0 \%$ Igepal CA-630, $0.5 \%$ sodium deoxycholate, $0.1 \%$ SDS, $50 \mathrm{mM}$ Tris $\mathrm{pH}$ 8.0; Sigma, Bornem, Belgium) and protein concentration was measured by the Bradford assay. $10-40 \mu \mathrm{g}$ of protein was loaded and run at $200 \mathrm{~V}$ in running buffer (MOPS SDS NuPAGE running buffer; Invitrogen, Carlsbad, CA) on a $10 \%$ BisTris-NuPAGE gel (Invitrogen, Carlsbad, CA). Protein bands were transferred to a nitrocellulose membrane (Hybond ECL, GE Healthcare) by electroblotting in transfer-buffer (NuPAGE transfer buffer $+10 \%$ methanol; Invitrogen, Carlsbad, CA). Membranes were blocked with $5 \%$ fat-free milk in T-TBS $(0.01 \%$ Tween 80 in $20 \mathrm{mM}$ Tris. $\mathrm{HCl}, \mathrm{pH} 7.5,0.5 \mathrm{M} \mathrm{NaCl}$ ) and incubated with primary antibody against Flt-1 (Table 2) and secondary antibody (horse radish peroxidase (HRP)-conjugated donkey-anti-mouse IgG from Santa-Cruz, SC2314; dilution 1:2000). Protein bands were visualised by chemoluminescence (using the ECL-kit, a system based on peroxidase-driven oxidation of luminal yielding black bands; Thermo Scientific, Erembodegem, Belgium). $\alpha$-tubulin was analysed as loading control, after stripping 
the membrane (2\% SDS, $0.063 \mathrm{M}$ Tris $\mathrm{pH} 6.8$, + mercapto-ethanol) and incubation with mouse anti-human $\alpha$-tubulin (Table 2) and secondary antibody (horse radish peroxidase (HRP)-conjugated donkey-anti-mouse IgG from Santa-Cruz, SC2314; dilution 1:2000).

\subsection{Cell proliferation/migration}

For hKeratinocyte proliferation assays, cells were plated on collagen type l-coated plates at low confluence in regular growth media in normoxic $\left(20 \% \mathrm{O}_{2}\right)$ or hypoxic $\left(1 \% \mathrm{O}_{2}\right)$ conditions in quadruplicate or in the presence of 90 hours conditioned media collected from hBOEC or hDFS (see 8.1.) or growth media incubated for 90 hours in the absence of cells (non-conditioned media or NCM). Ten days after plating, cells were harvested by and counted with a NucleoCounter (ChemoMetec, Vilvoorde, Belgium). hKeratinocyte migration was evaluated in collagen typelcoated plates by measuring the area taken up by the cells in a fixed $1 \mathrm{~mm}$ window, 6 or 24 hours after applying a standardised scratch wound in confluent cultures of keratinocytes grown in $20 \%$ or $1 \% \mathrm{O}_{2}$ or in the presence of (non)conditioned media. For studying the effect of hypoxia on keratinocyte migration, we preconditioned the cells for 10 days in $1 \%$ or $20 \%$ oxygen, in order to assess the effects of long-term exposure to certain oxygen levels, as this is what happens during wound healing.

\section{Statistical analysis}

Comparison of data, expressed as mean \pm SEM, was performed by using the unpaired Student's $t$-test. A Kolmogorov-Smirnov test was used to verify that the data had a Gaussian distribution, which justified the use of a parametric test. Instat3.0a software was used for statistical analyses and differences were considered significant when $P<0.05$. 
Materials \& Methods 

On fait la science avec des faits, comme on fait une maison avec des pierres; mais une accumulation de faits n'est pas plus une science qu'un tas de pierres n'est une maison.

(Henri Poincaré)

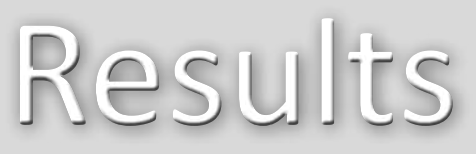





\section{1. hBOEC, early EPC, pBOEC and hDFS characterisation}

\section{1. hBOEC phenotype and function}

Colonies with cobble-stone morphology (Fig. 17A) grew out from the collagenadherent mononuclear fraction of peripheral blood after \pm 15 days (Table 5). qRT-PCR revealed robust EC marker expression ( $V W F$, Tie-1, Tie-2, Flt-1, KDR, VE-Cadherin, eNOS, CXCR4, CD31 and CD34) which remained stable for at least 5 passages, except for CD34 expression which decreased in later passages (Fig. 17B; Table 4). hBOEC uniformly expressed vWF, VE-cadherin, KDR, Tie-2 and CD31 protein (Fig. $17 C-G)$. hBOEC expressed little $A C 133$, an EPC marker, and were distinguished from terminally differentiated EC by their higher expansion capacity and a distinct expression pattern of growth factors (Table 7). hBOEC expressed no CD45 (Fig. 17H; Table 4). hBOEC functionally behaved as EC, demonstrated by uptake of acetylated LDL, tube formation on matrigel and UEA-lectin binding (Fig. 17I-K).
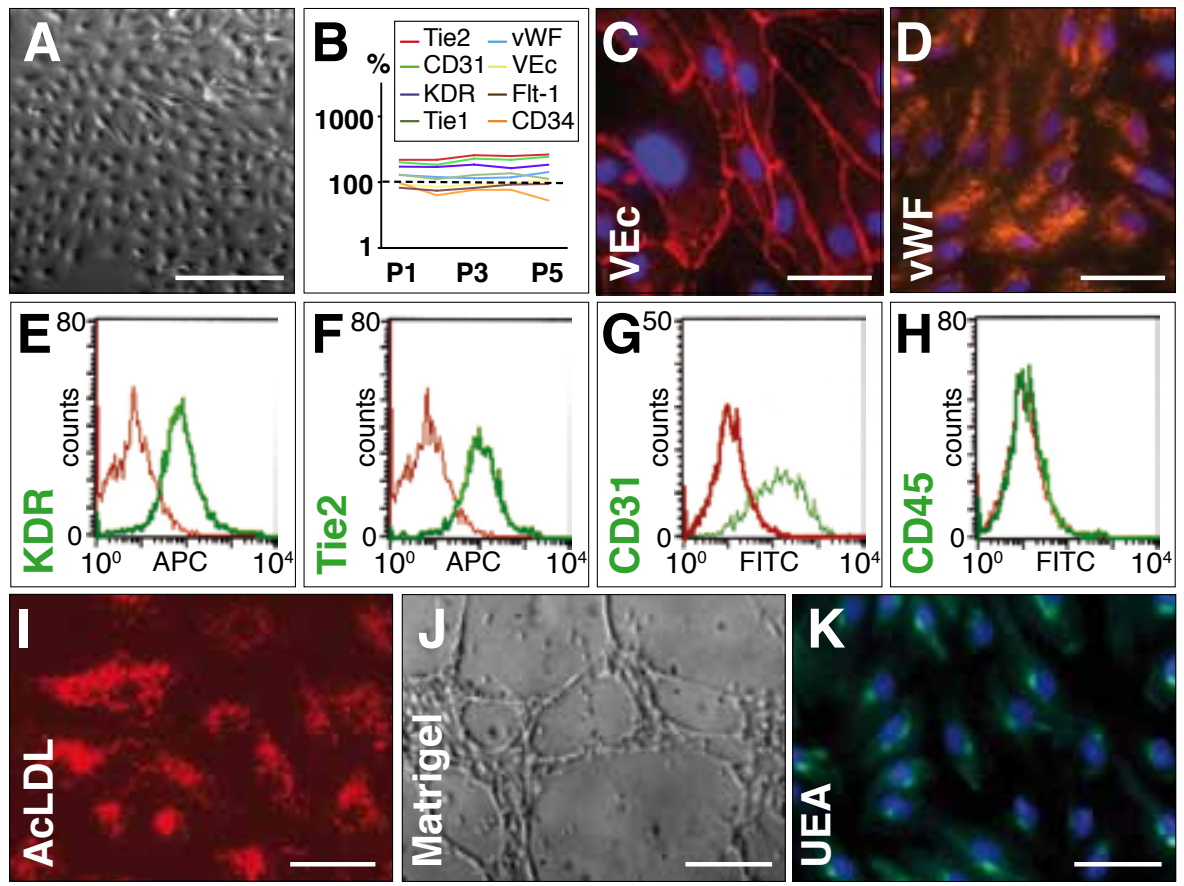

Figure. 17. Phenotypic and functional characterisation of hBOEC. A, Phase-contrast picture showing a cobble-stone hBOEC colony. $\boldsymbol{B}$, Diagram revealing stable expression of endothelial markers (vWF, KDR, Flt-1, Tie-2, VE-cadherin, CD31) and a slight down-regulation of CD34 (in yellow) during 5 passages $(P)$. Data were normalised to GAPDH and expressed as \% versus HUVEC (dotted line indicates expression level in HUVEC). $\boldsymbol{C}, \boldsymbol{D}$, hBOEC expressed VEc (VE-cadherin; red in $C$ ) and VWF (von Willebrand factor; red in $D$ ) in a typical pattern. $E-H$, FACS histograms revealing that hBOEC expressed endothelial markers (KDR, green in $E$; Tie2, green in F; CD31, green in $G$ ) but not the 
panleukocytic marker CD45 (green in $H$ ). Isotypes are shown in red. I-K, hBOEC functionally behaved like EC, as shown by acetylated LDL uptake (AcLDL; red in $l$ ), tube formation on matrigel $(J)$ and Ulex Europaeus Agglutinin (UEA)-lectin binding (green in $K$ ). DAPI (blue) was used as nuclear counterstain in $C, D, K$. Scale bars: $100 \mu \mathrm{m}$ in $C, D, I, K, 200 \mu \mathrm{m}$ in $J$ and $500 \mu \mathrm{m}$ in $A$.

\subsection{Early EPC phenotype and function}

Colonies with rounded cells in the centre and larger flat cells radiating from the centre grew out from the replated non-adherent fraction of peripheral blood within 7 days after replating (Fig. 18A). qRT-PCR revealed EC marker expression ( $v W F$, Tie-1, Tie-2, Flt-1, KDR, VE-Cadherin, eNOS, CD31 and CD34) that was however significantly lower compared to hBOEC (Table 4). Consistently, protein expression levels for KDR, Tie-2 and CD31 were lower as compared to hBOEC (compare Fig. $18 B-D$ and Fig. 17E-G). Compared to hBOEC, early EPC expressed higher levels of CXCR4, $\beta_{2}$-integrin (CD18) and MMP-9 (Table 4), yet lower levels of BMP-2 and -4 and eNOS (Table 4). Unlike hBOEC, early EPC uniformly expressed CD45 (Fig. 18E; Table 4), suggesting their hematopoietic origin. Early EPC took up AcLDL (Fig. 18F), however did not efficiently form tubular structures on matrigel (Fig. 18G), nor did they incorporate into the endothelial layer of blood vessels in vivo (Fig. 18H), suggesting that these cells lacked proper EC functions.
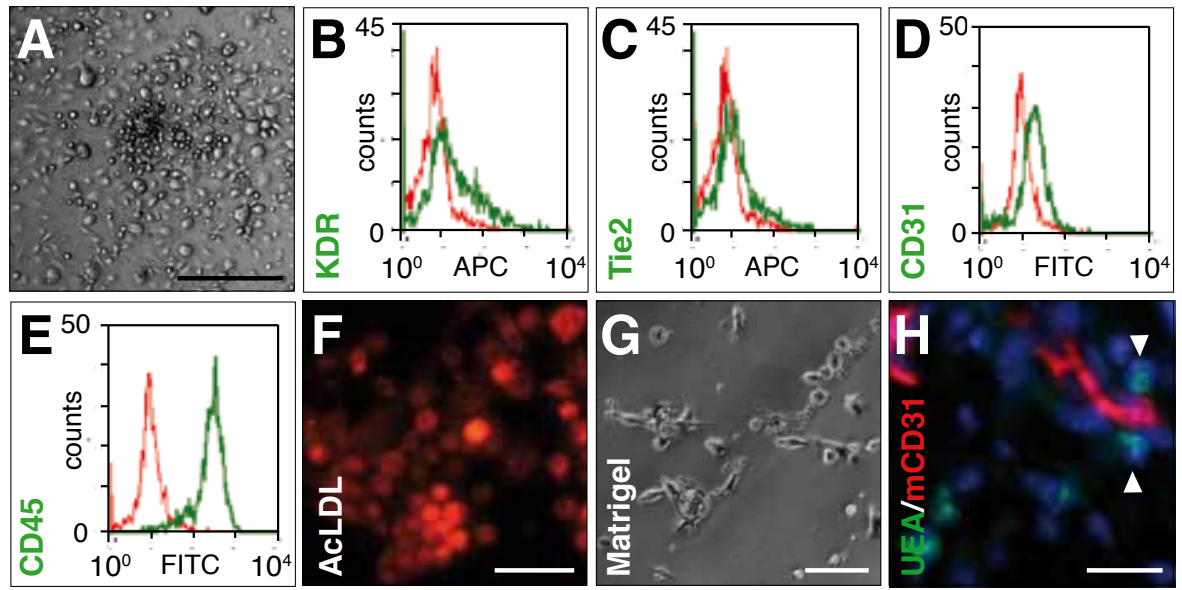

Figure 18. Phenotypic and functional characterisation of early EPC. A, Phase-contrast picture showing an early EPC colony consisting of small round cells in the centre and flattened cells around. $C-E$, FACS histograms revealing that early EPC expressed endothelial markers (KDR, green in $B$; Tie2, green in C; CD31, green in $D$ ), besides panleukocytic marker CD45 (green in $E$ ). Isotypes are shown in red. $\boldsymbol{F}-\boldsymbol{H}$, Although early EPC take up acetylated LDL (AcLDL; red in F), they did not form tubes on matrigel $(G)$ and did not incorporate into murine host vessels(stained with CD31 in red in $H$ ) in vivo but were located along the vessels, as shown by Ulex Europaeus Agglutinin (UEA)-lectin staining (green in $H$ ), DAPI (blue) was used as nuclear counterstain in $H$ ). Scale bars: $25 \mu \mathrm{m}$ in $F, 50 \mu \mathrm{m}$ in $G$, $100 \mu \mathrm{m}$ in $H$ and $250 \mu \mathrm{m}$ in $A$. 


\begin{tabular}{|c|c|c|c|c|c|c|c|}
\hline & HUVEC & & & hBOEC & & & Early EPC \\
\hline & P4 & P1 & P2 & P3 & P4 & P5 & P0 \\
\hline vWF & 100 & $165 \pm 44$ & $144 \pm 40$ & $223 \pm 91$ & $141 \pm 59$ & $203 \pm 96$ & $8 \pm 6^{a}$ \\
\hline Tie1 & 100 & $161 \pm 27$ & $120 \pm 14$ & $146 \pm 37$ & $172 \pm 49$ & $116 \pm 13$ & $12 \pm 8^{a}$ \\
\hline Tie2 & 100 & $483 \pm 127$ & $481 \pm 101$ & $661 \pm 165$ & $621 \pm 206$ & $638 \pm 106$ & $100 \pm 66^{a}$ \\
\hline VEc & 100 & $86 \pm 13$ & $72 \pm 11$ & $84 \pm 10$ & $91 \pm 16$ & $117 \pm 19$ & $7 \pm 4^{a}$ \\
\hline CD31 & 100 & $403 \pm 67$ & $338 \pm 55$ & $521 \pm 115$ & $482 \pm 100$ & $597 \pm 110$ & $294 \pm 113$ \\
\hline Flt-1 & 100 & $68 \pm 9$ & $55 \pm 11$ & $67 \pm 9$ & $85 \pm 21$ & $88 \pm 15$ & $58 \pm 32$ \\
\hline KDR & 100 & $298 \pm 31$ & $291 \pm 31$ & $345 \pm 62$ & $266 \pm 53$ & $338 \pm 86$ & $51 \pm 28^{a}$ \\
\hline eNOS & 100 & $2990 \pm 905$ & $4041 \pm 1270$ & $4679 \pm 1914$ & $4312 \pm 1839$ & $3884 \pm 1661$ & $56 \pm 36^{a}$ \\
\hline CXCR4 & 100 & $103 \pm 23$ & $86 \pm 29$ & $72 \pm 28$ & $100 \pm 41$ & $86 \pm 48$ & $1750 \pm 991^{a}$ \\
\hline CD34 & 100 & $95 \pm 38$ & $40 \pm 16$ & $59 \pm 30$ & $59 \pm 19$ & $28 \pm 9$ & $7 \pm 6$ \\
\hline CD18 & 100 & $3039 \pm 961$ & $221 \pm 101$ & $153 \pm 63$ & $97 \pm 29$ & $75 \pm 37$ & $6 \times 105 \pm 3 \times 105^{a}$ \\
\hline BMP-2 & 100 & $48 \pm 14$ & $55 \pm 34$ & $101 \pm 60$ & $25 \pm 11$ & $25 \pm 5$ & $1 \pm 1^{a}$ \\
\hline BMP-4 & 100 & $161 \pm 35$ & $104 \pm 30$ & $140 \pm 55$ & $111 \pm 28$ & ND & $3 \pm 1^{a}$ \\
\hline MMP-2 ${ }^{\mathrm{b}}$ & ND & $70 \pm 51$ & $162 \pm 74$ & $173 \pm 127$ & $225 \pm 135$ & ND & $136 \pm 35$ \\
\hline MMP-9b & ND & $1 \pm 1$ & $0.26 \pm 0.26$ & $0.03 \pm 0.02$ & $0.04 \pm 0.03$ & ND & $118 \pm 52^{c}$ \\
\hline CD45 ${ }^{b}$ & ND & 0 & 0 & 0 & 0 & 0 & $6 \pm 1^{a}$ \\
\hline
\end{tabular}

Table 4. Gene expression profile of $h B O E C$ and early EPC. Data represent mean ( \pm SEM) of 4-6 independent isolations, determined by qRT-PCR, expressed as \% versus HUVEC and normalised to GAPDH. a: $P<0.05$ versus hBOEC-passage (P)1; ${ }^{\text {: }}$ : MMP-2, -9 and CD45 expression levels were expressed as \% versus universal RNA, the mononuclear fraction of peripheral blood or bone marrow, respectively, and normalised to GAPDH; ${ }^{\text {: }} P=0.06$ versus hBOEC-P1;ND: not determined. 


\section{3. hDFS structure and function}

Human dermal fibroblasts were obtained from skin samples derived from healthy donors and tissue-engineered into a multilayered construct (Fig. 19A,B). The $\mathrm{N}$-terface carrier allowed us to superimpose multiple sheets, thereby increasing the thickness of the construct, and to easily apply it to the wound bed (Fig. 10). After 10 days of culture, fibroblasts deposited ECM components, including fibrillar collagens as demonstrated by Sirius Red staining (Fig. 19C,D), thus fulfilling the principal role of dermal fibroblasts in situ.
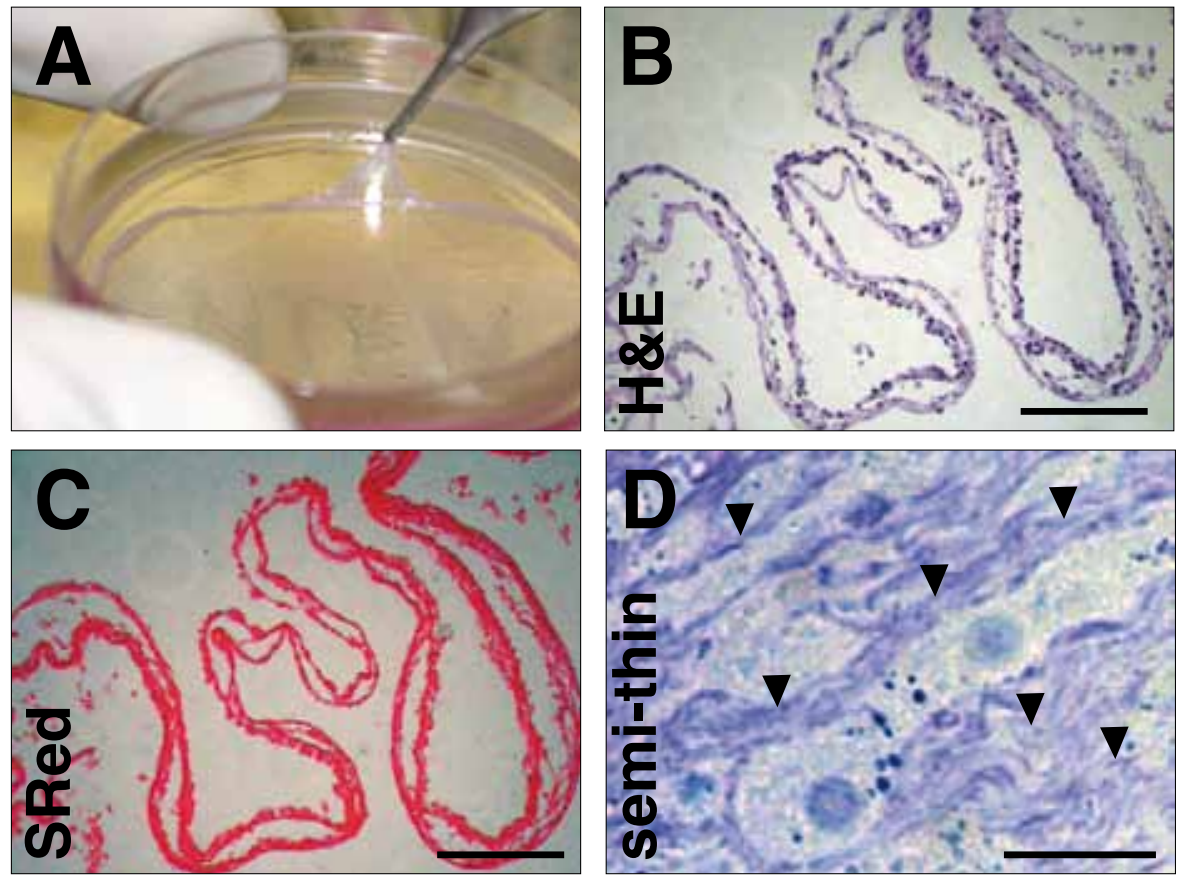

Figure19.Characterisation of hDFS. A. hDFS in vitro, as a thin sheet that can be manipulated with forceps.B-D, hDFS revealed on cross-sections by H\&E (B), Sirius red (SRed in $C$ ) and on toluidinblue-stained semi-thin sections $(D)$. Arrowheads in $D$ indicate extracellular matrix. Scale bars: $10 \mu \mathrm{m}$ in $D, 100 \mu \mathrm{m}$ in $B, C$.

\section{4. $P B O E C$ phenotype and function}

Porcine blood generally yielded higher numbers of mononuclear cells (MNC) and outgrowth of BOEC colonies, but the number of colonies per $10^{9} \mathrm{MNC}$ remained quite comparable to hBOEC (Table 5). The expression of surface markers and functional behaviour was very similar to that of hBOEC (Fig. 20; Table 6). 


\begin{tabular}{|c|c|c|c|c|c|}
\hline $\begin{array}{c}\mathbf{N}^{\circ} \text { of } \\
\text { Donors }\end{array}$ & $\begin{array}{c}\text { Donor } \\
\text { age } \\
\text { (years) }\end{array}$ & $\begin{array}{c}\mathbf{N}^{\circ} \text { of } \\
\mathbf{M N C} \\
\left(\mathbf{N}^{\circ} \times \mathbf{1 0}^{\mathbf{6}}\right)\end{array}$ & $\begin{array}{c}\mathbf{N}^{\circ} \text { of col- } \\
\text { onies }\end{array}$ & $\begin{array}{c}\text { Day appearance } \\
\text { of } \mathbf{1}^{\text {st }} \text { colony }\end{array}$ & $\begin{array}{c}\mathbf{N}^{\circ} \text { colonies } / \mathbf{1 0}^{9} \\
\text { MNC }\end{array}$ \\
\hline \multicolumn{5}{|c|}{ hBOEC } \\
\hline 6 males & $29 \pm 2$ & $97 \pm 11$ & $5 \pm 1$ & $15 \pm 1$ & $52 \pm 7$ \\
\hline 2 females & $22 \pm 2$ & $89 \pm 4$ & $6 \pm 1$ & $13 \pm 2$ & $68 \pm 19$ \\
\hline \multicolumn{5}{|c|}{ pBOEC } \\
\hline 8 females & $1 \pm 0$ & $511 \pm 1$ & $39 \pm 8$ & $6 \pm 0$ & $65 \pm 19$ \\
\hline
\end{tabular}

Table 5. $h B O E C$ and $p B O E C$ derivation parameters. In total, for $\mathrm{hBOEC}, 28$ isolations were done for the current and other studies from 8 different donors (6 males; 2 females). Isolations were successful in $7 / 8$ of these donors and in $26 / 28$ of the isolations. From the 26 successful isolations, on average 54 hBOEC colonies $/ 10^{9}$ mononuclear cells (MNC) (range: $11-100 / 10^{9}$ ) grew out beyond day 15 (range: $11-$ 26 days). The average data are given in the table for each gender separately. For pBOEC, 8 isolations were performed from 1 year old Yorkshire females. In comparison to hBOEC, a firmly increased MNC fraction yielded much more colonies that appeared much earlier, but the number of colonies per $10^{9}$ MNC stayed remarkably similar to that of hBOEC.

Endothelial markers VWF, Tie-2, KDR, CD31 and eNOS were stably expressed, whereas $C D 18$ expression firmly decreased upon passaging. pBOEC expressed little to no monocytic marker CD11b (Table 6). Unlike hBOEC isolation protocols, pBOEC isolation protocols are rather poorly documented. We therefore explored two coatings, i.e. collagen type I-coated and fibronectin-coated dishes but did not notice any difference in expression of $V W F, K D R, P E C A M$, eNOS, or CD34 (data not shown). Liquid nitrogen storage of therapeutic cells is important for proper planning of experiments. We therefore examined stability of endothelial marker expression after freezing and thawing and found no significant differences in endothelial marker expression before freezing and after thawing in 3 different isolations (Fig. 21; all $P$-values are $>0.05)$. 

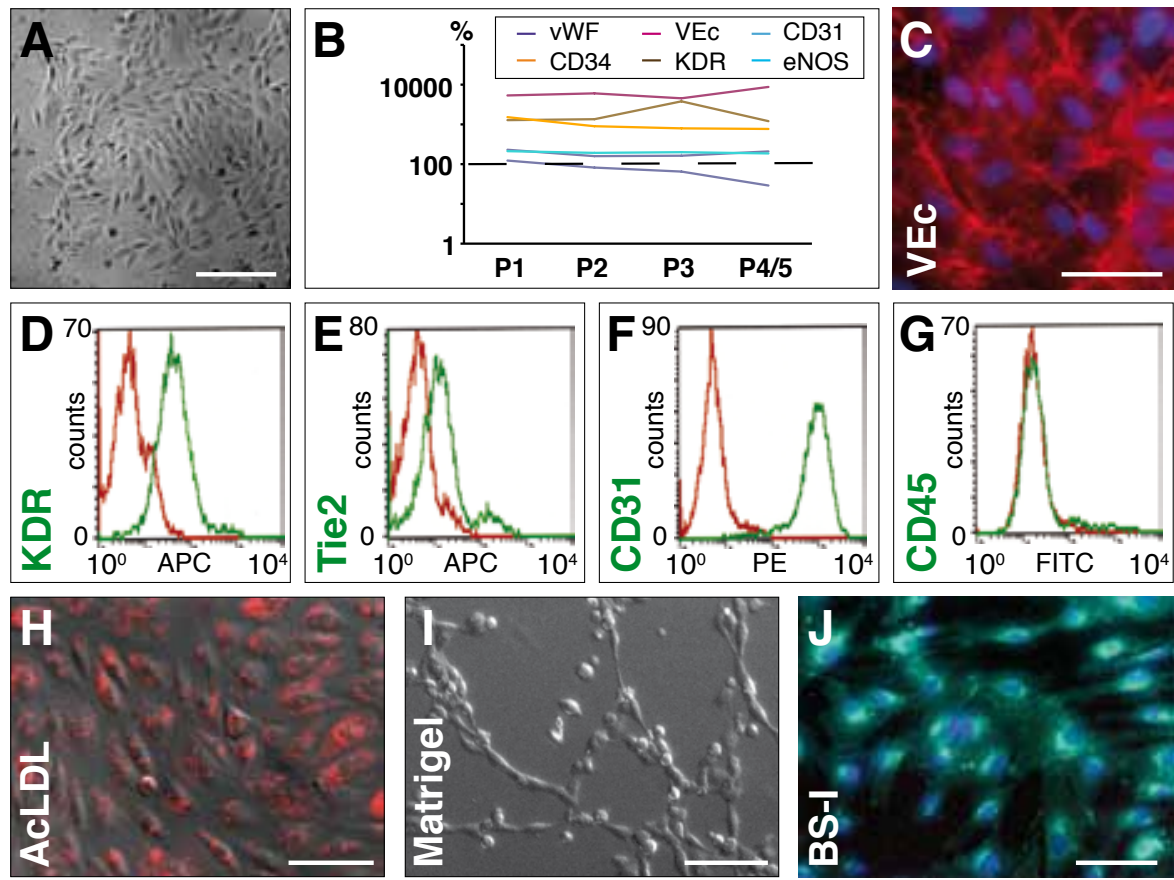

Figure 20. Characterisation of pBOEC.A, Phase-contrast picture showing a cobble-stonepBOEC colony. $\boldsymbol{B}$, Diagram revealing stable expression of endothelial markers ( $V W F, K D R, V E$-cadherin, $C D 31, C D 34$ and eNOS) during 5 passages (P). C,pBOEC expressed VEc (VE-cadherin) in a typical pattern. $D-G, F A C S$ histograms revealing that pBOEC expressed endothelial markers (KDR, green in $E$; Tie2, green in F; CD31, green in $G$ ) but not the panleukocytic marker CD45 (green in $H$ ). Isotypes are shown in red. $\boldsymbol{H}-\mathrm{J}, \mathrm{pBOEC}$ functionally behaved like EC, as shown by acetylated-LDL uptake (AcLDL; red in $H$ ), tube formation on matrigel $(I)$ and lectin binding (Bandeiraeasimplicifolia-I or BS-I; green in J). DAPI (blue) was used as nuclear counterstain in $C, J$. Scale bars: $50 \mu \mathrm{m}$ in $C, 100 \mu \mathrm{m}$ in $H-J, 200 \mu \mathrm{m}$ in $J$ and $500 \mu \mathrm{m}$ in $A$. 


\begin{tabular}{lccccc}
\hline & $\begin{array}{c}\text { Pig aorta } \\
\text { EC }\end{array}$ & \multicolumn{5}{c}{ PBOEC } \\
\hline & P3 & P1 & P2 & P3 & P4-P5 \\
\hline vWF & 100 & $64 \pm 44$ & $70 \pm 27$ & $50 \pm 27$ & $23 \pm 5$ \\
\hline Tie-2 & 100 & $130 \pm 26$ & $94 \pm 22$ & $128 \pm 65$ & $97 \pm 19$ \\
\hline Vec & 100 & $40901 \pm 1508$ & $5803 \pm 1619$ & $5130 \pm 1343$ & $9046 \pm 2155$ \\
\hline CD31 & 100 & $190 \pm 59$ & $173 \pm 52$ & $212 \pm 67$ & $325 \pm 84$ \\
\hline KDR & 100 & $679 \pm 480$ & $1034 \pm 616$ & $3174 \pm 1957$ & $944 \pm 546$ \\
\hline eNOS & 100 & $209 \pm 65$ & $219 \pm 78$ & $267 \pm 90$ & $262 \pm 58$ \\
\hline CD34 & 100 & $1213 \pm 353$ & $984 \pm 327$ & $1076 \pm 328$ & $883 \pm 183$ \\
\hline CD18 & 100 & $885 \pm 597$ & $183 \pm 164$ & $129 \pm 89$ & $7 \pm 4$ \\
\hline CD11b ${ }^{\mathbf{a}}$ & 100 & $3 \pm 2$ & $5 \pm 2$ & $2 \pm 1$ & $0 \pm 0$ \\
\hline
\end{tabular}

Table 6. Gene expression profile of pBOEC. Data represent mean ( \pm SEM) of 4-6 independent isolations, determined by qRT-PCR, expressed as \% versus Pig aorta EC and normalised to GAPDH. a: CD11b expression levels were expressed as \% versus the mononuclear fraction of peripheral blood and normalised to GAPDH.

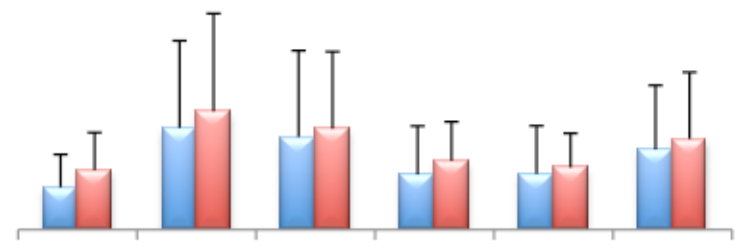

\section{vWF VEC KDR PECAM ENOS CD34}

Figure 21. Comparison of endothelial marker expression before freezing and after thawing. No significant differences were noticed in endothelial marker expression (VWF: $P=0.06$; VE-Cadherin: $\mathrm{P}=0.08$; KDR: $\mathrm{P}=0.34$; PECAM: $\mathrm{P}=0.1$; eNOS: $\mathrm{P}=0.43$; $C D 34: \mathrm{P}=0.09$ ) before freezing (blue bars) or after thawing (red bars).

\section{5. hBOEC, hDFS and pBOEC growth factor production}

\subsection{1. $h B O E C$ and $h D F S$}

We hypothesised that hBOEC exert trophic effects on wound healing by producing factors communicating with endogenous vascular and other cell types. As hDFS are thought to synthesise similar factors, we compared hBOEC and hDFS expression levels with those found in mature EC (HUVEC). hBOEC expressed higher levels of VEGF-A, PIGF, PDGF-B, Ang-2, MCP-1 and GM-CSF, allowing cross-talk with endogenous EC, SMC and inflammatory cells (Table 7). hBOEC also expressed several MMP (MMP-1, -9 and -14) that may modulate collagen metabolism, and, to a comparable extent as HUVEC, bFGF. hBOEC expressed factors that stimulate keratinocyte proliferation and migration, including KGF, IL-6, HGF and GM-CSF (Table 7). 
Most strikingly, KGF mRNA expression was 280 -fold higher in hBOEC compared to HUVEC. Interestingly, hDFS had a distinctly different growth factor expression profile from hBOEC: hDFS did not express PDGF-B, Ang-2, GM-CSF and only minimally $M C P-1$ and PIGF, but did produce readily detectable levels of Ang-1 (Table 7).

Compared to hBOEC, hDFS expressed $\sim 250$-fold and $\sim 19$-fold higher levels of $\mathrm{HGF}$ and $K G F$, respectively (Table 7). While MMP-14 expression was similar in hDFS and hBOEC, the latter secreted slightly more active MMP-9 (involved in vessel formation) than hDFS (Fig. 22). On the other hand, hDFS expressed significantly more mRNA for MMP-1, important for fibrillar collagen remodelling (Table 7).

\begin{tabular}{|c|c|c|c|c|c|c|}
\hline & \multicolumn{2}{|c|}{ HUVEC (P4) ${ }^{a}$} & \multicolumn{2}{|c|}{ hBOEC (P4) ${ }^{\mathrm{a}}$} & \multicolumn{2}{|l|}{ hDFS $^{a}$} \\
\hline & RNA & Protein & RNA (\%) & Protein & RNA (\%) & Protein \\
\hline \multicolumn{7}{|c|}{ Communication with vascular/inflammatory cells } \\
\hline $\begin{array}{l}\text {-VEGF-A } \\
\text {-PIGF } \\
\text {-PDGF-BB } \\
\text {-Angiopoietin-1 } \\
\text {-Angiopoietin-2 } \\
\text {-MCP-1 } \\
\text {-bFGF }\end{array}$ & $\begin{array}{l}100 \\
100 \\
100 \\
100 \\
100 \\
100 \\
100\end{array}$ & $\begin{array}{c}\text { ND } \\
1800 \pm 160 \\
<1.4 \\
\text { ND } \\
\text { ND } \\
\text { ND } \\
\text { ND }\end{array}$ & $\begin{array}{c}204 \pm 13^{b} \\
300 \pm 37^{b} \\
259 \pm 14^{b} \\
0 \pm 0^{b} \\
861 \pm 107^{b} \\
293 \pm 59^{b} \\
169 \pm 81\end{array}$ & $\begin{array}{c}\text { ND } \\
3300 \pm 160^{b} \\
46 \pm 18 \\
\text { ND } \\
\text { ND } \\
\text { ND } \\
\text { ND }\end{array}$ & $\begin{array}{c}199 \pm 78^{c} \\
3 \pm 1^{b, d} \\
0 \pm 0^{b, d} \\
855 \pm 50^{b, d} \\
0 \pm 0^{b, d} \\
4 \pm 1^{b, d} \\
65 \pm 3^{b}\end{array}$ & $\begin{array}{l}\text { ND } \\
7 \pm 2^{d} \\
0 \pm 0^{d} \\
N D \\
N D \\
N D \\
N D\end{array}$ \\
\hline \multicolumn{7}{|c|}{ Communication with fibroblasts (matrix) } \\
\hline $\begin{array}{l}\text {-MMP-9 } \\
-M M P-14 \\
-M M P-1\end{array}$ & $\begin{array}{l}100 \\
100 \\
100\end{array}$ & $\begin{array}{l}\text { ND } \\
\text { ND } \\
\text { ND }\end{array}$ & $\begin{array}{c}\text { ND } \\
73 \pm 9 \\
218 \pm 18^{b}\end{array}$ & $\begin{array}{l}\text { Fig.22 } \\
\text { ND } \\
\text { ND }\end{array}$ & $\begin{array}{c}\text { ND } \\
85 \pm 6 \\
7684 \pm 560^{\mathbf{b}, \mathbf{d}}\end{array}$ & $\begin{array}{c}\text { Fig.22 } \\
\text { ND } \\
\text { ND }\end{array}$ \\
\hline \multicolumn{7}{|c|}{ Communication with keratinocytes (proliferation/migration) } \\
\hline $\begin{array}{l}\text {-KGF } \\
\text {-Interleukin-6 } \\
\text {-HGF } \\
\text {-GM-CSF }\end{array}$ & $\begin{array}{l}100 \\
100 \\
100 \\
100\end{array}$ & $\begin{array}{l}0 \pm 0 \\
\text { ND } \\
\text { ND } \\
\text { ND }\end{array}$ & $\begin{array}{c}28000 \pm 3000^{b} \\
63 \pm 10 \\
132 \pm 43 \\
6000 \pm 900^{b}\end{array}$ & $\begin{array}{l}2 \pm 1^{\mathrm{b}} \\
\text { ND } \\
\text { ND } \\
\text { ND }\end{array}$ & $\begin{array}{c}525000 \pm 88000^{b, d} \\
26 \pm 17^{b} \\
34000 \pm 7000^{b, d} \\
0 \pm 0^{b, d}\end{array}$ & $\begin{array}{c}23 \pm 3^{b, d} \\
N D \\
N D \\
N D\end{array}$ \\
\hline
\end{tabular}

Table 7. Growth factor expression profile of hBOEC and hDFS. RNA data represent mean ( \pm SEM) of 3-5 independent isolations, determined by qRT-PCR and expressed as $\%$ versus HUVEC and normalised to $\beta$-actin. Protein data represent mean ( \pm SEM) of 3 independent supernatant samples, determined by ELISA and expressed as $\mathrm{pg} / \mathrm{mg}$ protein; Statistical comparisons were performed on the absolute (not relative to HUVEC) expression data; ${ }^{a}$ : Gene/protein levels were determined on cells incubated in normoxia $\left(20 \% \mathrm{O}_{2}\right)$; ${ }^{\text {b: }} P<0.05$ and ${ }^{\mathrm{c}}$ : $P=0.08$ versus HUVEC; ${ }^{\mathrm{d}}: P<0.05$ versus hBOEC; ND: not determined 


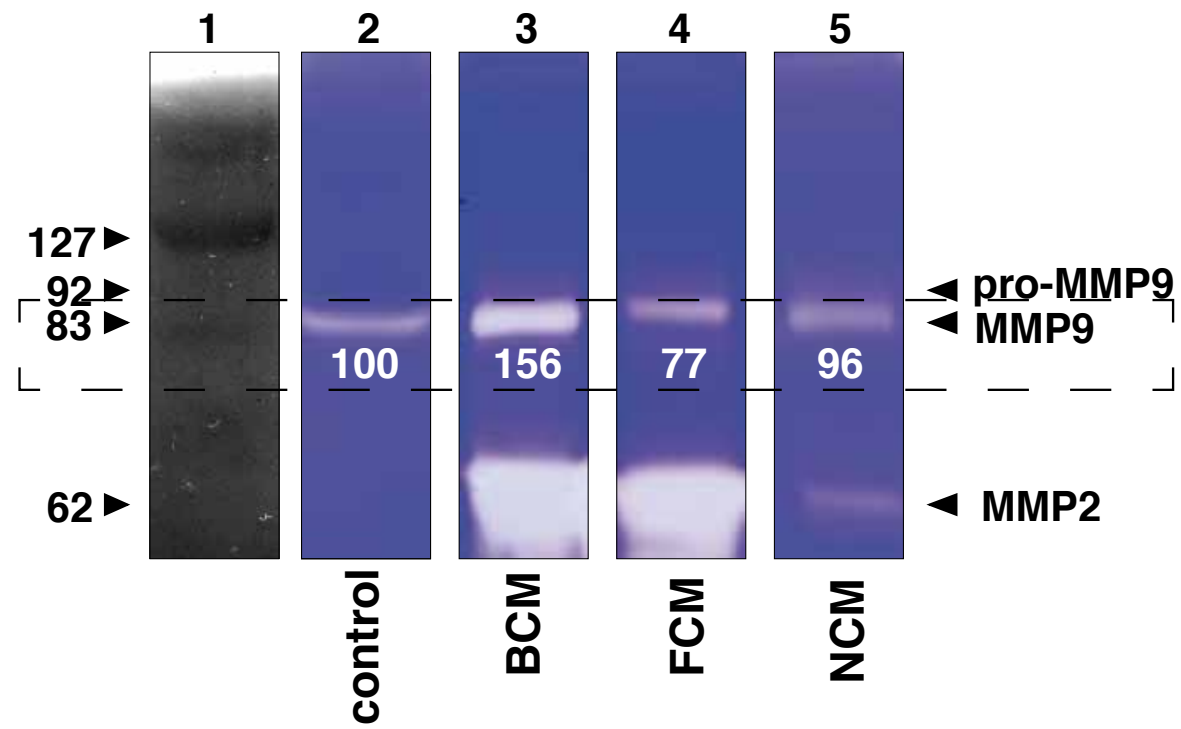

Figure 22. Zymography on hBOEC and hDFS supernatants. Zymogram on conditioned media of hBOEC (BCM; lane 3) or hDFS (FCM; lane 4) and on non-conditioned media (NCM; lane 5) compared to APMA-activated MMP-9 control (lane 2). The most prominent upper bands (indicated by a dashed rectangle) correspond to active MMP-9 (83 kDa), revealing more active MMP-9 in BCM. Values are arbitrary units determined by densitometry, using Image $\mathrm{J}$ software. Lower bands correspond to active MMP-2 (62 kDa). Lane 1 is a molecular weight ladder.

\subsection{2. $p B O E C$}

Comparable to hBOEC, pBOEC abundantly produced PIGF, but they seemed to produce less angiogenic factors and factors that communicate with fibroblasts or keratinocytes (Table 8). Unfortunately, the porcine genome is incompletely sequenced yet and therefore we were unable to perform the same extensive qRT-PCR analysis as for hBOEC. 


\begin{tabular}{|c|c|c|c|c|}
\hline Pig testis & \multicolumn{4}{|c|}{ pBOEC } \\
\hline \multicolumn{5}{|c|}{ Communication with vascular/inflammatory cells } \\
\hline & PIGF & Ang-1 & Ang-2 & MCP-1 \\
\hline 100 & $8596 \pm 1984$ & $0 \pm 0$ & $54 \pm 14$ & $29 \pm 7$ \\
\hline \multicolumn{5}{|c|}{ Communication with fibroblasts (matrix) } \\
\hline & MMP-2 & MMP-9 & MMP-14 & TGF $\beta 1$ \\
\hline 100 & $103 \pm 14$ & $7 \pm 1$ & $8 \pm 1$ & $134 \pm 10$ \\
\hline \multicolumn{5}{|c|}{ Communication with keratinocytes } \\
\hline \multicolumn{5}{|c|}{ KGF } \\
\hline 100 & $1 \pm 0$ & & & \\
\hline
\end{tabular}

Table 8. Growth factor expression profile of pBOEC. RNA data represent mean ( \pm SEM) of 3 separate sets of pBOEC, determined by qRT-PCR and expressed as $\%$ versus pig testis RNA and normalised to $\mathrm{PGAPDH}$.

\section{2. hBOEC, unlike HUVEC, induce robust wound vascularisation and re-oxygenation}

\section{1. hBOEC and HUVEC engraftment}

When acetylated LDL-labelled hBOEC were applied onto the full thickness wounds, they were evenly distributed over the wound bed two days later (Fig. 23A,B) and detected until day 10 , sometimes clearly co-localised with blood-filled vessels (Fig. $23 C, D$ ). Given the potential leakage of acetylated-LDL and subsequent uptake by host cells, the engraftment pattern as shown by acetylated-LDL was confirmed using a different method, i.e. by transplanting $\mathrm{hBOEC}$ transduced with a lentiviral construct harbouring a GFP expression cassette (Fig. 15A,B). Since UEA-lectin binds hBOEC (Fig. 14A) but not murine EC (Fig. 14B), we used UEA-lectin to quantify hBOEC engraftment. At day $5,138 \pm 23$ UEA-lectin ${ }^{+}$cells $/ \mathrm{mm}^{2}(N=4)$ were detected in the wound bed, some of which actively participated in the formation of large vessels at the wound borders (Fig. 23F), while others were scattered as single cells in the wound centre. At day 10, only few hBOEC were traceable. Using species-specific CD31 antibodies or human-specific UEA-lectin, we observed formation of functional hybrid vessels containing hBOEC and adjacent murine EC (Fig. 23E). 


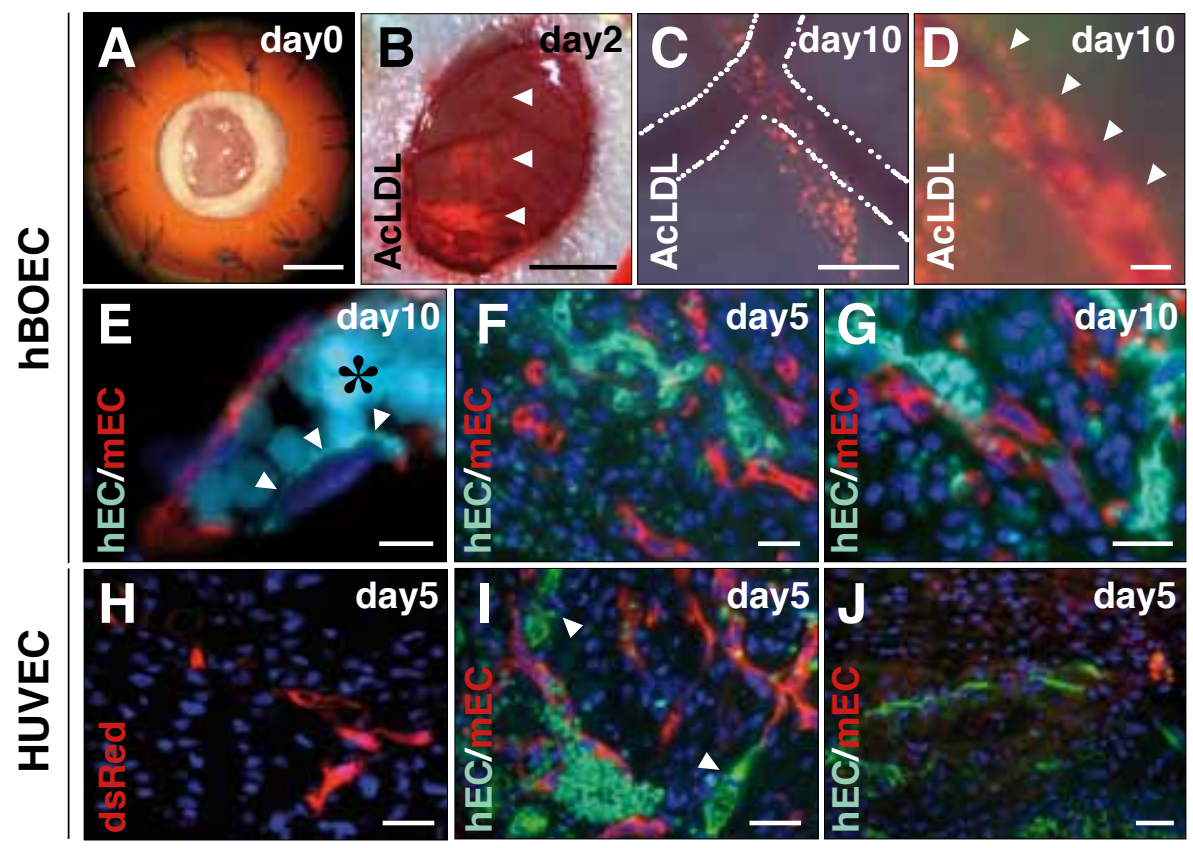

Figure 23. $h B O E C$ and HUVEC engraftment. $A$, Wound with silicone ring. $B-D, A C L D L-c a r r y i n g$ hBOEC were homogenously distributed (white arrowheads in $B$ ) in the wound at day 2 , were located in vicinity to vessels (dashed white lines in $C$ ) and sometimes formed a sleeve around blood-filled channels (white arrowheads; $D$ ). Green autofluorescence was used as background in $D$. E-G, hBOEC (revealed by green human-specific CD31) incorporated into mouse vessels (revealed by red mousespecific CD31) and formed hybrid vessels (incorporated hBOEC indicated by white arrowheads and lumen indicated by asterisk in E). hBOEC incorporated in vessels in the border (day 5) and in the centre (day 10) of wounds (hBOEC-derived vessels in green and mouse-derived vessels in red in $E-G) . H-J$, In some animals, HUVEC could be traced by their expression of dsRed in the wound edges at day $5(H)$. HUVEC (stained with UEA-lectin in green in $I, J$ ) also incorporated into murine vessels $(m C D 31$ in red in $I, J)$ in the wound edge at day 5 , however some cord-like structures in the centre of the wound were not connected to the host vasculature $(J)$. DAPI was used as nuclear counterstain in $E$-J. Scale bars: $3 \mu \mathrm{m}$ in $E, 20 \mu \mathrm{m}$ in $D, F, G, 25 \mu \mathrm{m}$ in $H-J, 150 \mu \mathrm{m}$ in $C, 1 \mathrm{~mm}$ in $B$, and $4 \mathrm{~mm}$ in $A$.

HUVEC were found in the wound edges at day 5, some of them making hybrid vessels with mouse cells (Fig. 23H, I). Cord-like structures of HUVEC were also found in the wound centre at day 5 , however these did not connect with the host vasculature and were therefore not functional (Fig. 23J). On the contrary, when human early EPC were applied in this wound healing model, we were unable to find cells of human origin incorporated into blood vessels (Fig. 18H). 


\subsection{Effect of $h B O E C$ and HUVEC on vascularisation and re-oxygenation}

Two vascularisation peaks were identified by Laser Doppler - at day 4 and 8 - in hBOEC but not in saline-treated wounds (Fig. 12C). At day 5, vessels were predominantly found at the wound borders, $8 \pm 1 \%$ of which contained hBOEC (Fig. 23F), indicating a significant direct contribution to wound vascularisation. HUVEC also incorporated in host vessels, although much less frequently. At day 10, vessels were observed throughout the wound, however hBOEC were only occasionally found in these (Fig. $23 E, G)$. The presence of erythrocytes in hBOEC-derived vessels indicated their functional connection to the host vascular network (Fig. 23E-G). In contrast, many HUVEC structures did not contain blood cells, perhaps indicating their failure to connect to the host vasculature (Fig. 23J). Based on their expression of angiogenic factors (Table 7), we assumed hBOEC to stimulate host angiogenesis. Indeed, wound edges of hBOEC-treated mice contained twice as much mouse $(\mathrm{m}) \mathrm{CD} 31^{+}$vessels than those of the saline-treated mice (Fig. 24A,B; Table 9). At day 10, the entire wound contained more $\mathrm{mCD} 31^{+}$vessels when seeded with hBOEC, compared to the saline group (Fig. 24C,D; In contrast, HUVEC treated wounds showed no increased host angiogenic response (Table 9).

Interestingly, dose-response studies revealed that upon increasing the hBOEC dose from $0.5 \times 10^{6}$ to $1 \times 10^{6}$ or $1.5 \times 10^{6}$, there was no increase in $\mathrm{mCD} 31^{+}$area fraction (data not shown), however, the number of vessels per area increased significantly when using higher hBOEC doses (Fig. 24/-J; number of mCD31+ vessels $/ \mathrm{mm}^{2}: 376 \pm 14$ for $1 \times 10^{6} \mathrm{hBOEC} ; 376 \pm 39$ for $1.5 \times 10^{6} \mathrm{hBOEC}$ and $271 \pm 27$ for $0.5 \times 10^{6} \mathrm{hBOEC}$; N=4-6; $P<0.05$ and $P<0.05$ versus $0.5 \times 10^{6} \mathrm{hBOEC}$ ). Interestingly, despite their engraftment in wounds, HUVEC transplantation did not increase the mCD31-positive area fraction compared to saline-treated wounds (Table 9).

Since hBOEC secreted PIGF and PDGF-BB, factors that have a chemo-attractive and/or proliferative effect on SMC, we determined whether hBOEC increased SMCcoated vessels. At day 5, hBOEC-treated wounds contained twice the amount of SMC-actin (SMA)-coated vessels compared to saline-treated or HUVEC-treated wounds (Fig. 24E,F; Table 9). hBOEC-treated wounds also contained more $\mathrm{SMA}^{+}$ vessels than the saline-infused wounds at day $10(265 \pm 22$ versus $179 \pm 16 ; N=5$; $P<0.05$; Fig. 24G,H). 


\begin{tabular}{|c|c|c|c|c|c|}
\hline \multicolumn{6}{|c|}{ Wound revascularisation and closure in early phase (day 5) } \\
\hline & Saline & HUVEC & hBOEC & hDFS & $\begin{array}{c}\text { hDFS } \\
+ \text { hBOEC }\end{array}$ \\
\hline $\begin{array}{l}\text { Wound revascularisation; } N=6-12 \\
-m C D 31^{+} \text {area fraction }(\%)^{\mathrm{a}} \\
-\mathrm{N}^{\circ} \alpha-\mathrm{SMA}^{+} \text {vessels } / \mathrm{mm}^{2}\end{array}$ & $\begin{array}{c}6 \pm 1 \\
97 \pm 11 \\
\end{array}$ & $\begin{array}{c}5 \pm 1 \\
87 \pm 11 \\
\end{array}$ & $\begin{array}{c}12 \pm 1^{b, d} \\
208 \pm 29^{b}\end{array}$ & $\begin{array}{c}10 \pm 1^{b} \\
205 \pm 26^{b}\end{array}$ & $\begin{array}{c}13 \pm 1^{\mathrm{b}, \mathrm{c}} \\
180 \pm 15^{\mathrm{b}}\end{array}$ \\
\hline $\begin{array}{l}\text { Wound closure; } N=6-12 \\
\text {-\% contraction (day4) } \\
\text {-myofibroblast area fraction (\%) } \\
\text {-epidermal closure } \\
\quad-\% \text { epithelial coverage }{ }^{f} \\
\quad-\mathrm{N}^{\circ} \text { of keratinocytes } / \mathrm{mm}^{\mathrm{g}} \\
\quad-\% \text { connexin } 43^{\text {low }} \text { keratinocytes }\end{array}$ & $\begin{array}{c}14 \pm 3 \\
410 \pm 40 \\
59 \pm 3\end{array}$ & $\begin{array}{c}19 \pm 3 \\
\text { ND } \\
57 \pm 2 \\
\end{array}$ & $\begin{array}{c}21 \pm 7 \\
3.3 \pm 1.0 \\
34 \pm 7^{\mathrm{b}, \mathrm{e}} \\
410 \pm 30 \\
77 \pm 4^{\mathrm{b}, \mathrm{d}}\end{array}$ & $\begin{array}{c}17 \pm 4 \\
0.7 \pm 0.3^{\mathrm{b}} \\
60 \pm 14^{\mathrm{b}} \\
440 \pm 30 \\
\mathrm{ND}\end{array}$ & $\begin{array}{c}21 \pm 4 \\
0.4 \pm 0.1^{b} \\
43 \pm 10^{b} \\
590 \pm 40^{b, c} \\
\text { ND }\end{array}$ \\
\hline \multicolumn{6}{|c|}{ Wound revascularisation, closure and matrix organisation in late phase (day 10) } \\
\hline & Saline & HUVEC & hBOEC & hDFS & $\begin{array}{c}\text { hDFS } \\
+ \text { hBOEC }\end{array}$ \\
\hline $\begin{array}{l}\text { Wound revascularisation; } N=8-11 \\
-m C D 31^{+} \text {area fraction }(\%)^{\mathrm{h}}\end{array}$ & $8 \pm 2$ & $5 \pm 1$ & $25 \pm 5^{b}$ & $10 \pm 3$ & $24 \pm 5^{\mathrm{b}, \mathrm{c}}$ \\
\hline $\begin{array}{l}\text { Wound closure } \\
-\% \text { contraction; } N=6-12 \\
\text {-epidermal closure }\end{array}$ & $81 \pm 3$ & $84 \pm 3$ & $79 \pm 4$ & $67 \pm 5^{i}$ & $59 \pm 8^{j}$ \\
\hline $\begin{array}{l}\text {-\% epithelial coverage }{ }^{\mathrm{f}} ; N=6-23 \\
\text {-epithelial thickness }(\mu \mathrm{m})^{\mathrm{k}} ; N=7-11\end{array}$ & $\begin{array}{l}87 \pm 4 \\
66 \pm 6\end{array}$ & $\begin{array}{l}94 \pm 3 \\
\text { ND }\end{array}$ & $\begin{array}{l}99 \pm 1^{b} \\
53 \pm 6\end{array}$ & $\begin{array}{l}98 \pm 4^{b} \\
47 \pm 8\end{array}$ & $\begin{array}{l}100 \pm 0^{b} \\
98 \pm 13^{b, c}\end{array}$ \\
\hline $\begin{array}{l}\text { Wound matrix organisation; } N=6-15 \\
-\% \text { fibrillar collagen } \\
-\% \text { red-birefringent collagen }\end{array}$ & $\begin{array}{l}58 \pm 3 \\
28 \pm 3\end{array}$ & $\begin{array}{l}62 \pm 3 \\
28 \pm 3\end{array}$ & $\begin{array}{c}63 \pm 3 \\
47 \pm 2^{b, d}\end{array}$ & $\begin{array}{l}67 \pm 3^{b} \\
32 \pm 3\end{array}$ & $\begin{array}{l}71 \pm 2^{b, 1} \\
48 \pm 5^{c}\end{array}$ \\
\hline
\end{tabular}

Table 9. Early and late effects of HUVEC, hBOEC, hDFS or hDFS+hBOEC on wound healing. Data represent mean ( \pm SEM). a: \% of total area in wound borders; ${ }^{\text {b }}: P<0.05$ versus saline; ${ }^{\text {c: }} P<0.05$ versus hDFS; ${ }^{\text {d: }} P<0.05$ versus HUVEC; ${ }^{e}: P=0.06$ versus HUVEC; $f: \%$ of total wound length, defined as the distance between the two first appearing hair follicles; 9 : counted in the advancing epithelial edges;, $\mathrm{h}$ : $\%$ of total area in entire wound bed; i: $P=0.07$ versus saline; $\mathrm{j}: P<0.05$ versus $\mathrm{hBOEC}$; : average thickness determined over the entire wound length; ' $P=0.05$ versus saline hBOEC; SMA: smooth muscle cell actin; ND: not determined. 


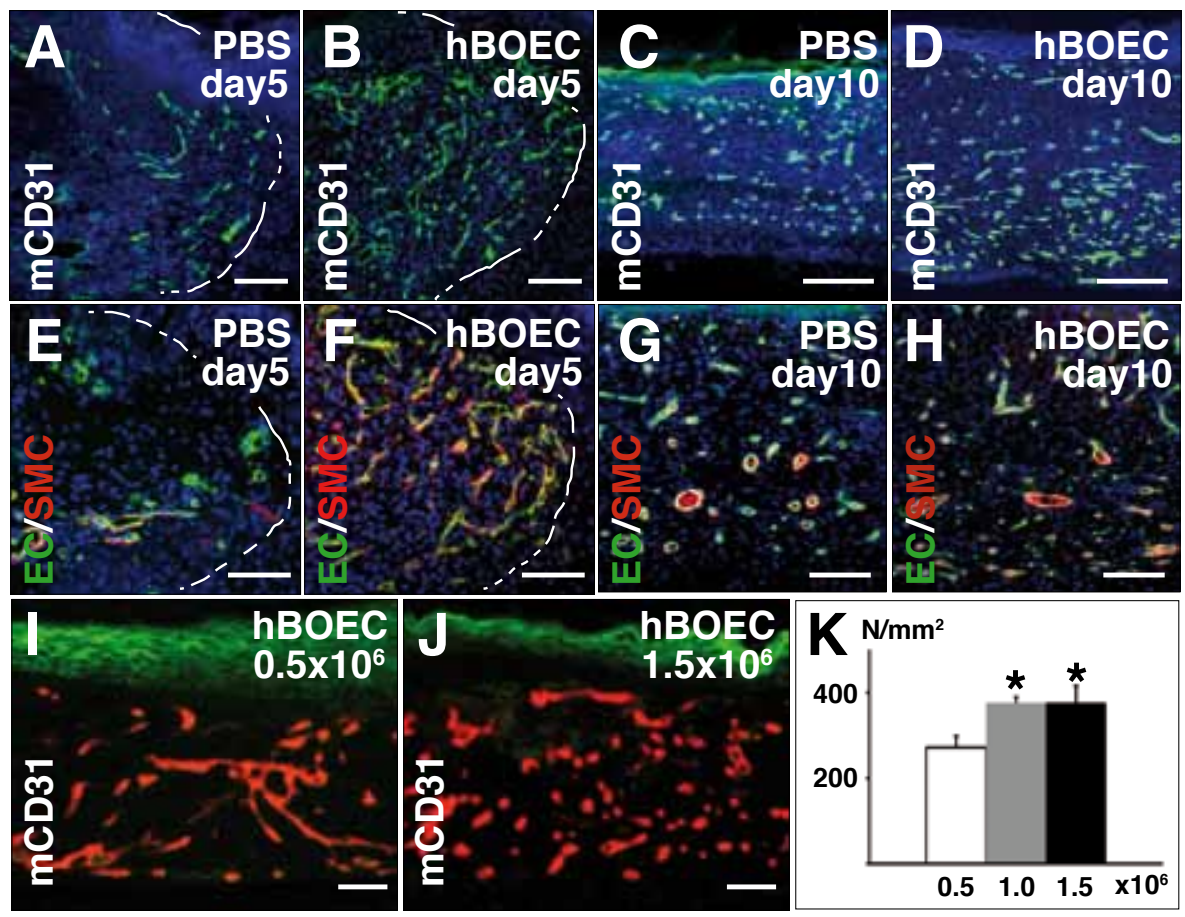

Figure 24. hBOEC induce angiogenesis and vessel maturation in murine wounds. $A-D$, Crosssections of wound borders at day $5(A, B)$ and wound centres at day $10(C, D$; stained with green mouse-specific CD31) revealing more vessels in hBOEC-treated $(B, D)$ compared to PBS-treated wounds $(A, C)$. $\boldsymbol{E}-\boldsymbol{H}$, Wound cross-sections at day $5(E, F)$ and day $10(G, H)$ double-stained for EC in green (revealed by a combination of mouse-specific CD31 and human-specific Ulex Europaeus Agglutinin (UEA)-lectin) and SMC(revealed by red SMC- $\alpha$-actin) showing more SMC-coated vessels in hBOEC-treated $(F, H)$ than in PBS-treated $(E, G)$ wounds. I-K, In comparison to wounds treated with regular dose of $5 \times 10^{5} \mathrm{hBOEC}(I)$, doubling or tripling $(J)$ BOEC doses resulted in significantly increased vessel number $(K)$. Scale bars: $30 \mu \mathrm{m}$ in $I, J, 150 \mu \mathrm{m}$ in $E, F$, and $200 \mu \mathrm{m}$ in $A-D, G, H$.

Since wound revascularisation is supposed to relieve hypoxia, we tested whether hBOEC-induced vascular expansion decreased the amount of hypoxic cells at 5 days. Therefore, a separate set of animals was injected with Hypoxyprobe ${ }^{\mathrm{TM}}$ and hypoxic cells were traced by immunohistochemistry. hBOEC treatment significantly reduced the hypoxic cell fraction by $\sim 40 \%$ ( $24 \pm 1$ in saline-treated versus $15 \pm 1$ in hBOEC-treated wounds; $N=5$; $P<0.05$; Fig. $25 A C$ ). Moreover, the decrease in hypoxic cell fraction inversely correlated with the area taken up by blood vessels $\left(R^{2}=0.545: P<0.05\right.$; Fig. $\left.25 F\right)$ and hypoxic cells mainly resided in avascular areas (Fig. 25D,E). 

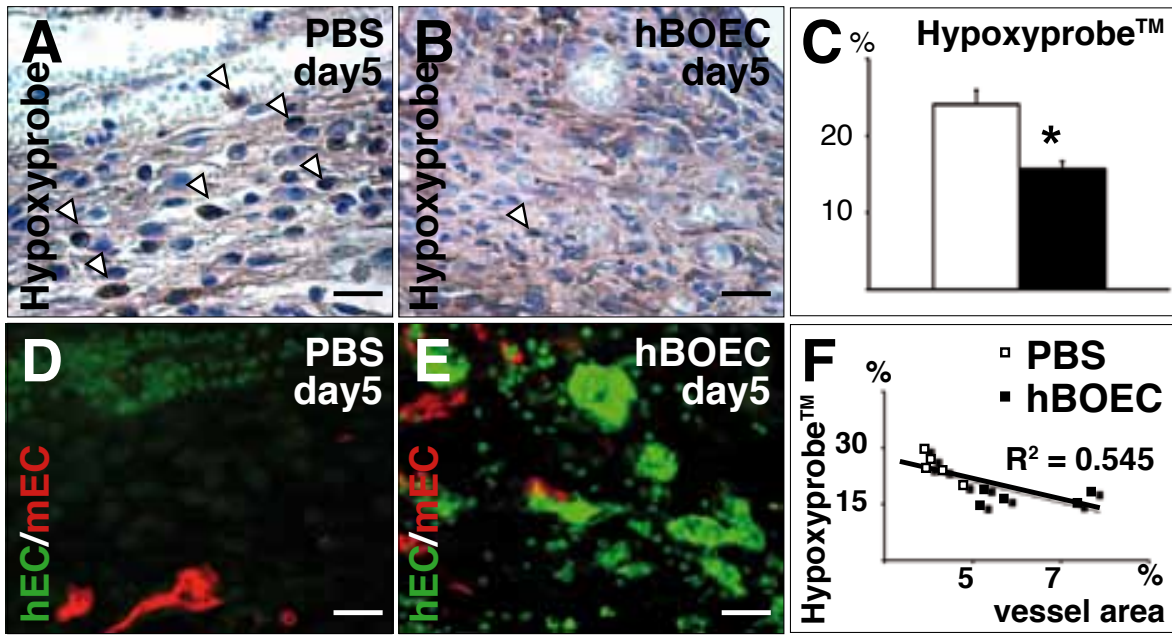

Figure 25. Increased wound bed vascularisation by BOEC correlates with decreased hypoxia. $\boldsymbol{A}-\boldsymbol{C}$, Wound cross-sections at day 5 stained with a mAb against Hypoxyprobe ${ }^{\mathrm{TM}}$, revealing more hypoxic cells in saline-treated ( $A$; white bar in $C$; expressed as \% of total cell number) versus hBOECtreated wounds $(B$; black bar in $C)$. $D-F$, Cross-sections $(D, E$ serial to $A, B)$ of wounds at day 5 double-stained for mouse/human EC (revealed by red mouse-specific CD31 and green UEA-lectin, respectively) revealing more vessels in hBOEC-treated $(E)$ compared to saline-treated wounds $(D)$. Note that hypoxic cells (indicated by white arrowheads in $A, B$ ) resided in avascular areas. Panel $F$ reveals that the extent of hypoxia (expressed as \% hypoxic cells) inversely correlated with the vascular area (expressed as $\%$ of the total area). Scale bars: $20 \mu \mathrm{m}$ in $A, B, D$ and $E$.

\section{3. hBOEC, unlike HUVEC, improve dermal matrix organisation and accelerate re-ep- ithelialisation}

Next, we evaluated epidermal and dermal healing in terms of re-epithelialisation and collagen deposition/organisation. Compared to saline and HUVEC, hBOEC transplantation increased re-epithelialisation at day 5 (Fig. 26A,B; Table 9). The fraction of migrating keratinocytes, detected by down-regulation of connexin43, was higher in the presence of hBOEC (Fig. 26C,D; Table 9), while HUVEC did not affect connexin43 expression (Table 9). At day 10, all hBOEC-treated wounds were reepithelialised completely, while re-epithelialisation was only $87 \pm 4 \%$ in the saline group and $94 \pm 3 \%$ in the HUVEC group (Table 9). 


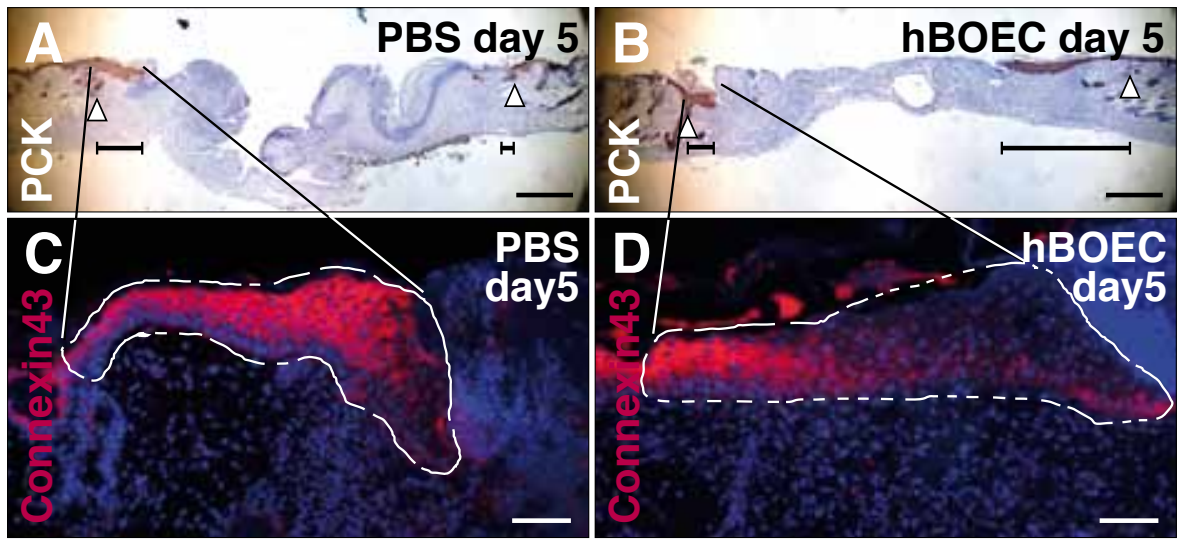

Figure 26. $h B O E C$ induce re-epithelialisation in vivo. $A, B$, The epidermal front (revealed by pancytokeratin (PCK)) moved faster over the wound in hBOEC-treated $(B)$ compared to PBS-treated wounds $(A)$. Hair follicles marking wound boundaries and the length covered by the epidermis are indicated by white arrowheads and black lines, respectively. $\boldsymbol{C}, \boldsymbol{D}$, Cross-sections stained with connexin43 in red showing more migrating (i.e. cells that have down-regulated connexin43) keratinocytes in the epidermal tongue (indicated by white dashed lines) of hBOEC-treated $(D)$ versus PBS-treated $(C)$ wounds. Scale bars: $75 \mu \mathrm{m}$ in $C, D$, and $500 \mu \mathrm{m}$ in $A, B$.

To evaluate fibrillar collagen deposition and organisation, we analysed Sirius redstained sections under bright (deposition) and polarised (organisation) light. The presence of neither hBOEC nor HUVEC increased collagen deposition (\% fibrillar collagen; Table 9) but unlike HUVEC, hBOEC improved organisation at day 10 (\% red birefringent collagen; Fig. 27A,D; Table 9). This improvement in organisation was confirmed on semi-thin sections (Fig. 27B,E) and TEM images that clearly visualise thick aligned collagen bundles in BOEC treated wounds (Fig. 27C,F). Intuigingly, tripling the hBOEC dose to $1.5 \times 10^{6}$ nearly doubled the percentage of organized collagen (not shown). 

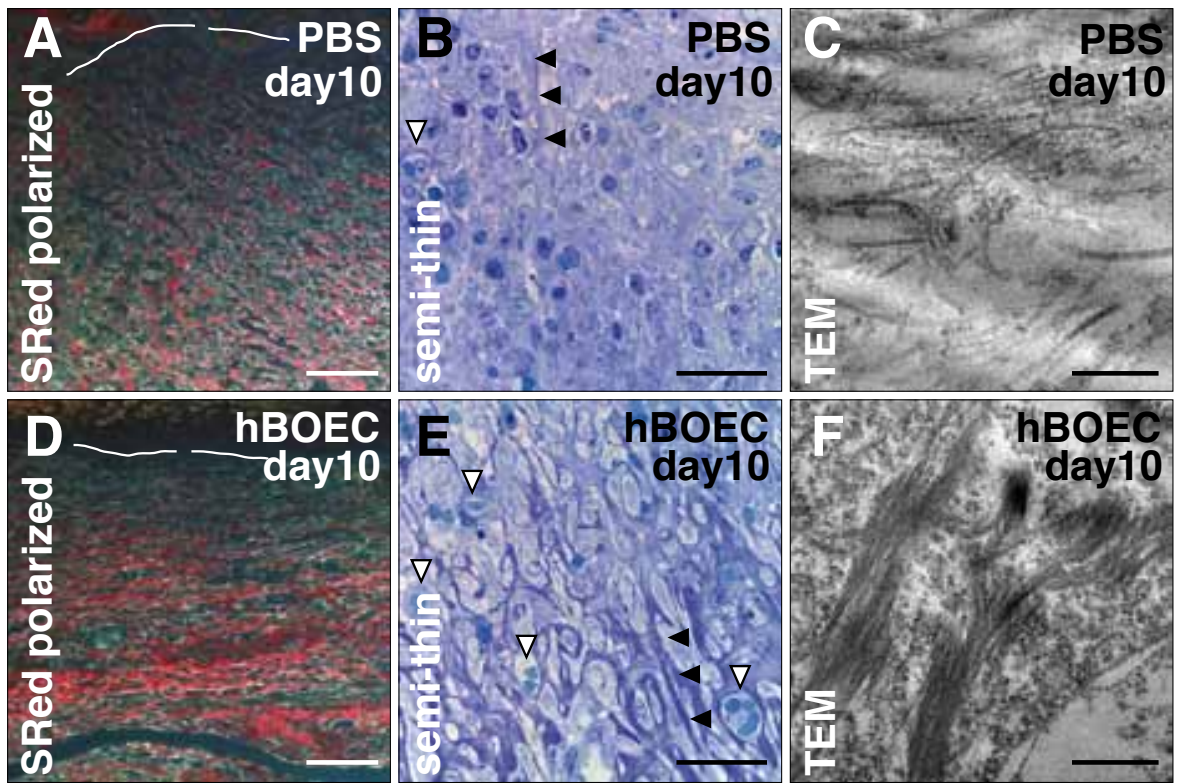

Figure 27. $h B O E C$ improve dermal matrix organisation in vivo. Collagen organisation was analysed by Sirius red polarisation microscopy $(A, D)$, on semi-thin sections $(B, E)$ and by $\operatorname{TEM}(C, F)$, revealing that collagen was more aligned in thick bundles (shown by the red birefringence, the thicker blue matrix structures (indicated by black arrowheads) on semi-thin sections and the parallel positioning of the collagen fibres on TEM) in hBOEC-treated $(D-F)$ compared to PBS-treated $(A-C)$ wounds. Blood vessels are indicated by white arrowheads in $B, E$. Scale bars: $0.5 \mu \mathrm{m}$ in $C, F, 25 \mu \mathrm{m}$ in $B, E$ and $50 \mu \mathrm{m}$ in $A, D$.

\section{3. hBOEC stimulate healing by improving oxygenation and by growth factor cross-talk}

\subsection{Effect of oxygenation}

As increased vascularisation by hBOEC improved wound bed oxygenation (Fig. 25), we studied the effect of increased $\mathrm{O}_{2}$ levels on cultured hDFS and keratinocytes. hDFS or keratinocytes were cultured in hypoxic $\left(1 \% \mathrm{O}_{2}\right)$ or normoxic $\left(20 \% \mathrm{O}_{2}\right)$ conditions for 10 days (corresponding to the duration of our in vivo experiment). A review of the literature reveals that $\mathrm{O}_{2}$ levels in healing human wounds are estimated to be $<1.5 \% \mathrm{O}_{2}$ in the wound centre ${ }^{138,171}$. The use of occlusive dressings even further decreases $\mathrm{O}_{2}$ tension in wounds ${ }^{172}$. Measurement of $\mathrm{O}_{2}$ tension by electron paramagnetic resonance (EPR) oximetry ${ }^{164}$ revealed that the oxygen levels in the wound centre of mice were in a similar low range $(2.7 \pm 0.6 \%$ and $2.1 \pm 0.5 \% 1$ and 5 days after wounding, respectively $(N=3-6)$ ). 


\subsubsection{Oxygen and collagen organisation}

High $\mathrm{O}_{2}$ levels resulted in increased organisation of fibrillar collagen in hDFS (\% red birefringent collagen: $13 \pm 3$ at $1 \% \mathrm{O}_{2}$ vs. $32 \pm 2$ at $20 \% \mathrm{O}_{2} ; N=4 ; P<0.005$; Fig. $28 A, B$ ), further confirmed by semi-thin sections (Fig. 28E,F). Interestingly, qRT-PCR analysis revealed higher MMP-1 expression in hDFS in hypoxic conditions, perhaps causing increased collagen destruction (Fig. 28H).

$1 \% \mathrm{O}_{2}-\mathrm{BCM}$
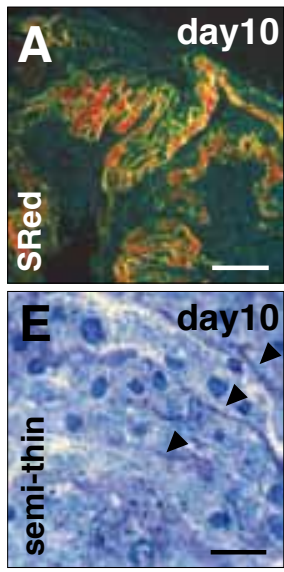

$20 \% \mathrm{O}_{2}-\mathrm{BCM}$
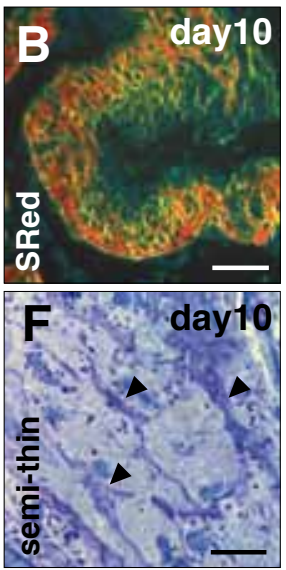

\section{$20 \% \mathrm{O}_{2}+\mathrm{BCM}$}
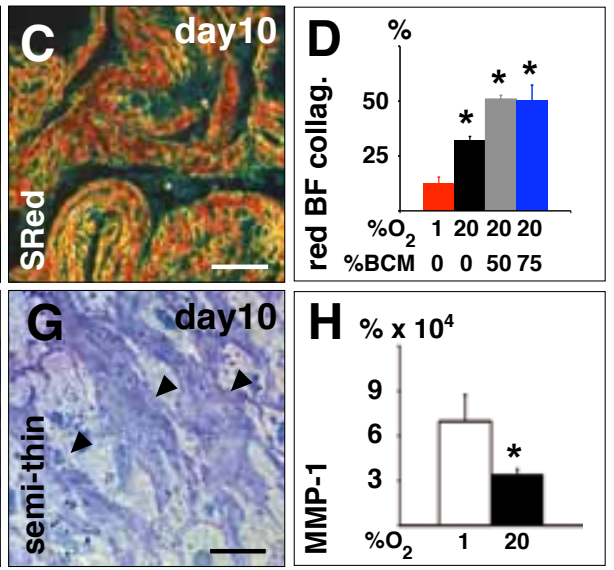

Figure 28. Collagen organisation in hDFS in vitro is stimulated by $\mathrm{O}_{2}$ and BOEC-CM. A-C, Sirius red-stained cross-sections (viewed under polarised light) of hDFS in $1 \% \mathrm{O}_{2}$ without hBOEC-conditioned media (BCM; $A$, red bar in $D$ ) or $20 \% \mathrm{O}_{2}$ in the absence $(B$, black bar in $D$ ) or presence $(C$, grey and blue bar in $D$ ) of $\mathrm{BCM}$, revealing more organised (i.e. red-birefringent collagen; red $\mathrm{BF}$ collag.; $\%$ versus total area in $D$ ) collagen in $20 \% \mathrm{O}_{2}$, further increased by BCM. E-G, Semi-thin sections revealing thicker collagen bundles (black arrowheads in $E-G$ ) in normoxia $(F)$ compared to hypoxia $(E)$ and even more thick bundles in the presence of BCM $(G)$. qRT-PCR analysis revealed higher MMP-1 expression in hDFS in hypoxic conditions $(H)$ Scale bars: $10 \mu \mathrm{m}$ in $E-G$ and $50 \mu \mathrm{m}$ in $A-C$.

\subsubsection{Oxygen and keratinocyte behaviour}

Keratinocytes migrated more slowly on a collagen-coated surface after long-term exposure to hypoxia in a scratch-wounding assay (area covered by keratinocytes in a $1 \mathrm{~mm}$ window 24 hours after wounding $\left(\mu \mathrm{m}^{2} \times 10^{5}\right): 2.8 \pm 0.4$ at $1 \% \mathrm{O}_{2}$ versus $5.1 \pm 0.3$ at $20 \% \mathrm{O}_{2} ; N=4 ; P<0.05 ;$ Fig. 29A,B). In agreement, qRT-PCR revealed that 24 hours after wounding, keratinocytes expressed 3-fold more connexin43 in hypoxia ( $N=3$; $P<0.05$; Fig. 30), corresponding to a less migratory phenotype. In addition, lowering $\mathrm{O}_{2}$ levels significantly decreased keratinocyte proliferation by a factor of 1.5 ( $N=4-6$; $P<0.005$; Fig. 29F,G). 


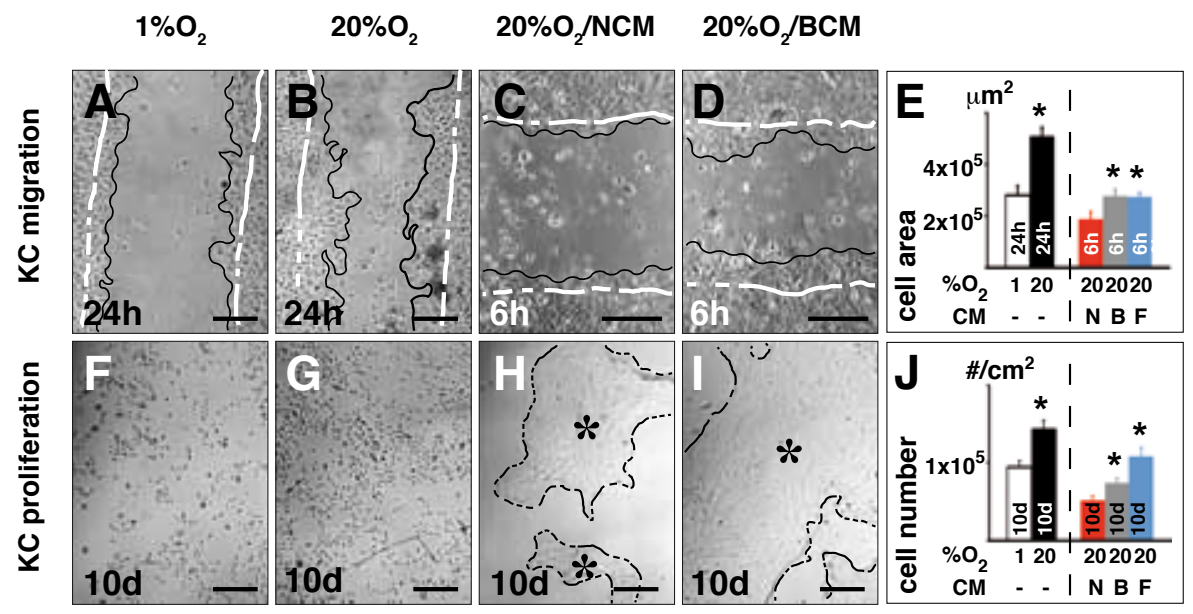

Figure 29. Keratinocyte migration and proliferation in vitro is stimulated by $\mathrm{O}_{2}$ and BOEC-CM. $A-E$, Wounding assay revealing more migrating keratinocytes (KC; area in $\mu \mathrm{m}^{2}$ occupied by migrating $\mathrm{KC}$ in a $1 \mathrm{~mm}$ window in $M$ ) at 24 hours in normoxia ( $B$; black bar in $E$ ) versus hypoxia $(A$, white bar in $E)$. Migration was also increased with $\mathrm{BCM}(D$; ' $\mathrm{B}$ ' and grey bar in $E)$ compared to $\mathrm{NCM}(C$; ' $\mathrm{N}$ ' and red bar in $E$ ). Moreover, hDFS-CM ('F' and blue bar in $E$ ) also increased KC migration. Original wound is indicated by dashed white lines and the moving $\mathrm{KC}$ front by wavy black lines. F-J, Proliferation assay of KC grown in normoxia ( $G$; black bar in $J$ ) or hypoxia ( $F$; white bar in $J$ ) revealing more cell expansion in normoxia (number of cells $/ \mathrm{cm}^{2}$ in $\left.J\right)$. In addition, BCM ( $I$; 'B' and grey bar in $J$ ), and even more so, hDFS-CM ('F' and blue bar in $J$ ) increased KC proliferation compared to NCM $(H$; ' $N$ ' and red bar in $J$ ). *: $P<0.05$ versus hypoxia or NCM. Scale bars in all panels: $300 \mu \mathrm{m}$.

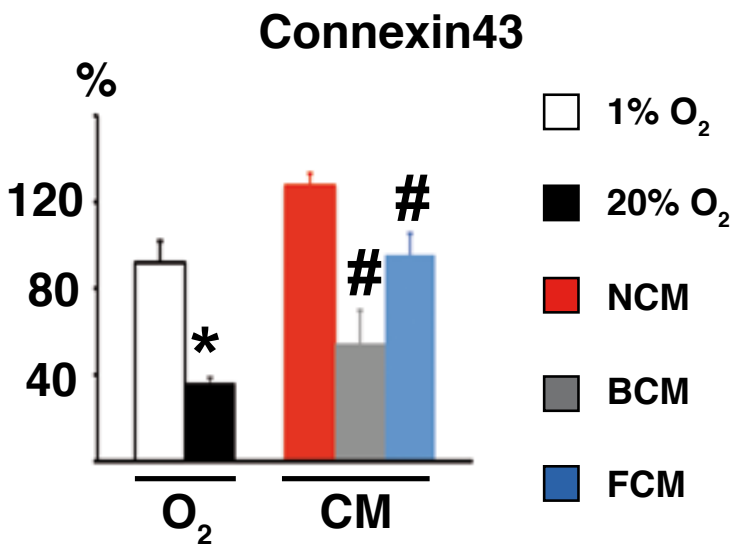

Figure 30. Connexin43 expression by keratinocytes is down-regulated due to low $\mathrm{O}_{2}$ and hBOEC-CM in vitro. Diagram showing the expression of connexin 43 (Cx43), expressed as \% ( \pm SEM) versus universal RNA, in keratinocytes grown under hypoxic $\left(1 \% \mathrm{O}_{2}\right)$ and normoxic $\left(20 \% \mathrm{O}_{2}\right)$ conditions or with hBOEC-CM (BCM), hDFS-CM (FCM) or non-conditioned media (NCM), using HPRT1 as a housekeeping gene. Keratinocytes had significantly less expression of $C \times 43$ (corresponding to a more migrating phenotype) under normoxic conditions and in the presence of BCM or FCM. *: $P<0.05$ versus $1 \% \mathrm{O}_{2}$; $: P<0.05$ versus NCM. 


\subsection{Effect of growth factor cross-talk}

hBOEC communicate with fibroblasts and keratinocytes via factors that influence dermal organisation or keratinocyte migration/proliferation (Table 7). Collagen produced by hDFS cultured in hBOEC-conditioned media was significantly more organised compared to non-conditioned media (\% red birefringent collagen: $32 \pm$ 2 with non-conditioned media versus $51 \pm 2$ with hBOEC-conditioned media; $N=4$; $P<0.005$; Fig. 28B,C; confirmed on semi-thin sections; Fig. 28F,G) suggesting a paracrine effect of hBOEC on hDFS.

No significant differences in collagen organisation were seen when $50 \%$ or $75 \%$ BOEC-conditioned medium was used, suggesting a saturation of the effect induced by hBOEC (Fig. 28D). On the other hand, hBOEC-conditioned media contained factors that boosted keratinocyte migration (area covered by keratinocytes in a 1 $\mathrm{mm}$ window 6 hours after wounding $\left(\mu \mathrm{m}^{2} \times 10^{5}\right): 2.8 \pm 0.3$ with $\mathrm{hBOEC}$-conditioned media versus $1.9 \pm 0.3$ with non-conditioned media; $N=4$; $P<0.05$; Fig. 29C,D) and proliferation (number of keratinocytes $\times 10^{3} / \mathrm{cm}^{2}$ after 10 days: $74 \pm 6$ with hBOECconditioned media vs. $51 \pm 6$ with non-conditioned media; $N=4$; $P<0.05$; Fig. 29H,I). In accordance, keratinocytes had a more migratory phenotype in hBOEC-conditioned media, shown by their 2.3-fold lower expression of connexin43 compared to nonconditioned media $(N=4 ; P<0.05$; Fig. 30$)$.

\section{4. hBOEC improve matrix organisation and re-epithelialisation of hDFS in wounds}

\subsection{Effect of $h D F S(+/-h B O E C)$ on wound contraction and re-epithelialisation}

While hBOEC alone did not reduce contraction, the presence of hDFS -singly or in combination with hBOEC- significantly decreased contraction near the end of the healing period (Fig. 31A,B; Table 9). Reduced contraction in the presence of hDFS was accompanied by a decrease in the area taken up by SMA-expressing myofibroblasts at the wound edges 5 days after wounding (Fig. 31C-F; Table 9). Like hBOEC alone, HUVEC did not affect wound contraction (Table 9).

In addition, the presence of hDFS - singly or in combination with hBOECsignificantly increased collagen deposition in the wounds at 10 days, compared to the corresponding conditions without hDFS (\% fibrillar collagen; Table 9). Finally, filling the wound gap with hDFS - singly or in combination with hBOEC- had markedly increased the epithelialisation rate at 5 days compared to saline (Fig. $26 A, B$ and $32 A, B$; Table 9). At 10 days, wounds containing hDFS and hDFS+hBOEC were significantly more re-epithelialised than those in the saline group (Table 9). Regarding the (nearly) complete epithelial coverage of wounds treated with hBOEC or hDFS, no additional effect was noticed in the hDFS+hBOEC group. 


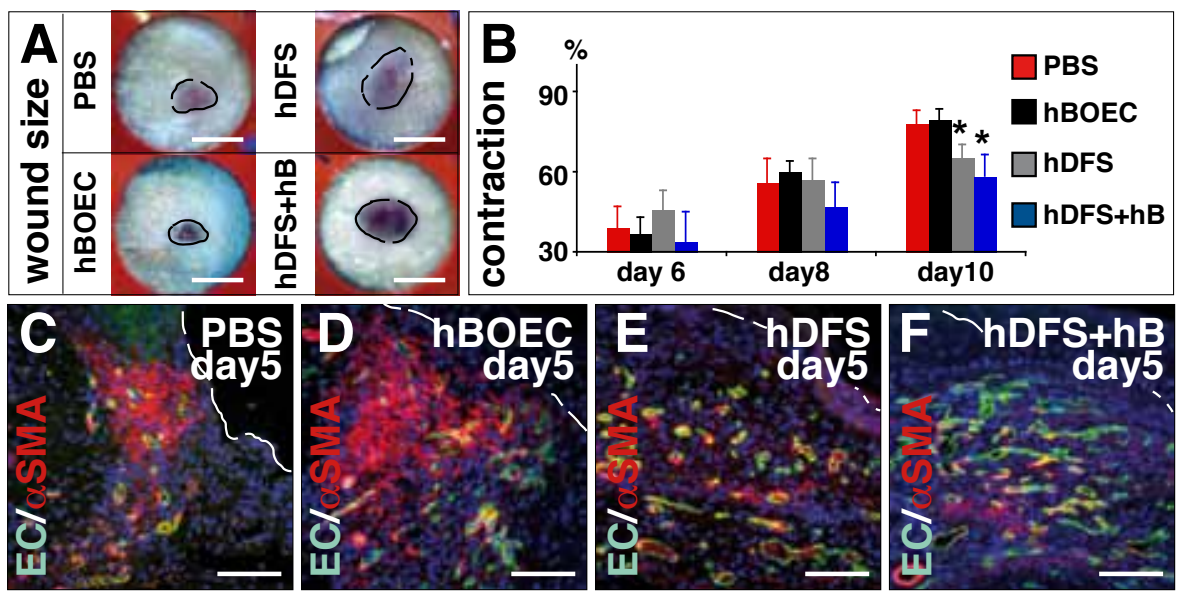

Figure 31. hDFS reduce wound contraction. $A, B$, Size $(A)$ and contraction (\% relative to original wound size in $B$ ) in wounds treated with PBS (red bars in $B$ ), hBOEC (black bars in $B$ ), hDFS (grey bars in $B$ ) or hBOEC+hDFS (blue bars in $B$ ) revealing reduced contraction in conditions with hDFS. $\boldsymbol{C}-\boldsymbol{F}$, Cross-sections of PBS $(C)$, hBOEC $(D)$, hDFS $(E)$ or hBOEC $(\mathrm{hB})+\mathrm{hDFS}(F)$ treated wounds doublestained for EC (mouse and human, using mouse-specific CD31 and human-specific Ulex Europaeus Agglutinin (UEA)-lectin in green) and SMC (revealed by red SMC- $\alpha$-actin) showing less myofibroblasts (corresponding to $\mathrm{SMC}-\alpha$-actin ${ }^{+}$signal not associated with green EC) at the wound edges (lined by dashed white lines) in conditions with hDFS. DAPI (blue) was used as nuclear counterstaining in $C-F$. Scale bars: $75 \mu \mathrm{m}$ in $C-F$ and $3 \mathrm{~mm}$ in $A$.

However, in the latter group, thickness of the epithelium was significantly increased, with less nucleated keratinocytes, suggesting improved differentiation (Fig. 32C,D). Growth factor analysis (Table 7) and keratinocyte proliferation/migration assays in the presence of hDFSconditioned media (Fig. 29E,J) further support the notion that the improved epithelial coverage is related to cross-talk of fibroblasts and keratinocytes. In accordance, keratinocytes had a more migratory phenotype in the presence of hDFS-conditioned media, as shown by their 1.3-fold lower expression of connexin 43 compared to non-conditioned media $(N=4 ; P<0.05$; Fig. 30$)$. 

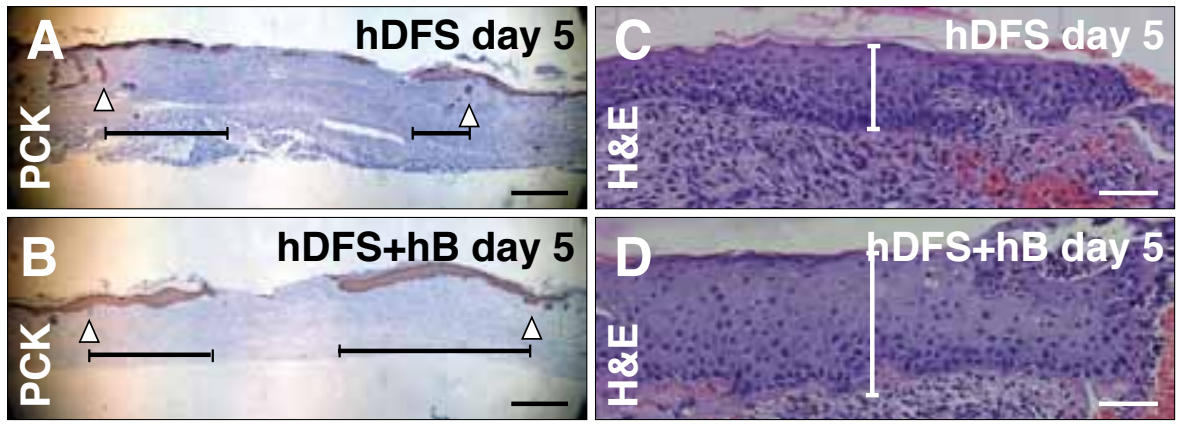

Figure 32. hDFS stimulate wound re-epithelialisation. $A, B$, Cross-sections of wounds treated with hDFS alone $(A)$ or combined with $\mathrm{hBOEC}(\mathrm{hB} ; B)$ stained with pancytokeratin (PCK) revealing faster epithelial coverage in conditions with hDFS compared to PBS-treated wounds (see Fig. 26A, $B$ ). Hair follicles marking wound boundaries and the length covered by epidermis are indicated by white arrowheads and black lines, respectively. C,D, Cross-sections stained with H\&E revealing that the epithelial tongue has a larger thickness (indicated by white lines) in hBOEC containing hDFS $(D)$ than in hDFS alone (C). Scale bars: $75 \mu \mathrm{m}$ in $C, D$ and $500 \mu \mathrm{m}$ in $A, B$.

\subsection{Effect of $h B O E C$ on vascularisation of $h D F S$}

Next, we assessed whether hBOEC were able to increase vascularisation of hDFS. At day 5 , compared to saline, the presence of hDFS alone was sufficient to increase the number of $\mathrm{mCD} 31^{+}$vessels in the wound borders, likely by a trophic effect (Table 7) on angiogenesis. Addition of hBOEC further increased this trophic effect on the host vasculature (Fig. 33A,B; Table 9). The presence of hDFS alone also proved to be sufficient to increase the number of SMA-coated vessels, an effect that was not further enhanced by hBOEC (Table 9). At 10 days, vessels occupied the entire wound, including the hDFS. While hDFS alone did not increase vascularisation compared to saline, the presence of hBOEC did enhance vascularisation of the entire wound (mCD31+ area fraction; Fig. 33C,D and 24C,D; Table 9).
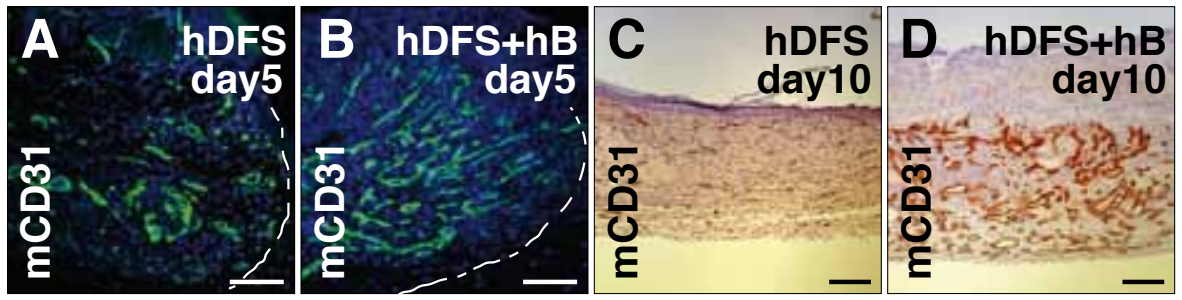

Figure 33. BOEC enhance angiogenesis in hDFS. Cross-sections of wound borders at day 5 (stained with green mouse-specific CD31 in $A, B$ ) and wound centres at day 10 (stained with mouse-specific CD31 in $C, D)$ revealing more vessels in hDFS combined $(B)$ or not $(A)$ with $\mathrm{hBOEC}$ as compared to PBS-treated wounds at day 5 (see Fig. 24A). At day 10, hBOEC increased vascularisation of hDFS in the wound centre ( $D$ versus $C$ ). DAPI (blue) was used as nuclear counterstaining in $A, B$. Scale bars: $200 \mu \mathrm{m}$. 


\subsection{Effect of $h B O E C$ on matrix organisation in and re-epithelialisation of $h D F S$}

Finally, we investigated whether hBOEC-mediated neo-vascularisation of hDFS was consistent with our in vitro findings at increased $\mathrm{O}_{2}$ levels. Although hBOEC did not affect collagen deposition (\% fibrillar collagen; Table 9), they did improve collagen organisation within hDFS implanted in wounds (\% red birefringent collagen; Fig. $34 A, D$; Table 9).

This increased organisation was confirmed by TEM (Fig. 34C,F) and on semi-thin sections (Fig. 34B,E). Consistent with the observed in vitro effect of increased $\mathrm{O}_{2}$ levels on keratinocyte proliferation, hBOEC increased the number of keratinocyte layers in the advancing epithelial tongues at 5 days on top of the implanted hDFS (number of keratinocytes/mm: $590 \pm 40$ in hDFS+hBOEC versus $440 \pm 30$ in hDFS; $N=6 ; P<0.05$; Fig. $32 C, D$ ). Moreover, at day 10 , the epithelium covering the hDFS was thicker in the presence of hBOEC (epithelial thickness; Table 9). Interestingly, under low $\mathrm{O}_{2}$ conditions, hDFS secreted significantly less KGF as compared to normoxic conditions (pg/mg protein: $14 \pm 1$ in hypoxia versus $23 \pm 3$ in normoxia; $N=4 ; P<0.05$ ).
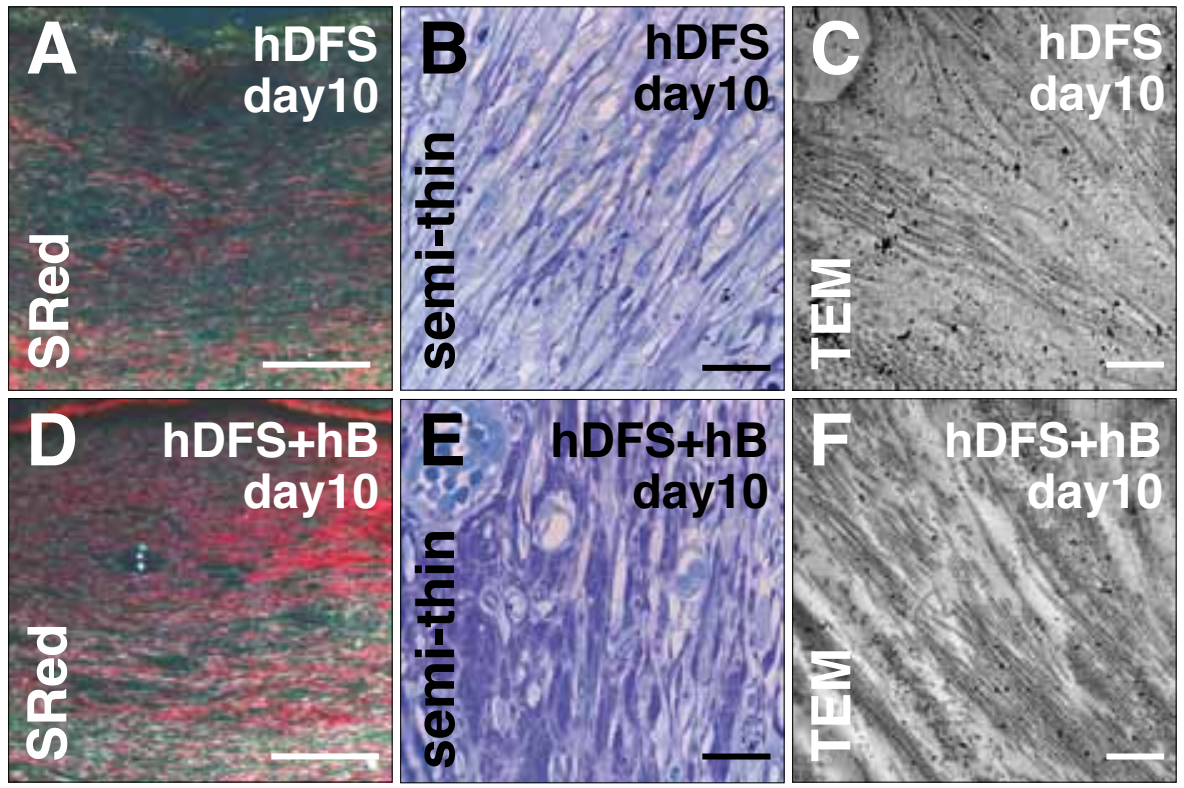

Figure 34. hBOEC improve dermal matrix organisation in hDFS in vivo. Collagen, analysed by Sirius red polarisation microscopy $(A, D)$, semithin sections $(B, E)$ and TEM $(C, F)$, was more aligned in thick bundles in hDFS+hBOEC(hB)- $(D-F)$ compared to hDFS-treated $(A-C)$ wounds. Scale bars: 0.5 $\mu \mathrm{m}$ in $C, F, 20 \mu \mathrm{m}$ in $B, E$ and $75 \mu \mathrm{m}$ in $A, D$. 


\section{Effect of PIGF on keratinocytes and hDFS}

As we found PIGF to be abundantly produced by hBOEC, and given its documented role in wound healing ${ }^{134,173,167}$, we hypothesised that at least some of the beneficial effects of hBOEC on wound healing were mediated by PIGF. Therefore, we used a number of 'gain-of-function' (by using recombinant PIGF) and 'loss-of-function' (by knocking-down the PIGF gene in hBOEC and thereby generating PIGF ${ }^{\mathrm{KD}}$-hBOEC conditioned media, i.e. hBOEC-conditioned media without PIGF) strategies to test the effect of PIGF on hDFS, keratinocytes and hBOEC in vitro. First, we determined whether dermal fibroblasts and keratinocytes, like hBOEC (Table 4), readily expressed FIt-1, the receptor for PIGF. We confirmed previous findings ${ }^{166}$ that both keratinocytes and dermal fibroblasts express Flt-1 protein (Fig. 35A). Using an shRNA-encoding lentivirus (Fig. 9C), PIGF was successfully knocked-down as compared to hBOEC transduced with a virus encoding a scrambled shRNA(Fig. $9 B$ ), as shown by a dramatic decrease in PIGF protein secretion in their growth media(Fig. 35B). While knocking-down PIGF in hBOEC did not significantly change their expression levels of endothelial markers (i.e. Tie-1, Tie-2, Flt-1, KDR, VE-cadherin, CD31, eNOS; data not shown), absence of PIGF expression in hBOEC significantly decreased their proliferation, suggesting a role for PIGF as an autocrine mitogen for hBOEC(Fig. 35C). Importantly, except for PDGF-BB that was slightly lower in PIGF ${ }^{\mathrm{KD}}-\mathrm{hBOEC}$ (\% expression relative to universal human RNA: $930 \pm 93$ in hBOEC transduced with scrambled shRNA versus $685 \pm 49$ in PIGFKD-hBOEC; $N=3$; $P<0.05$ ), PIGF knockdown in hBOEC did not alter the expression of other growth factors (i.e. VEGF-A, $K G F, G M-C S F$, Ang2) or MMP (MMP-1, -2, -9). This means that the observed biological effects were a direct consequence of the absence of PIGF. 

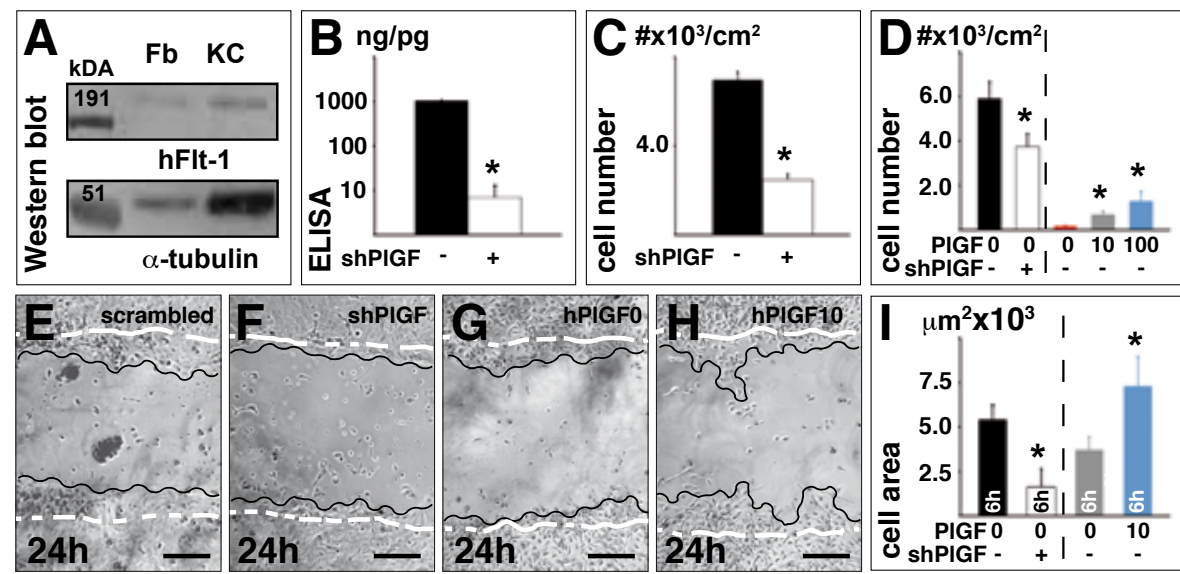

Figure 35. PIGF knock-down in hBOEC decreases their proliferation and effect on keratinocytes. $\boldsymbol{A}$, Western blot revealing the expression of Flt-1 protein on dermal fibroblasts $(\mathrm{Fb})$ and keratinocytes $(\mathrm{KC}) . \alpha$-Tubulin was used as loading control. $B, C$, ELISA on supernatants $(B)$ and proliferation rate (C) of hBOEC cultures transduced with PIGF shRNA (white bars) or scrambled shRNA (black bars) revealing efficient PIGF knock-down and reduced hBOEC proliferation upon PIGF knock-down. *: $P<0.05: N=3-4)$. $D$, Proliferation assay of $\mathrm{KC}$ grown in the presence of $50 \%$ conditioned media from hBOEC treated with scrambled shRNA (black bar), or shPIGF (white bar); normal KC growth media (red bar), KC growth media supplemented with $10 \mathrm{ng} / \mathrm{ml} \mathrm{PIGF} \mathrm{(grey} \mathrm{bar)} \mathrm{or} 100 \mathrm{ng} / \mathrm{ml}$ PIGF (blue bar) revealing more cell expansion (number of cells $/ \mathrm{cm}^{2}$ )upon addition of PIGF and decreased cell expansion upon PIGF knock-down. ${ }^{*}: P<0.05: N=4$.E-I, Wounding assay revealing less migrating keratinocytes $\left(\mathrm{KC}\right.$; area in $\mu \mathrm{m}^{2}$ occupied by migrating $\mathrm{KC}$ in a $1 \mathrm{~mm}$ window at 6 hours in $/$ or at 24 hours in $E-H)$ in the presence of $50 \%$ conditioned media from hBOEC treated with shPIGF $(F$; white bar in $I)$ as compared to $50 \%$ conditioned media from hBOEC treated with scrambled shRNA(E, black bar in I). Migration was however increased in $\mathrm{KC}$ growth media supplemented with $10 \mathrm{ng} / \mathrm{ml} \mathrm{PIGF}(H$, blue bar in I)as compared to without supplemented PIGF (G, grey bar in I); *: $P<0.05: N=4$.

Despite the expression of Flt-1 on dermal fibroblasts (and hence their ability respond to PIGF), increasing or lowering PIGF exposure to hDFS did not alter collagen organisation (data not shown). However, PIGF ${ }^{\mathrm{KD}}$-BOEC conditioned media applied to keratinocytes significantly decreased keratinocyte proliferation (Fig. 35D) and migration(Fig. 35E,F,I) in a scratch wound assay, as compared to conditioned media derived from hBOEC transduced with a scrambled shRNA. Accordingly, adding recombinant PIGF to keratinocytes cultures increased keratinocyte proliferation (Fig. 35D) and migration (Fig. 35G-I)in vitro. Thus, PIGF secreted by hBOEC could - at least in part - be responsible for the effects of hBOEC on vascularisation and reepithelialisation, but perhaps not on dermal matrix organisation. 



\section{Truth is a constant variable. We seek it, we find it, our viewpoint changes, and the truth changes to meet it.}

(William J. Mayo; Annals of Surgery 94: 799 (1931))

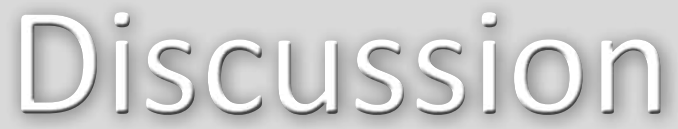





\section{BOEC, an all-round player in wound healing}

Impaired wound healing finds its origin in many deficits. Nevertheless, in cases where wounds tend not to heal properly (e.g. diabetic wounds, pressure sores and vascular ulcers), impaired vascularisation seems a common denominator ${ }^{168}$. Especially in the early inflammation and granulation phases of wound healing, new capillary formation is essential to re-establish the supply of oxygen and nutrients to the wounded tissue ${ }^{169}$. Therefore, our principal objective was to find a suitable strategy to increase wound vascularisation. Besides, when using dermal substitutes to restore the dermal component in large cutaneous defects, quick and stable vascularization is quintessential. We explored the effect of BOEC singly and in combination with an engineered human dermal fibroblast construct on vascularisation in full thickness wound healing. BOEC improved wound vascularisation by direct incorporation into the host vasculature, and via trophic expansion of the host vessel network. The ultimate result was faster re-epithelialisation and better wound matrix organisation (Fig. 36). Most current cell-related wound vascularisation strategies focus on the use of MSC 177,171 . However, they may cause excessive contraction by differentiating into myofibroblasts ${ }^{72}$. Moreover, direct vascular contribution of MSC is debated ${ }^{32,79}$. Early EPC have also proven effects on angiogenesis in vivo, albeit that they do not actively incorporate in vessels. Likewise, in our wound model, we did not find vascular incorporation of early EPC. In addition, it remains questionable whether early EPC can be obtained in sufficient numbers to be used clinically in humans. We opted for peripheral blood-derived BOEC as a source of new vessels. While they may have the molecular signature and functional behaviour of mature EC ${ }^{173}$, we demonstrated that BOEC show several distinctly differential characteristics. Indeed, a thorough characterisation of BOEC involves documentation of their differential behaviour not only from early EPC but also mature EC (Fig. 37). We determined for the first time that the latter difference concerns their proliferative behaviour, as well as other functional aspects, including, for example, secretion of MMP and growth factors. Although others have suggested that BOEC do not contribute to vessel growth by secreting growth factors, these investigators restricted their assays to an in vitro transwell system ${ }^{20}$. We demonstrated an important trophic role for BOEC in vessel growth in vivo where cell-cell contact is critical for optimising this cross-talk (Fig. 36). Importantly, BOEC also secreted significant quantities of factors that facilitated communication with non-EC cells (e.g. keratinocytes and fibroblasts), as shown in our in vitro assays. We believe that these interactions add to the observed effects on re-epithelialisation and matrix organisation in vivo. The difference between mature EC and BOEC is further underscored by the fact that, unlike BOEC, mature EC (e.g. HUVEC) did not efficiently contribute to neo-vascularisation in ischemic hind limbs ${ }^{179,174}$ or in wound healing (this thesis). 


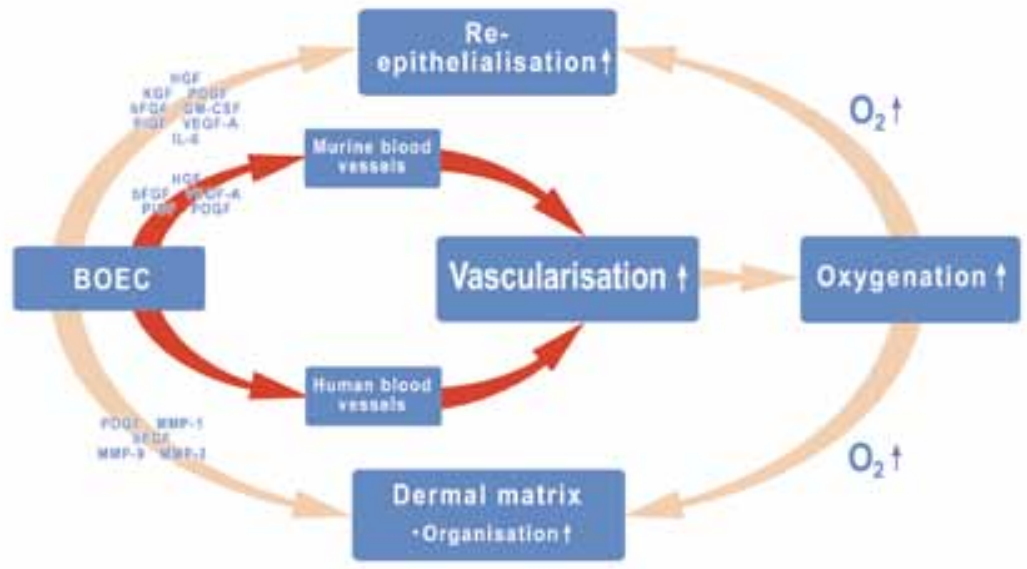

Figure 36. Role of BOEC in wound healing. BOEC induce vascularisation both by direct incorporation and by secretion of angiogenic factors, with subsequent increased wound bed oxygenation, leading to improved epidermal and dermal healing. Besides, BOEC produce factors that stimulate keratinocyte and fibroblast behaviour.

Integration of BOEC in a multilayered fibroblast construct resulted in quick vascularisation and further promoted epithelial coverage and improved matrix organisation. Our in vitro studies suggested that the effects of BOEC on reepithelialisation and matrix organisation were at least partly due to the improved vascularisation of the wound bed, in addition to the growth factor cross-talk with surrounding wound cells, i.e. keratinocytes and fibroblasts (Fig. 36). All of these cells can be harvested from the host and thus offer the possibility of an exclusively autologous and safe approach to tissue engineering for wound repair.

\section{Will the 'true EPC' please stand up?}

One of the objectives of this thesis was to extensively characterise BOEC, a subset of the EPC family, with the intention to better position them in the endothelial (progenitor) cell (EPC) family tree (Fig. 37). Indeed, since the initial description of circulating cells contributing to neo-vascularisation in the seminal paper of Asahara et al. in 1997 (ref. ${ }^{41}$ ), much confusion has arisen on the exact nature and function of EPC. In this milestone article (Fig. 5), they used minimally enriched populations of $\mathrm{CD} 34^{+}$and Flk-1 $1^{+}$cells to culture a fibronectin-adherent cell population that homed to sites of neo-angiogenesis in vivo and these cells were named 'progenitor endothelial cells'. Since then, multiple investigators have used a myriad of isolation protocols to obtain endothelial progenitors. All protocols start from the mononuclear cell fraction 
and obtain cells with endothelial characteristics through culture adherence, surface marker selection or a combination of both.

To illustrate this briefly here, we only discuss the most authoritative publications. Ito et al. ${ }^{175}$ and Hill et al. ${ }^{176}$ used a respectively 24 and 48 hour adherence depletion step on fibronectin-coated dishes to obtain clusters of hematopoietic cells that were surrounded by spindle-shaped cells that expressed endothelial markers but did however not incorporate in vessels in vivo. Vasa et al. ${ }^{177}$ described a different isolation method by plating mononuclear cells on fibronectin- and gelatin-coated dishes and discarding non-adherent cells after 4 days. These cells readily ingested India ink, a functional characteristic consistent with macrophage activity ${ }^{178}$. Adherent cells were stained with ACLDL and UEA-1-lectin and double-positive cells were considered as EPC. In another landmark paper, Lin et al. described delayed massive outgrowth of cells with endothelial characteristics after plating mononuclear cells on collagencoated dishes and named these cells 'Outgrowth Endothelial Cells (OEC)' ${ }^{51}$ (Fig. 5). OEC behave in vivo as real EC, actively integrating in functional vessel networks, unlike the previously mentioned EPC. It is beyond doubt that these different isolation protocols yield entirely different populations of supposed EPC ${ }^{47}$.

Regarding the obvious abundance and variety of cell populations in the EPC family, it is quintessential to find a consensus on and clearly define what EPC really are. As the term is commonly used today, in the broadest interpretation of the publications in the field, EPC are "circulating cells that promote neo-vascularisation in sites of hypoxia". This broad definition encloses multiple cell types that could play important roles in different stages of vascularisation, and this is the cradle of the controversies currently affecting the field ${ }^{47}$. Reaching back to the initial description of EPC as circulating cells that in vivo participate in vasculogenesis ${ }^{41}$, we prefer to narrow the definition of 'true EPC' to "circulating cells that produce endothelial progeny and spontaneously form endothelial tubes in vivo" ${ }^{47}$. Only the OEC described by Lin et al. and ECFC described by Ingram et al. ${ }^{44}$, meet these requirements. To obtain BOEC for our studies, we used a slightly modified isolation protocol as described by Ingram et al. ${ }^{44}$ and demonstrated endothelial characteristics and - most importantly - active incorporation into the host vasculature. We therefore consider BOEC to be progeny of 'true EPC' (Fig. 37). The numerous other types of circulating cells involved in angiogenesis are however beyond this definition. Considering their isolation protocols, we prefer to group them under the common denominator 'early EPC', as they appear much earlier in culture compared to (B)OEC. To obtain early EPC for our comparative studies with BOEC, we used the method described by Hill et al. ${ }^{176}$ and confirmed that these cells display endothelial surface markers, bind UEA-1-lectin, take up AcLDL, but do not form vascular tube-like structures on matrigel in vitro nor do they actively incorporate in the host vasculature. Derived from the hematopoietic lineage, we confirmed that they display hematopoietic markers such as CD45 and CD14 (Fig. 18; Table 4). In some reports, early EPC are described to be able to ingest 
bacteria ${ }^{52}$, thus combining endothelial with monocyte markers and functions. They play an important role in vascular homeostasis by stimulating angiogenesis through the secretion of paracrine factors ${ }^{28,179}$, by degrading the extracellular matrix to allow for angiogenesis or vasculogenesis ${ }^{70,180}$ and possibly by temporarily lining of the vessel wall where the vascular integrity is disrupted ${ }^{27,181}$. There is also evidence that early EPC act in synergy with BOEC during neo-vascularisation ${ }^{55}$.

Thus, according to our comparative studies and our resulting narrow definition, we distinguish two branches in the EPC family tree (Fig. 37), one called 'early EPC' which combines endothelial characteristics with monocyte features, another that we call 'true EPC' given their potential to functionally behave like an EC, that is, becoming part of the endothelial lining of blood vessels. A perhaps ironic consequence of this narrow definition of 'true EPC' is that the original EPC described by Asahara et al. may not be considered as 'true EPC' after all.

\section{On the origin of 'true EPC'}

Apart from the confusion on the identity of EPC, the exact origin of these cells remains also uncertain. Knowing the correct ancestor of EPC is important not only because this may help to better define these cells, but also because it may teach us how to better isolate these cells for therapeutic use and, moreover, the origin of EPC likely predetermines their functional behaviour. A first question is about which cell lineage gives rise to EPC. It has been put forward that the endothelial and hematopoietic lineage share a common progenitor, the so-called 'hemangioblast' (Fig. 37). The idea of a common progenitor of both hematopoietic cells and EC has been suggested as early as in the 1920's ${ }^{182}$. More recently, evidence has arisen on the existence of hemogenic endothelium during embryogenesis. Jaffredo et al. ${ }^{183}$ described the emergence of clusters of hematopoietic cells from the CD45- VEGFR2 ${ }^{+}$EC lining of the aortic lumen during embryogenesis. When these hematopoietic cells bulged into the aortic lumen, all cells became $\mathrm{CD} 45^{+}$. Besides, hematopoietic cells express surface markers common with EC, like CD34, CD31, VEGFR2 and VE-Cadherin ${ }^{184}$. As indirect evidence for the existence of hemangioblast-like cells during adult life, hematopoietic stem cell transplantation in irradiated mice was shown to contribute to vasculogenesis. Indeed, when single HSC were transplanted in animals who subsequently underwent retinal injury, newly formed vessels were of donor origin, suggesting the endothelial progeny of the transplanted HSC ${ }^{185}$. Cogle et al. ${ }^{186}$ used human umbilical cord blood-derived $\mathrm{CD}_{3} 4^{+} \mathrm{HSC}$ in irradiated mice. These cells effectively repopulated the murine hematopoietic system and were found in newly formed vessels upon retinal injury. These findings strongly suggest the existence of a CD $34^{+}$cell with both 'true' endothelial and hematopoietic progeny ${ }^{187}$, even though there is still a chance that 'true EPC contamination' in the hematopoietic stem cell transplant can explain the vasculogenic potential of these repopulated bone marrows. 
How then do the two EPC types defined in the previous chapter relate to such a common precursor? In patients with polycythemia vera, known to bear the JAK2 V617F mutation, Oppliger Leibundgut et al. ${ }^{188}$ succeeded in isolating CD34+CD133+ $\mathrm{KDR}^{+}$early EPC bearing the mutation, once more suggesting that early EPC originate from the hematopoietic arm derived from hemangioblasts. On the other hand, Yoder et al. ${ }^{52}$ were unable to demonstrate the JAK2 V617F mutation in BOEC derived from patients with this mutation, suggesting that the mutation is only committed to the hematopoietic lineage and that BOEC are not derived from this lineage, but perhaps from a more distant mesodermal progenitor (Fig. 37). Nevertheless, it is still possible that 'true EPC' or BOEC derive directly from hemangioblasts and have lost hematopoietic characteristics and gained EC characteristics instead (Fig. 37). While our extensive characterisation of BOEC also excluded a hematopoietic origin for these cells, we did not resolve the issue concerning a hemangioblast or other mesodermal precursor origin of BOEC.

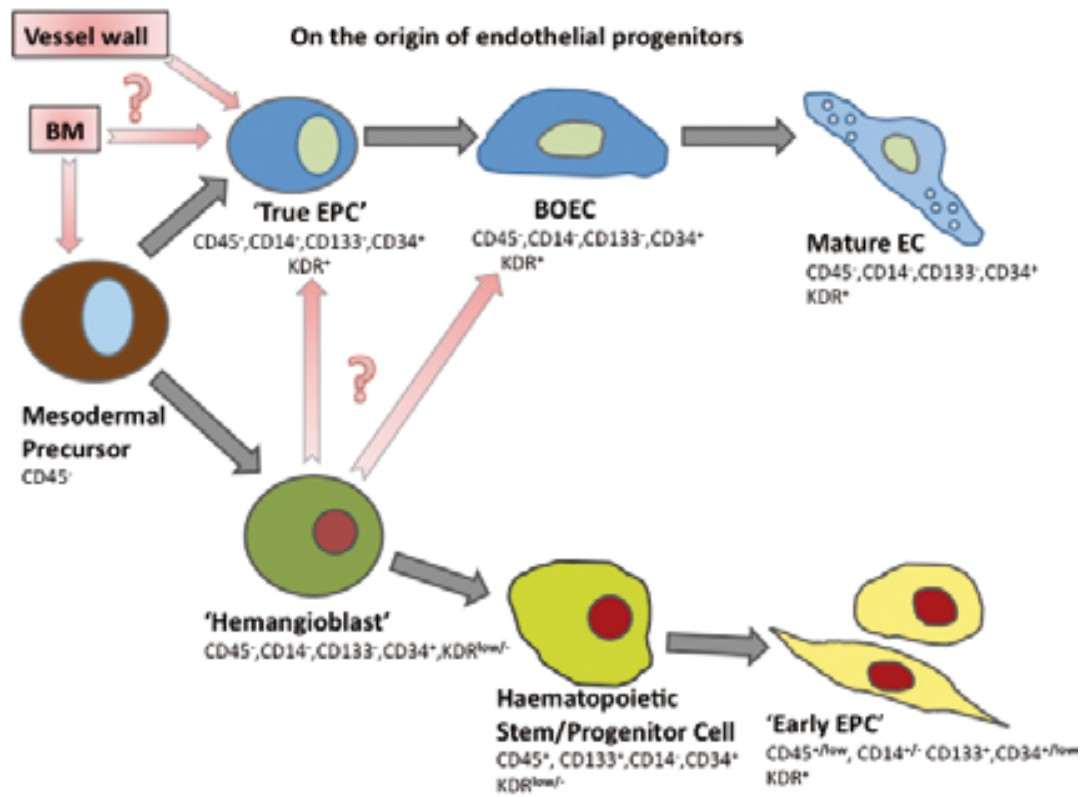

Figure 37. On the origin of EPC. This schematic representation outlines what is known and still uncertain in the confusing field of EPC biology. Only 'true EPC' can give rise to BOEC and subsequently $\mathrm{EC}$, whereas early EPC are derived from the hematopoietic lineage, which is reflected in the expression of cell surface markers. Both BOEC and early EPC are probably derived from a common progenitor, the 'hemangioblast', even though another more distant mesodermal precursor may give rise to 'true EPC' and $B O E C$ without going through a hemangioblast intermediate. Furthermore, in addition to bone marrow $(\mathrm{BM})$ as a source for BOEC, there is evidence for vessel wall-derived EC with high proliferative capacity, suggesting that BOEC may have a vessel wall origin. Our contribution to this schematic outline is that our comparative characterisation studies have firmly established the position of BOEC as being clearly distinct from mature EC and being in the non-hematopoietic branch of the EPC family tree. 
In addition to the question about cell lineage, a second question is related to the anatomical location of the EPC ancestors. In the seminal paper by Lin et al. in which (B)OEC were initially described, they were identified as circulating bone marrowderived cells with high proliferation capacity that contributed to vasculogenesis, as opposed to circulating EC that were of vessel wall origin and had low proliferation capacity ${ }^{51}$. There is however mounting evidence for vessel wall-derived EC with a high proliferative capacity. Using single cell assays, Ingram et al. further defined this vessel wall-derived OEC population and described an entire proliferative hierarchy ranging from non-replicating to very highly proliferative EC ${ }^{196}$. Cord blood-derived BOEC ${ }^{189}$ and peripheral blood-derived BOEC ${ }^{190}$ are however superior to vessel-wall derived EC in terms of vasculogenesis. In summary, there is evidence for a vessel wall-derived EC with high proliferative potential but its relevance for vasculogenesis needs to be determined. Notwithstanding the elaborate identification we performed on BOEC, we were unable to demonstrate whether the BOEC we used for our experiments are vessel wall-derived cells or bone marrow-derived cells, as actually no surface marker can be used to distinguish OEC by their anatomic origin (Fig. 37). Nevertheless, the evidence in the paper by Lin et al. ${ }^{51}$ strongly suggests a bone marrow origin for the BOEC we used.

\section{The quest for the ultimate EPC marker}

A unique surface marker - or a panel of markers - for EPC would allow to directly select the 'true' EPC and - if so desired - expand them ex vivo to BOEC quantities sufficient for clinical application, thereby bypassing the time consuming culture selection step as we described in the Materials \& Methods section. Initially, CD34 and VEGFR2 were used to select EPC ${ }^{41}$. The rationale for using these markers lies in the abovementioned hypothesis that both endothelial and hematopoietic cells originated from a common precursor, the so-called hemangioblast ${ }^{188,}{ }^{185}$. CD34 is widely recognised as the principal marker to isolate hematopoietic stem cells ${ }^{191}$ and is expressed on a range of cells of mesodermal origin, varying from fibroblasts to blood and endothelial cells. VEGFR2 (KDR in humans, Flk-1 in mice) is typically expressed by EC, but also occurs on other cells of the mesodermal lineage, even on hematopoietic stem cells ${ }^{192}$ (Fig. 37). Enrichment for both markers gave rise to cells that homed to and induced angiogenesis in sites of neo-vascularisation ${ }^{41}$. Peichev et al. expanded this panel of markers with a third marker, AC133 (CD133 in humans, prominin-1 in mice), a surface marker on epithelial, hematopoietic and neuronal precursors and cancer cells ${ }^{181}$. As both CD34 and CD133 are down-regulated during hematopoietic cell differentiation, they considered the $\mathrm{CD} 133^{+} \mathrm{CD} 34^{+} \mathrm{KDR}{ }^{+}$cells to be the endothelial progenitor fraction. Indeed, these cells expressed endothelial markers in vitro and were found on cells on the luminal surfaces of implanted left ventricular assist devices in humans. As the combination of these markers gave rise to cells that 
undoubtedly contributed to adult neo-vascularisation, CD34, KDR and CD133 were used in a variety of experiments to identify EPC ${ }^{187}$.

It later appeared however that more than $99 \%$ of the cells expressing these markers were also positive for CD45, a common leukocyte marker, and were unable to give rise to EC that actively contributed to vessel formation in vivo ${ }^{50}$. This elucidates that the progeny of cells expressing hematopoietic markers CD34, KDR and CD133 are monocytic cells with endothelial characteristics that contribute to angiogenesis without active vessel formation and are therefore to be considered 'early EPC' (Fig. 37).

Thus, until now there is no (panel of) surface marker(s) that identifies 'true EPC' and the isolation of BOEC therefore still depends on time consuming culture adherence ${ }^{47}$. When searching for specific EPC-markers, it should also be taken into account that the expression profile of surface markers may change upon ex vivo culture ${ }^{187}$. When we examined the expression of multiple markers over different passages in BOEC, we found no major differences over time, except for CD34 expression that was decreased with senescence, in agreement with findings of others ${ }^{21}$. However by the time of our first RNA sampling (i.e. the first passage), the majority of population doublings is already beyond, assuming that each colony stems from one 'true EPC'. In the absence of a reliable surface marker for isolation of true EPC, it is impossible to judge whether the expression pattern really changes during the transition from true EPC to BOEC. Also, BOEC colonies are derived through adherence on type I collagen in specific endothelial growth medium. It might therefore be possible that BOEC do not really exist as such in vivo, but are an in vitro generated population derived from 'true EPC'. Even though no surface marker for 'true EPC' is identified yet, progress is made in the field of peptide ligands that selectively bind BOEC and have no affinity for HUVEC, lymphocytes or neutrophils ${ }^{193}$. Further research is necessary to distinguish whether these ligands are also able to select the 'true EPC' and have no affinity for 'early EPC'.

Thus, despite more than a decade of EPC research, several issues concerning EPC described in chapter 2-4 of this discussion are still not resolved. Therefore, the main conclusion from all of this is that when working with EPC, it remains of utmost importance to thoroughly identify the cells that are used in an experimental setting, so that other investigators would have a benchmark for comparison. Therefore, we combined extensive expressional, phenotypic and functional characteristics in vitro, together with in vivo vasculogenesis analysis to characterise $B O E C$ and prove the true endothelial identity of BOEC. Based on this extensive characterisation, we propose to position BOEC as direct descendants of 'true EPC', distinct from mature EC that are a step lower on the endothelial lineage hierarchy (Fig. 37). 


\section{Back to the basics of wound healing: vascularisation and oxygenation}

While many revascularisation therapies have merely suggested a link between revascularisation and re-oxygenation, here we directly demonstrated, by means of hypoxy-probe ${ }^{\mathrm{TM}}$ staining, that BOEC-induced revascularisation inversely correlated with the extent of hypoxia. The deleterious effect of long-term hypoxia on wound cell behaviour was further tested by exposing the cells to high or low oxygen fot 10 days. Keratinocyte migration and proliferation were compromised by sustained low oxygen levels. These results appear to be in conflict with earlier studies. O'Toole et al. ${ }^{141}$ described increased keratinocyte migration in an in vitro scratch wound assay, whereas we found keratinocyte migration to be decreased in hypoxia. However, this study evaluated the effect of acute hypoxia on keratinocytes, whereas in our experiments, keratinocytes were cultured in low oxygen conditions for 10 days, which is the duration of our in vivo experiment, and were then subjected to the in vitro scratch wound assay. On the other hand, in support of a positive role for oxygen in keratinocyte behaviour, hyperbaric oxygen treatment is a well-known strategy to improve epithelialisation ${ }^{200,295 .}$

In accordance with the well-known effect of oxygen on collagen hydroxylation ${ }^{144,143}$, we noticed decreased collagen matrix remodelling when DFS were cultured for 10 days in low oxygen conditions. The expression and activity levels of the key matrixmodulating factors, the MMP, may be affected by changes in oxygen levels. Indeed, we (this thesis) and others ${ }^{296}$ have shown in a three-dimensional fibroblast culture that MMP-1 levels are up-regulated by hypoxia. Based on the notion that improved oxygenation enhances healing, several approaches to deliver oxygen to wounds may be considered. While 'exogenous' oxygen delivery can be performed by hyperbaric oxygen therapy ${ }^{294}$, oxygen can also be provided 'from within' by forming new vessels. We have proven BOEC to be effective in wound vascularisation and subsequent oxygenation and we suggest that this in part explains the improved re-epithelialisation and matrix organisation in BOEC-treated wounds.

\section{BOEC: conductor of the wound healing cytokine orchestra?}

Unlike previously assumed ${ }^{20}$, we demonstrated for the first time that BOEC produce a broad range of growth factors and cytokines that are known to be involved in wound healing (Table 7). We specifically analysed BOEC for production of cytokines involved in angiogenesis, re-epithelialisation and matrix production/remodelling. We showed VEGF-A, PIGF, PDGF-BB, Ang-2, MCP-1, bFGF, GM-CSF and HGF to be produced/ expressed by BOEC, all factors that induce angiogenesis (Table 10). Combined action of these factors at least in part explained the angiogenic effect of BOEC in wound healing. 
Interestingly, the expression profile was often complementary which supports the strategy of combining BOEC and DSF in a tissue engineering construct. For instance, we found that Ang-2 and Ang-1 were complementarily expressed by BOEC and DFS, respectively (Table 7),suggesting an autocrine role for BOEC in vascular remodelling through Ang-2 and a supportive role for DFS in stabilising the vessel network through Ang-1. Moreover, it appears that BOEC are much more responsive to the effects of Ang-2 than mature EC, as in the latter the effect of Ang-2 is attenuated due to formation of heterocomplexes between Tie-1 and Tie-2 (ref ${ }^{297}$ )

\begin{tabular}{|c|c|c|c|}
\hline Cytokine & $\begin{array}{l}\text { Effect on } \\
\text { vascularisation }\end{array}$ & $\begin{array}{l}\text { Effect on epidermal } \\
\text { healing }\end{array}$ & $\begin{array}{l}\text { Effect on dermal } \\
\text { healing }\end{array}$ \\
\hline VEGF-A & $\begin{array}{l}\text {-vascularisation } \uparrow^{133} \\
\text {-migration and } \\
\text { proliferation of } E C \uparrow^{133} \\
\text {-survival of } B O E C \uparrow^{204}\end{array}$ & -re-epithelialisation $\uparrow^{12}$ & $\begin{array}{l}\text {-granulation tissue } \\
\text { formation } \uparrow^{133}\end{array}$ \\
\hline PIGF & $\begin{array}{l}\text {-angiogenesis } \uparrow^{136} \\
\text {-vessel maturation } \uparrow \\
\text {-BOEC proliferation } \uparrow^{68}\end{array}$ & $\begin{array}{l}-K C \text { migration } \uparrow \\
-K C \text { proliferation } \uparrow^{68}\end{array}$ & \\
\hline PDGF-BB & $\begin{array}{l}\text {-angiogenesis } \uparrow \\
\text {-vessel maturation } \uparrow^{128}\end{array}$ & -re-epithelialisation $\uparrow^{128}$ & $\begin{array}{l}\text {-production of matrix } \uparrow \\
\text {-matrix remodelling } \uparrow^{128}\end{array}$ \\
\hline Ang-2 & -vascular remodelling $\uparrow^{132}$ & & \\
\hline MCP-1 & -angiogenesis $\uparrow^{127}$ & -re-epithelialisation $\uparrow^{127}$ & \\
\hline bFGF & -angiogenesis $\uparrow^{125}$ & -re-epithelialisation $\uparrow^{125}$ & $\begin{array}{l}\text {-FB proliferation and } \\
\text { migration } \uparrow \\
\text {-matrix protein } \\
\text { synthesis } \uparrow^{125}\end{array}$ \\
\hline KGF & & $\begin{array}{l}\text {-KC proliferation and } \\
\text { migration } \uparrow 125,126\end{array}$ & \\
\hline IL-6 & & $-K C$ proliferation $\uparrow^{9}$ & \\
\hline GM-CSF & -angiogenesis $\uparrow^{128}$ & $-\mathrm{KC}$ proliferation $\uparrow^{128}$ & \\
\hline HGF & -angiogenesis $\uparrow^{129}$ & $-K C$ migration $\uparrow^{129}$ & -regulation of $\mathrm{MMP}^{129}$ \\
\hline
\end{tabular}

Table 10. BOEC-derived cytokines that exert trophic effects on wound healing.

Also, BOEC are more sensitive to the anti-apoptotic and proliferative stimuli of VEGF than HUVEC ${ }^{204}$. It furthermore appears that other factors produced by BOEC may enhance VEGF expression in a paracrine way, such as KGF, bFGF and PDGF ${ }^{128}$. 
Of particular interest is PIGF, which is produced in high amounts by BOEC and acts as a strong autocrine mitogen. Moreover, BOEC in which the expression of PIGF is silenced by shRNA partially lose their angiogenic effect on wound healing in vivo (not shown), in comparison with BOEC transduced with a scrambled-shRNA vector.

Considering epidermal healing, nearly all cytokines we looked for in BOEC, are somehow involved in keratinocyte migration and/or proliferation (Table 10). Accordingly, BOEC conditioned medium stimulated keratinocyte migration and proliferation in vitro. Interestingly, the effect of PIGF on keratinocyte behaviour had not been documented before. We showed both by 'loss-of-function' and 'gain-offunction' experiments that this factor strongly activates keratinocyte migration and proliferation in vitro and re-epithelialisation in vivo (data not shown). Consistent with a keratinocyte response to PIGF, we and others ${ }^{205}$ (Print have demonstrated the expression of the PIGF receptor FIt-1 on keratinocytes. Besides, numerous cytokines made by BOEC are involved in dermal matrix deposition and/or remodelling (Table $10)$.

While others documented an effect of PIGF on dermal fibroblast migration ${ }^{173}$, we did not see a significant effect of recombinant PIGF on collagen organisation in DFS in vitro, nor did we see organisational changes upon exposure of DFS to conditioned media of BOEC in which PIGF expression was knocked-down (data not shown). Therefore, other factors produced by BOEC may be responsible for their favourable effect on dermal matrix organisation. We hypothesise that a favourable MMP expression profile of BOEC (see 7.) may correlate with better matrix organisation.

It is important to emphasise that the role of cytokines in wound healing depends on a delicate balance of those factors and that distortion of this balance in either direction, by loss or over-expression of a specific growth factor, might lead to an impaired healing response. On the other hand, as many growth factors act on multiple components of the wound healing cascade, loss of a specific growth factor might be compensated for by other factors, thus concealing the expected effect. In addition, while a certain factor can be provided by different cell sources in the wound bed, the relative contribution of each of these cell sources can be different. Consistent herewith we found that the presence of DFS in the wound was the ratelimiting factor for re-epithelialisation, likely because some factors (e.g. KGF and HGF) acting on keratinocyte migration and proliferation were more abundantly expressed by DFS compared to BOEC. 


\section{Dermal matrix organisation as a benchmark for dermal maturation}

The exact mechanisms by which the initially formed fibrin cloth is transformed, first in a fibronectin and hyaluronic acid matrix, later in a collagen-proteoglycan matrix and afterwards in an organised network of collagen fibres which is called a scar, is still largely unknown. Collagen deposition starts as early as after 24 hours, but this initially deposited collagen is merely collagen type III and is poorly organised. This is no more than a temporary filling of the defect, as this jumbled matrix is replaced by neatly organised collagen fibres in a basket weave-pattern ${ }^{206}$. In uninjured skin, the dermis consists of neatly woven, densely packed collagen fibres (Fig. 38), which results in skin pliability and elasticity. We found that BOEC had a favourable effect on collagen remodelling, which was even more pronounced in the presence of DFS, resulting in collagen fibres that started to resemble those found in uninjured skin (Fig. 38). Collagen remodelling consists of a delicate balance between destruction and production. In molecular terms, collagen remodelling is mediated through enzymatic digestion by proteinases (mainly MMP), through inhibitors of these MMP (Tissue Inhibitors of MMP or TIMP) and through the production and orderly deposition of collagen fibrils. As we noticed a considerable effect of BOEC on dermal matrix organisation, we considered some of the molecular pathways that can explain this effect.

We suggest that the BOEC-mediated increased matrix organisation is both due to increased tissue oxygenation (and hence the improved function of fibroblasts involved in matrix deposition and remodelling) and the secretion of trophic factors (Fig. 36 and 39). Amongst these factors, some may affect matrix production by fibroblasts (e.g. PDGF-BB and bFGF), while others may affect collagen remodelling directly (such as MMP) or indirectly by controlling MMP expression (e.g. PDGF, KGF, bFGF, MCP-1 or VEGF-A) (Fig. 39). 

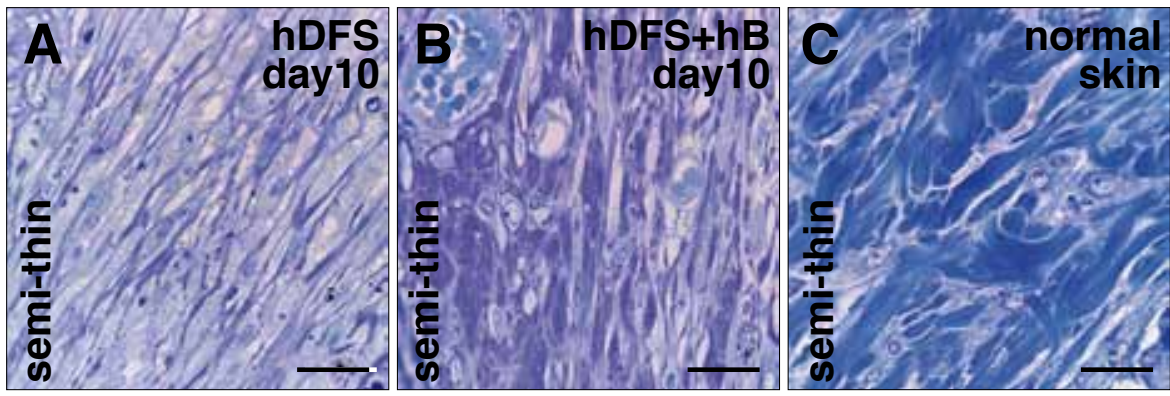

Figure 38. Matrix organisation on semi-thin sections. In the presence of hDFS alone $(A)$, collagen is deposited in between the cells, however the alignment is poor. In contrast, when hDFS are combined with hBOEC $(B)$, collagen alignment is much better and the overall organisation is more close to that of normal skin $(C)$, in which collagen is aligned in very thick, basket-weave patterned collagen bundles. Scale bars: $20 \mu \mathrm{m}$ in all panels.

While TGF- $\beta 1$ was suggested as a potential 'organiser' ${ }^{207}$, BOEC did not synthesise this factor in measurable amounts (data not shown). They did however produce PDGF-BB, although there is no consensus on whether this factor improves collagen organisation ${ }^{207,}{ }^{208}$. Perhaps, MMP-9 expression by BOEC contributed to collagen organisation, since a lack of this MMP results in disordered fibrillogenesis ${ }^{209}$. Furthermore, BOEC produce MMP-2, an enzyme that is presumably involved in matrix remodelling, as it is expressed in the early remodelling phases of wound healing ${ }^{210}$. Moreover, synthesis of MMP is stimulated by FGF, MCP-1, VEGF-A, KGF and PDGF ${ }^{211}$, expressed by BOEC, providing an alternative pathway of increased collagen remodelling by BOEC. BOEC abundantly produce PIGF. However, as mentioned above (see 6.), PIGF did not affect collagen organisation of DFS in vitro.

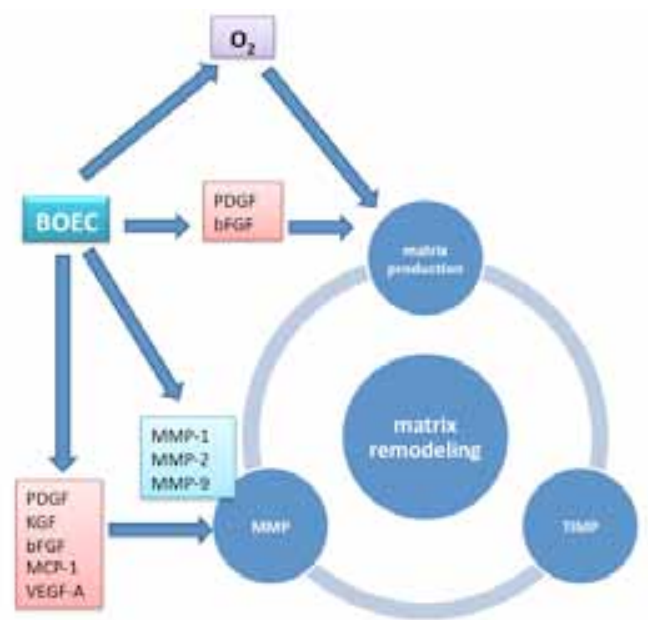

Figure 39. Suggested mechanisms of action of BOEC on matrix remodelling in wound healing. 


\section{DFS-BOEC marriage: will it stand the test of time?}

We already briefly touched upon the remarkably complementary growth factor expression profiles of BOEC and DFS as a strong argument for combining them in a tissue-engineered dermal substitute (see 6.). Importantly, this complementarity was manifested within each category of factors, i.e. those related to vessel growth/ inflammation, those involved in matrix remodelling/deposition and those mediating keratinocyte migration/proliferation (Table 11; Fig. 40).

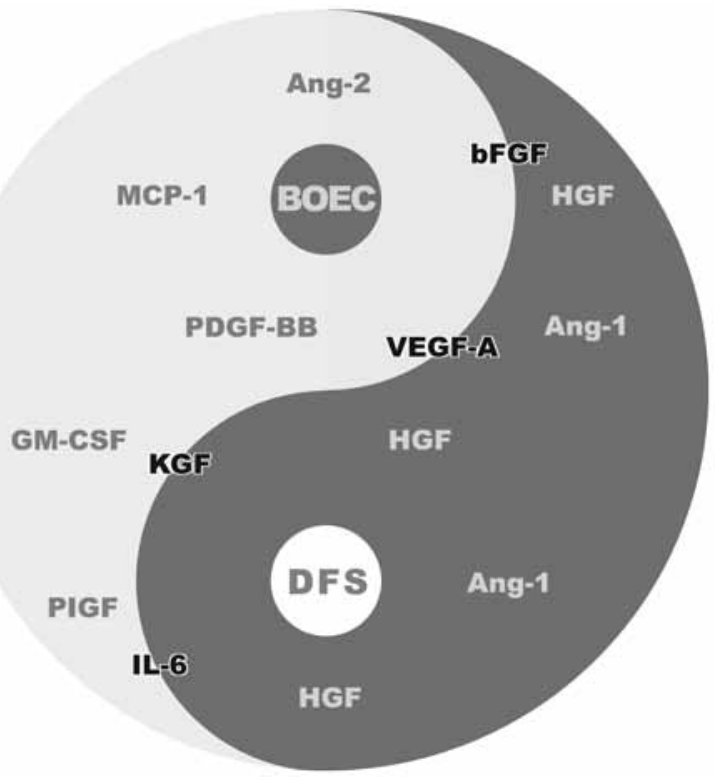

Figure 40: Synergism between cytokines produced by BOEC and DFS.

Below we demonstrate that this complementarity is also reflected in the different processes of wound healing, i.e. wound contraction, re-vascularisation, dermal matrix homeostasis and re-epithelialisation and give some suggestions on how this may relate to differential growth factor expression (Table 11).

\subsection{Wound contraction}

Mice differ from humans during skin wound healing since they are loose-skinned animals. Therefore, unlike in humans, murine wounds heal mostly by contraction, instead of re-epithelialisation ${ }^{212,}{ }^{213}$ and the contraction rate is strain-dependent ${ }^{214}$. In order to mimic human wound healing and to allow evaluation of certain treatments 
on re-epithelialisation, contraction can be limited by physically restraining the skin ('splinting'). This is done by suturing a ring around the wound, which reduces contraction ${ }^{215}$. Nevertheless, there was still a significant degree of contraction in our wound model to also allow an evaluation of the effect of our cell treatment strategies on contraction. While wound contraction may be less pronounced in humans, it does represent a significant problem when it occurs at certain anatomical locations, e.g. the back of the ear ${ }^{216}$. Contraction also occurs after skin grafting ${ }^{217}$ (Fig. 1), which gives rise to detrimental functional/aesthetic results, as in joint regions or in the face. Besides increasing elasticity and augmenting the aesthetic appearance of the skin, reducing wound contraction should therefore be the principal goal of using dermal substitutes.

\begin{tabular}{lll}
\hline Wound contraction & BOEC & DFS \\
\hline \multirow{2}{*}{ Re-vascularisation } & Vasculogenesis & Inhibition \\
& Angiogenesis: early and late & no effect \\
& Vessel stabilisation & Vessel stabilisation \\
\hline \multirow{2}{*}{ Re-epithelialisation } & Speed of epithelial coverage & \\
& & speed of epithelial coverage \\
\hline Dermal matrix & Organisation & \\
\hline
\end{tabular}

Table 11. Complementarity of BOEC and DFS in wound healing.

Many commercially available dermal substitutes are seeded with allogeneic dermal fibroblasts. However, allogeneic fibroblasts induce an inflammatory reaction, display higher numbers of myofibroblasts and have reduced collagen organisation ${ }^{218}$. Moreover, seeding dermal fibroblasts in a dermal equivalent might result in phenotypic changes that might negatively influence dermal regeneration after transplantation ${ }^{151}$. We therefore tried to mimic the composition of natural dermis by superimposing several human dermal fibroblast sheets, which can easily be derived from a donor, and stimulating these sheets to produce their own interstitial matrix over time. We applied these DFS to our mouse wound healing model and noticed decreased contraction. Importantly, BOEC alone did not affect the contraction rate of the wounds, thus the presence of DFS was absolutely required to limit contraction.

The underlying mechanisms for counteracting contraction may be multifactorial. For instance, in accordance to studies where fibroblasts were seeded in dermal substitutes ${ }^{219}$, DFS showed in vivo increased collagen deposition. As total collagen deposition correlates with remaining wound surface, matrix deposition by DFS might provide an explanation for reduced wound contraction. On the other hand, a causal link between myofibroblasts 
and wound contraction has been previously suggested ${ }^{217}$. In our model, the presence of DFS correlated with a reduction in myofibroblast content at the wound edges, thus providing an alternative explanation for reduced wound contraction.

While wound contraction was significantly reduced when using DFS in our wound healing model, we did not look for skin elasticity and aesthetic appearance, as this can only be appreciated later on. Furthermore, we believe the mouse model is not the right animal model to score the latter items, as mice have a naturally elastic skin and the appearance is completely different from human skin.

\subsection{Re-vascularisation}

There is a body of data suggesting that fibroblasts produce several factors that induce angiogenesis (for review, see: ref. ${ }^{128}$ ). This is in agreement with our findings that DFS produce angiogenic growth factors, such as VEGF and bFGF (Table 7). These findings correlated with enhanced revascularisation in DFS treated conditions in vivo (Table 9).

It should however be noted that the increased vascularisation in the DFS-treated condition was limited to the initial healing phases (day 5), whereas this effect had disappeared by day 10 . Therefore, notwithstanding the angiogenic effect of DFS, it makes sense to combine DFS and BOEC, the latter which may guarantee a sustained vascularisation of DFS. In order for vessels to be sustained in the wound bed, it is important that the endothelial layer is stabilised by a smooth muscle or pericyte coat. In agreement with such a stabilising effect, BOEC, unlike DFS, secreted chemoattractant factors for peri-endothelial cells, such as PDGF-BB and PIGF $128,134,136,173$.

\subsection{Re-epithelialisation}

BOEC alone were sufficient to accelerate the epithelial coverage of the wound. This accelerated movement of the epithelial tongues over the wound bed correlated inversely with the number of connexin43 expressing keratinocytes. Connexin 43 is an anchoring molecule that is expressed on basal keratinocytes and down-regulated during keratinocyte migration ${ }^{220}$. Consistent with such an effect, BOEC abundantly expressed/secreted some factors that have been associated with keratinocyte behaviour, such as KGF and GM-CSF. Here we identified another factor, PIGF, which was previously not associated with keratinocyte migration and proliferation.

Nevertheless, the presence of DFS was also sufficient for an improved re-epithelialisation and was to some extent more effective than BOEC. This more dramatic effect may be related to the secretion of higher amounts of keratinocyte-responsive factors (e.g. 
KGF and HGF) and/or by providing a scaffold on top of which keratinocytes could efficiently move forward to the wound centre. On the other hand, the added value of BOEC was to increase the thickness of the epithelial cover, perhaps related to the stimulation of keratinocyte proliferation.

\subsection{Dermal matrix deposition and organisation}

Ultra-structural analysis and histology revealed that DFS in vitro produced their own collagen matrix. In accordance with studies where fibroblasts were seeded in dermal substitutes ${ }^{219}$, DFS showed in vivo increased collagen deposition, whereas collagen organisation was not altered. Matrix organisation by DFS could be improved by increasing oxygen levels and adding BOEC-conditioned media to the growth media. While the BOEC transplantation had a stimulating effect on collagen deposition, this effect was not additive to that of DFS. Thus, while DFS are important for collagen deposition, the BOEC are determinant for organisation of the deposited collagen. In fact combining both in a dermal construct resulted in the formation of a matrix, the abundance and organisation of which started to resemble the dense basket-weave pattern of normal skin (Fig. 38). Exactly which factors in BOEC-conditioned media are responsible for this improved organisation, remains to be determined. However, we suggested a potential mechanism for this by considering a number of growth factors and MMP (see 7.).

\section{Wound repair or wound regeneration?}

In contrast to foetal wound repair, postnatal wound healing always results in scar tissue that is distinct from uninjured skin. The final aim of skin tissue engineering, however, is to create a skin substitute for reconstruction of large skin defects that, after healing, resembles normal skin as much as possible. We wish to underscore that our initial goal in this doctoral project was to test the effects of improved vascularisation on the wound healing process in the earlier stages and that our latest observation end-point (i.e. 10 days after wounding) therefore is well before reaching that final aim of obtaining a normal skin texture. Indeed, when comparing normal skin to wounds treated with the combination of BOEC and DFS, we acknowledge that certain aspects are still quite different, such as the incomplete remodelling of the dermal matrix (see above; Fig. 38), the intense hyper-vascularity of the wound bed, and the presence of an epidermal layer that is quite thicker than the one covering normal skin.

While the high metabolic demands of the initial stages of wound healing require intense vascularisation, the continuous abundance of blood vessels seems undesirable. Therefore, during the later stages, the wound is further extensively remodelled and EC, macrophages and (myo)fibroblasts undergo apoptosis or exit 
from the wound, leaving a scar consisting mostly of collagen and only few cells and vessels ${ }^{221}$.

In our wound model, we did not examine scar tissue at later time points to look for scar maturity or persisting hypervascularisation, but we believe this item should be addressed before clinical application of BOEC in wound healing. In our model, BOEC were only sporadically found in the wound bed at 10 days after wounding. Nevertheless, this temporary presence was however sufficient to sustain the effect on re-vascularisation, perhaps due to a prolonged effect of the trophic factors they released.

On the other hand, the fact that BOEC were no longer abundantly present at day 10 may be compatible with vascular regression in later stages of the wound healing process beyond day 10. The reason why BOEC persisted longer (e.g. 2 to 3 weeks) in wound healing studies reported by others ${ }^{78,67}$ may be related to the use of another genetic background of the recipient mice, the use of another matrix or the continuous replenishment with bone marrow-derived cells from the donor marrow following marrow reconstitution.

Along the same lines, restoration of the epidermal barrier in wound healing should mimic the natural situation. Epithelial tongues in wound healing however display firm keratinocyte proliferation, with several layers of nucleated keratinocytes superimposed, unlike the thin epidermis in non-injured skin. The primary goal of wound healing is the restoration of the epidermal barrier and therefore keratinocyte proliferation and subsequent migration is needed, leading to increased thickness of the epithelial tongues in wound healing. After wound closure, i.e. total re-epithelialisation, the keratinocytes further differentiate gradually towards corneocytes ${ }^{128}$, thus leading to the different epidermal layers (stratum basale, stratum granulosum, stratum spinosum, stratum corneum). Our results clearly demonstrate that BOEC-induced wound oxygenation and growth factor production is likely to stimulate this epidermal healing response. The BOEC-driven increased keratinocyte proliferation and migration we observed in vitro was translated in thicker epithelial tongues in vivo and increased keratinocyte migration (as evidenced by connexin43 down-regulation). However, at our latest observation time point, epithelial coverage of the wound was just completed and the process of keratinocyte differentiation was only just started. Therefore, to fully score, keratinocyte differentiation, it might be interesting to examine the epidermis at a later time point in future studies. 


\section{Is there a backside of the medal?}

We successfully applied BOEC to induce vascularisation in secondary wound healing and in combination with a dermal substitute. In addition, we demonstrated the beneficial effects of BOEC on dermal and epidermal healing. Are BOEC and DFS therefore the ideal candidates for clinical use in chronic wound healing and for vascularisation of all kind of dermal substitutes? Although both cell components appear to be very promising, some considerations must be made.

\subsection{BOEC need time to expand}

Isolating and expanding BOEC is a time-consuming process. It easily takes 6 weeks before BOEC are expanded to a clinical scale, which may impede autologous use of these cells. In case of burn wounds, surgical debridement is classically postponed until clinical evidence has arisen on the depth of the burn - and therefore the likeliness to properly heal without surgical intervention - which is normally after 3 weeks. Moreover, large burns often require staged reconstruction with multiple surgical interventions, and the total treatment often takes months. Thus, in case of burn patients, the longterm procedure for BOEC upscaling is not an impediment. Furthermore, if BOEC are intended to treat chronic wounds, time lag for BOEC expansion neither is a major drawback.

Whereas we almost always succeeded in isolating BOEC (success ratio: 26/28 isolations, in $7 / 8$ individuals), other authors report lower isolation success rates ${ }^{222,223}$. This may be related to the fact that we worked with young donors from whom it may be easier to retrieve BOEC than from older individuals. An unsuccessful isolation can easily delay treatment with 4 weeks, which is regrettable not only for the patient, but also for the hospital and society, in terms of prolonged hospital stay and increased costs related to the new isolation. To optimise BOEC isolation, Kolbe et al. ${ }^{223}$ recently proposed to fit in an additional passaging step at day 7 of BOEC isolation, thereby increasing outgrowth efficiency.

\subsection{The need for animal-related ingredients for cell-based tissue engineering?}

For both the isolation and expansion of BOEC and DFS, FBS is used, which inherently raises questions on disease transmission. In a recent report however, Reinisch et al. ${ }^{224}$ describe a large scale, animal protein-free humanised expansion strategy for BOEC that preserves their proliferation potential. They sidestep the histopaque density centrifugation step by plating whole blood and replace FBS by human pooled platelet lysate from more than 40 donors. This humanised protocol is an important headway towards clinical application of BOEC. Serum-free isolation and culture of 
fibroblasts has lately been described as well ${ }^{225}$. Whether or not the thus obtained fibroblasts are able to be grown in multiple layers, produce matrix in vitro and be transformed in an applicable DFS, needs to be determined. It should however be noted that animal-free protocols are not indispensable for allowance of clinical use. Keratinocyte sheets, for example, are used clinically, even though their expansion and differentiation depends on (irradiated) FBS and cholera toxin.

\subsection{Lower numbers and dysfunctionality of BOEC?}

The number and function of EPC derived from patients with chronic wounds and burns might be altered due to co-morbidity. Patients with chronic wounds often have cardiovascular co-morbidity. Except for an acute ischemic event, where the number of early EPC is increased in the circulating blood ${ }^{226,227}$, chronic cardiovascular disease is known to be related to lower numbers of early EPC and therefore several isolation methods of early EPC are used to predict clinical outcome in cardiovascular disease ${ }^{182,}{ }^{183}$. Heiss et al. ${ }^{228}$ demonstrated that - although the numbers of early EPC are not altered with age - their function, survival, proliferation and migration was significantly reduced in healthy elderly (average 61 year old) people, compared to healthy young (average 25 year old) people. Likewise, dysfunctional early EPC were found in patients with ischemic cardiomyopathy ${ }^{229,230}$. Sugihara et al. ${ }^{231}$ noted decreased incorporation of bone marrow cells derived from elder mice in a mouse hind limb ischemia model.

These findings suggest that the vasculogenic potential of undifferentiated mononuclear cells derived from aged bone marrow is decreased. Equivalent studies examining the in vivo vasculogenic potential of BOEC in pathological conditions have not been carried out yet. Nevertheless, like early EPC, BOEC number/outgrowth appear to be increased in patients with acute myocardial infarction ${ }^{232}$. Moreover, in a pig model, Huang et al. describe that besides the number of colonies, the expansion capacity of BOEC is dramatically increased following acute myocardial ischemia ${ }^{233}$. However, unlike with early EPC, in the absence of acute ischemic events, the number of BOEC is also increased, not decreased. There even appears to be a positive correlation between the severity of coronary stenosis and the number of BOEC ${ }^{234}$. Besides, there are no differences in functional behaviour in vitro between BOEC isolated from patients with coronary artery disease and BOEC isolated from young healthy donors ${ }^{222}$. Thus, from these initial observations it seems that, in contrast to early EPC, 'true EPC' function and release into circulation is stimulated in both acute and chronic pathologic conditions, yielding increased BOEC outgrowth. On the other hand, it appears that even though the number of BOEC is increased in chronic diabetic disease with retinopathy, their function was impaired ${ }^{235}$. Additional studies will be needed to confirm these initial observations. 
The occurrence of burns (which can be considered as an acute event) is associated with increased mobilisation of bone marrow-derived cells. Increased levels of CD $34^{+}$CD $133^{+}$VEGFR2 ${ }^{+}$cells (corresponding to early EPC) were detected upon burn injury ${ }^{236}$. In a porcine burn injury model ${ }^{237}$ and in human burn patients ${ }^{238}$ increased levels of $\mathrm{CD}_{3} 4^{+}$mobilised cells were detected. As BOEC originate from CD $34^{+}$ precursors (Fig. 37), BOEC outgrowth might be increased upon burn injury. However, no reports have been made on BOEC outgrowth or characteristics following burn injuries. We isolated BOEC from a single burn patient and noted increased outgrowth (data not shown), but further research is indispensable to verify this finding.

In summary, as BOEC levels appear to be increased in acute and chronic pathologic conditions that are linked to extensive or chronic wounds, BOEC therapy - combined or not with DFS - seems an appealing approach. We are currently investigating the use of BOEC in pathologic wound healing, such as in diabetes.

\subsection{Off-target vascularisation or tumour formation by BOEC?}

BOEC may theoretically assist in undesired vessel growth in vivo. Depending on the animal model used, type of tumour and time point of analysis, the contribution of bone marrow derived cells to tumour angiogenesis is either limited ${ }^{239,240}$ or substantial ${ }^{241}$. However, when BOEC are considered for clinical use in wound healing, they are ex vivo expanded to large quantities and subsequently applied locally to the wound. It seems therefore unlikely that they will exert considerable systemic effects on any possible malignant process at a distant site. Yet, it appears that in patients with agerelated macular degeneration, BOEC number is significantly increased, in comparison with age-matched non-affected controls ${ }^{242}$. It remains to be determined whether the raised $B O E C$ levels directly give rise to the pathologic vessel formation in the retina, or BOEC mobilisation occurs secondarily to the pathologic circumstances in macular degeneration.

On the other hand, regarding their vast expansion capacity in vitro, BOEC might theoretically give rise to endothelial cell tumours in vivo. Cord blood-derived BOEC are known to have a greater expansion potential compared to peripheral bloodderived BOEC, but also have a high incidence of cytogenetic aberrations whereas no karyotype alterations have been observed in peripheral blood-derived BOEC ${ }^{30}$. Therefore, it is unlikely that peripheral blood-derived BOEC would form tumours upon in vivo application. Furthermore, while BOEC display a large proliferative capacity in vitro, it is questionable whether BOEC maintain this large proliferation capacity to the same extent upon transplantation in vivo. Indeed, we noticed firmly decreased numbers of BOEC 10 days after transplantation to the wound in mice, suggesting that their proliferative features can only be maintained under angiogenic conditions in vitro. 

L'heure de la fin des découvertes ne sonne jamais

(Collette)

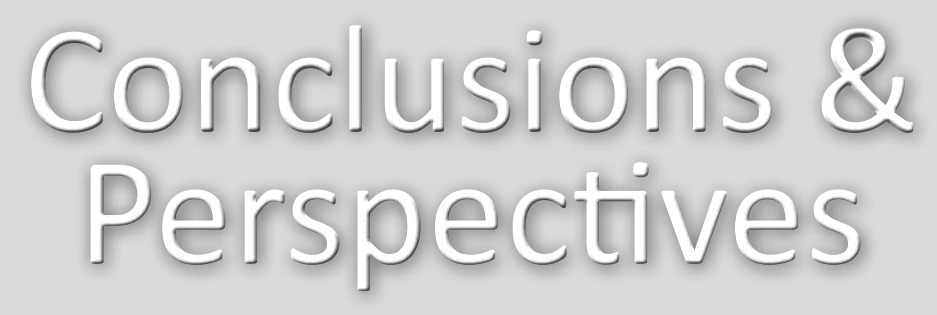





\section{A vascularised three-dimensional skin substitute for clinical use: are we there yet?}

Restoring the epidermis is hardly ever a problem in non-infected, well-debrided wounds, using very thin split thickness grafts or even cultured keratinocyte grafts. Even patients with very extensive full thickness burns can successfully be grafted, reusing donorsites and massively expanding split thickness skin grafts. Nevertheless, cultured keratinocyte grafts often lead to very unstable epidermal healing ${ }^{243}$. However, restoring the deeper layers of skin, i.e. the dermis and the subcutis, is more complicated and therefore we focussed on vascularization of a dermal substitute.

The work in this thesis demonstrates a body of evidence on the beneficial effects of both BOEC and DFS for dermal skin tissue engineering. However, some important steps lay ahead before clinical translation of this concept is feasible.

\subsection{The stop-over in the pig model}

As mentioned above, wound healing in mice is different from human wound healing in terms of composition of skin and degree of contraction. Before making the switch from this mouse model to clinical trials in humans, exploration of the effect of BOEC in a large animal model should be done. As porcine skin much resembles human skin, we focused on isolating porcine BOEC for use in a porcine wound healing model. We successfully isolated porcine BOEC and demonstrated the phenotypic and functional resemblance with human BOEC. We already described application of porcine BOEC to full thickness wounds in pigs, in combination with an autologous platelet-rich plasma gel, and noted firmly increased vascularisation in BOEC treated conditions ${ }^{244}$. Although these data corroborate the findings in our mouse wound healing models further research in pigs will give a decisive answer about the effect of BOEC +/- DFS on dermal and epidermal wound healing. Also, we included no epidermal layer in our skin construct, as the wounds were limited in size and easily reepithelialized spontaneously. This limited the number of clinical groups, which allowed us to clearly dissect out the mechanisms by which BOEC interact with fibroblasts and keratinocytes. It is beyond doubt that an epidermal layer should be included when aiming at restoration of big defects and we therefore included a multilayered keratinocyte sheet with pDFS and pBOEC in our experiments in a porcine model with larger wounds (data not shown). 


\subsection{The temptation of pre-vascularisation}

Considering the in vitro vasculogenic effect of BOEC, another strategy might be to combine BOEC and DFS and culture them for some time in vitro, in order to make a pre-vascularised dermal substitute. This procedure complicates the construction of the dermal template, but has the theoretic advantage of allowing direct inosculation of the pre-formed vessels in the dermal substitute to the host vasculature, whereas in the current setting BOEC have to form vessels upon transplantation in vivo 5 , leading to initial hypoxia of the dermal fibroblasts. However, as hypoxia initially triggers the healing response 143,147, 245 and DFS appear to be quickly vascularised by BOEC, the need for in vitro pre-vascularisation is a matter of dispute. To our knowledge, no BOEC-mediated in vitro pre-vascularisation experiments prior to in vivo transplantation of dermal substitutes have been described. However, the idea of a turnkey vascularised dermal substitute is very appealing and needs further exploration.

\subsection{Digging deeper into engineered skin}

When aiming at restoring full thickness skin, attention should be paid to the subcutaneous fat layer as well, since it is important for thermoregulation, skin elasticity and aesthetics (Fig. 41). MSC of different origins can differentiate into adipocytes ${ }^{104}$, and can thus be used as a source of adipocytes in skin substitutes ${ }^{246}$. However, fat itself is highly vascular and a rich vascular network is essential to support the demands of an adipose construct 101 and a rather thick subcutaneous layer tremendously impedes oxygen supply to the more superficial layers. Adipose tissue-derived MSC could also be differentiated towards angiogenic cells and provide therefore interesting candidates for subcutis tissue engineering. Growth factor therapy has been used for vascularisation of subcutaneous fat grafts, however leading to unstable vessels ${ }^{101}$. Several pre-lamination or pre-fabrication steps will be mandatory to induce quick neovascularisation in the fat tissue in first stage, to allow for survival of the superficial dermal and epidermal layers. Alternatively, subcutaneous fat can be restored after wound repair with a dermal substitute. This can be achieved either by classical fat grafting ${ }^{247}$ or by in vitro expansion of pre-adipocytes and subsequent application under the reconstructed skin ${ }^{246}$. 


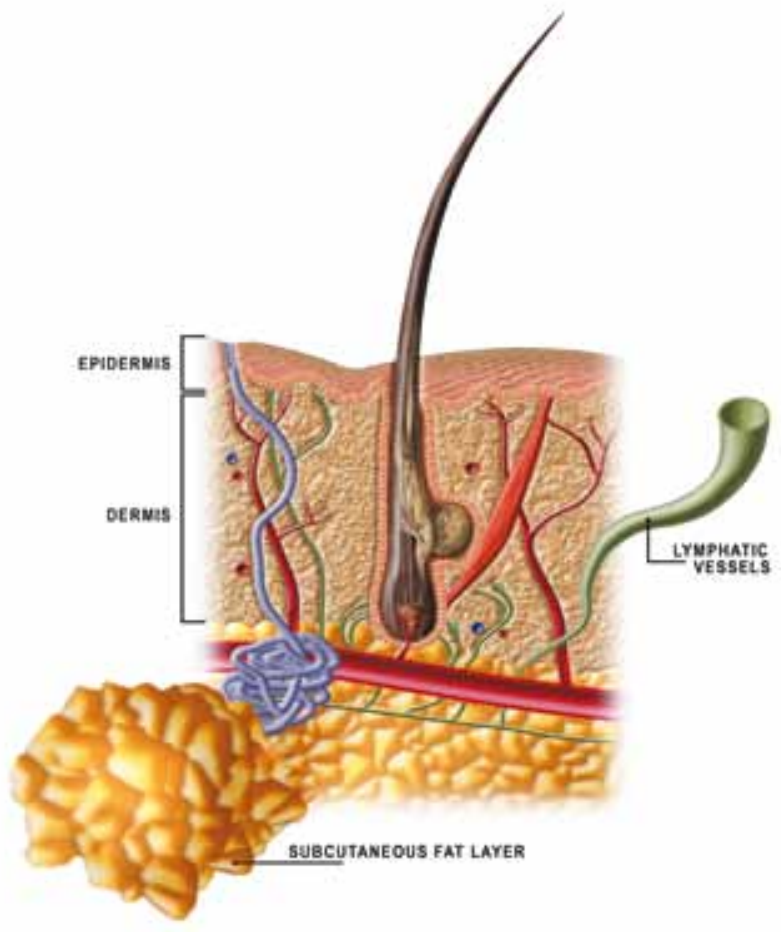

Figure 41. Future challenges in STE. While vascularization is an important cornerstone, future challenges in skin tissue engineering (STE) include the implementation of additional anatomical features into the STE construct, such as lymphatic vessels (in green) and a subcutaneous fat layer (in yellow).

\subsection{Lymphatic vessels: the often neglected counterparts of blood vessels}

In addition to blood vessels, the skin also contains another vascular network, the lymphatic vessels which drain fluid ('lymph') and inflammatory cells from the tissues (Fig. 41). From studies in diabetic mice that feature impaired wound healing, it was shown that the reduced healing process is in part due to lymphatic defects ${ }^{248}$. Impaired lymph drainage may lead to fluid accumulation and lymphedema. Therefore, ideal cell-based approaches for skin tissue engineering may have to consider including a lymphatic network in addition to blood vessels to avoid edema formation. Recently, it was shown that after implantation of AlloDerm, an acellular dermal matrix, host-derived lymphatic EC infiltrated into this matrix after two weeks ${ }^{249}$. So far, this paradigm has however not been tested in an in vivo wound setting using exogenous cells. 


\section{General conclusion}

In this project, a dermal tissue engineering strategy that allows a completely autologous approach is described. BOEC appear to be extremely potent in wound vascularisation. Besides, they exert multiple advantageous effects on dermal and epidermal healing. The dermal substitute consisting of multilayered dermal fibroblast sheets meets the needs of dermal matrix in terms of inhibition of contraction. Integration of BOEC in this dermal substitute combined the positive effects of both components and is therefore very attractive for clinical use. Future studies will have to focus on applying this strategy in a diabetic wound healing model as well as on expanding this vascularised dermal layer with a subcutis and a lymphatic vessel network. 
Conclusions \& Perspectives 

Croire à la médecine serait la suprême folie si n'y pas croire n'en était pas une plus grande, car de cet amoncellement d'erreurs se sont dégagées, à la longue, quelques vérités.

(Marcel Proust, A l'ombre des jeunes filles en fleurs, 1920)

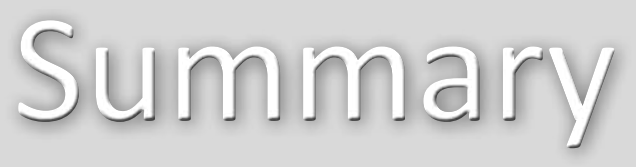



Vascularisation is the cornerstone of wound healing. We therefore aimed to test a revascularisation strategy for wound healing based on the use of human blood outgrowth endothelial cells (hBOEC), a subset of endothelial progenitor cells (EPC), combined or not with a self-assembled human dermal fibroblast sheet (hDFS), intended as a tissue-engineered dermal substitute with inherent vascular potential.

We first thoroughly characterised hBOEC by comparing them to early EPC and human umbilical vein endothelial cells (HUVEC) and firmly established that hBOEC are molecularly and functionally quite distinct from both other cell types. We next tested hBOEC in a preclinical mouse model of wound healing. Unlike HUVEC, hBOEC alone efficiently re-vascularised and re-oxygenated the wound bed, both by active incorporation into new vessels and by trophic stimulation of host angiogenesis. Furthermore, hBOEC alone accelerated epithelial coverage and matrix organisation of the wound bed. In addition, integration of hBOEC in hDFS not only further improved vascularisation, epithelial coverage and matrix organisation, but also prevented excessive wound contraction.

In vitro analyses with $\mathrm{hBOEC}$, fibroblasts and keratinocytes revealed that these effects were both due to growth factor cross-talk and to short cutting hypoxia. These in vitro studies also revealed that hBOEC-derived Placenta Growth Factor (PIGF) was - at least in part - responsible for stimulating keratinocyte migration and proliferation. Furthermore, we found that the growth factor expression profile of hBOEC and hDFS and their effects on re-vascularisation, re-epithelialisation and dermal matrix remodelling was remarkably complementary, which likely explained the success of using them in combination.

Overall, this combined tissue engineering approach paves the way for clinical development of a fully autologous vascularised dermal substitute for patients with large full thickness skin defects. 

Science is but an image of the truth.

(Francis Bacon) 

Vascularisatie is de hoeksteen van wondgenezing. We beoogden daarom een manier te ontwikkelen om de vorming van bloedvaten in een wonde te verbeteren met behulp van een bepaald type Endotheliale Progenitor Cel (EPC), met name human Blood Outgrowth Endothelial Cells (hBOEC). Deze cellen werden, al dan niet in combinatie met dermale fibroblasten enten (hDFS), gebruikt om via tissue engineering een dermaal substituut te genereren dat de capaciteit heeft om bloedvaten te vormen.

Vooreerst hebben we hBOEC zeer grondig gekarakteriseerd door ze te vergelijken met een ander type EPC, met name 'vroege EPC', en met endotheliale cellen uit de navelstrengvene (HUVEC). We hebben aangetoond dat hBOEC uitermate verschillend zijn van deze celtypes, zowel op moleculair als op functioneel niveau. Vervolgens hebben we hBOEC getest in een pre-klinisch wondgenezingsmodel in muizen. In tegenstelling tot HUVEC, waren hBOEC op zich in staat de wonde efficiënt te voorzien van bloedvaten en zuurstof, deels door zelf actief bloedvaten te vormen (vasculogenese), deels door de vorming van bloedvaten door de gastheer te stimuleren (angiogenese). hBOEC zorgden verder voor een snellere genezing van de opperhuid en betere organisatie van matrix proteïnen in de lederhuid. De integratie van $\mathrm{hBOEC}$ in hDFS leidde bovendien niet alleen tot een verdere verbetering van zowel de vascularisatie van het wondbed als de genezing van de opper-en lederhuid, maar verminderde daarnaast de wondcontractie ook aanzienlijk.

Met behulp van in vitro experimenten toonden we aan dat deze effecten enerzijds te wijten waren aan een intensieve groeifactor-communicatie tussen hBOEC, fibroblasten (uit de lederhuid) en keratinocyten (uit de opperhuid), en anderzijds aan het verbeteren van de zuurstofvoorziening van het wondbed. We konden bovendien aantonen dat de door hBOEC aangemaakte groeifactor Placenta Growth Factor (PIGF) - op zijn minst ten dele - verantwoordelijk was voor het gunstige effect op keratinocyten. Daarenboven stelden we vast dat de aanmaak van groeifactoren door hBOEC en hDFS en hun effecten op vascularisatie en genezing van de opper- en lederhuid opmerkelijk complementair was, hetgeen hoogstwaarschijnlijk het succes van de combinatie van beide in wondgenezing verklaart.

Deze gecombineerde aanpak om huid te herstellen effent het pad voor de ontwikkeling van een volledig autoloog, gevasculariseerd, dermaal substituut om patiënten met grote huiddefecten te behandelen. 



\section{Il faut n'appeler science que l'ensemble des recettes qui réussissent toujours. Tout le reste est littérature.}

(Paul Valéry)

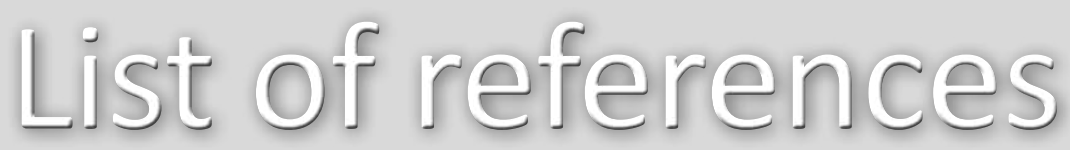


1. Capla JM, Ceradini DJ, Tepper OM, et al. Skin graft vascularization involves precisely regulated regression and replacement of endothelial cells through both angiogenesis and vasculogenesis. Plast Reconstr Surg. 2006;117:836-844.

2. Meagher PJ, Morrison WA. Free fibula flap-donor-site morbidity: case report and review of the literature. J Reconstr Microsurg. 2002;18:465-468; discussion 469-470.

3. Burke JF, Yannas IV, Quinby WC, Jr., et al. Successful use of a physiologically acceptable artificial skin in the treatment of extensive burn injury. Ann Surg. 1981;194:413-428.

4. Gallico GG, 3rd, O'Connor NE, Compton CC, et al. Permanent coverage of large burn wounds with autologous cultured human epithelium. N Engl J Med. 1984;311:448-451.

5. Tremblay PL, Hudon V, Berthod F, et al. Inosculation of tissue-engineered capillaries with the host's vasculature in a reconstructed skin transplanted on mice. Am J Transplant. 2005;5:10021010.

6. Folkman J, Hochberg M. Self-regulation of growth in three dimensions. J Exp Med. 1973;138:745-753.

7. Schuringa $\mathrm{MC}$, Hartman $\mathrm{EH}$, Ruhe $\mathrm{PQ}$, et al. Pedicled prelaminated capsular flaps for coverage of skin defect in a rat model. J Plast Reconstr Aesthet Surg. 2009;62:230-234.

8. Wilcke I, Lohmeyer JA, Liu S, et al. VEGF(165) and bFGF protein-based therapy in a slow release system to improve angiogenesis in a bioartificial dermal substitute in vitro and in vivo. Langenbecks Arch Surg. 2007;392:305-314.

9. Perets $\mathrm{A}$, Baruch $\mathrm{Y}$, Weisbuch $\mathrm{F}$, et al. Enhancing the vascularization of three-dimensional porous alginate scaffolds by incorporating controlled release basic fibroblast growth factor microspheres. J Biomed Mater Res A. 2003;65:489-497.

10. Shea LD, Smiley E, Bonadio J, et al. DNA delivery from polymer matrices for tissue engineering. Nat Biotechnol. 1999;17:551-554.

11. Spiekstra SW, Breetveld M, Rustemeyer T, et al. Wound-healing factors secreted by epidermal keratinocytes and dermal fibroblasts in skin substitutes. Wound Repair Regen. 2007;15:708-717.

12. Dickens S, Vermeulen P, Hendrickx B, et al. Regulable vascular endothelial growth factor165 overexpression by ex vivo expanded keratinocyte cultures promotes matrix formation, angiogenesis, and healing in porcine full-thickness wounds. Tissue Eng Part A. 2008;14:19-27.

13. Kannan RY, Salacinski HJ, Sales K, et al. The roles of tissue engineering and vascularisation in the development of micro-vascular networks: a review. Biomaterials. 2005;26:1857-1875.

14. Dengler TJ, Pober JS. Human vascular endothelial cells stimulate memory but not naive CD8+ T cells to differentiate into CTL retaining an early activation phenotype. J Immunol. 2000;164:51465155.

15. Pober JS, Collins T, Gimbrone MA, Jr., et al. Lymphocytes recognize human vascular endothelial and dermal fibroblast la antigens induced by recombinant immune interferon. Nature. 1983;305:726729.

16. Morhenn VB, Nickoloff BJ. Interleukin-2 stimulates resting human T lymphocytes' response to allogeneic, gamma interferon-treated keratinocytes. J Invest Dermatol. 1987;89:464-468.

17. Davison PM, Bensch K, Karasek MA. Isolation and growth of endothelial cells from the microvessels of the newborn human foreskin in cell culture. J Invest Dermatol. 1980;75:316-321.

18. Gupta K, Ramakrishnan S, Browne PV, et al. A novel technique for culture of human dermal microvascular endothelial cells under either serum-free or serum-supplemented conditions: isolation by panning and stimulation with vascular endothelial growth factor. Exp Cell Res. 1997;230:244-251.

19. Oberringer $M$, Meins $C$, Bubel $M$, et al. A new in vitro wound model based on the co-culture of human dermal microvascular endothelial cells and human dermal fibroblasts. Biol Cell. 2007;99:197-207.

20. Nor JE, Peters MC, Christensen JB, et al. Engineering and characterization of functional human microvessels in immunodeficient mice. Lab Invest. 2001;81:453-463.

21. Supp DM, Wilson-Landy K, Boyce ST. Human dermal microvascular endothelial cells form vascular analogs in cultured skin substitutes after grafting to athymic mice. FASEB J. 2002;16:797-804.

22. Sahota PS, Burn JL, Heaton M, et al. Development of a reconstructed human skin model for angiogenesis. Wound Repair Regen. 2003;11:275-284. 
23. Sorrell JM, Baber MA, Caplan Al. A self-assembled fibroblast-endothelial cell co-culture system that supports in vitro vasculogenesis by both human umbilical vein endothelial cells and human dermal microvascular endothelial cells. Cells Tissues Organs. 2007;186:157-168.

24. Schechner JS, Nath AK, Zheng L, et al. In vivo formation of complex microvessels lined by human endothelial cells in an immunodeficient mouse. Proc Natl Acad Sci U S A. 2000;97:9191-9196.

25. Nienhuis AW, Dunbar CE, Sorrentino BP. Genotoxicity of retroviral integration in hematopoietic cells. Mol Ther. 2006;13:1031-1049.

26. Hannan RL, Kourembanas S, Flanders KC, et al. Endothelial cells synthesize basic fibroblast growth factor and transforming growth factor beta. Growth Factors. 1988;1:7-17.

27. Hirschi KK, Ingram DA, Yoder MC. Assessing identity, phenotype, and fate of endothelial progenitor cells. Arterioscler Thromb Vasc Biol. 2008;28:1584-1595.

28. Rehman J, Li J, Orschell CM, et al. Peripheral blood "endothelial progenitor cells" are derived from monocyte/macrophages and secrete angiogenic growth factors. Circulation. 2003;107:11641169.

29. Sander AL, Jakob H, Henrich D, et al. Systemic Transplantation of Progenitor Cells Accelerates Wound Epithelialization and Neovascularization in the Hairless Mouse Ear Wound Model. J Surg Res. 2009.

30. Corselli M, Parodi A, Mogni M, et al. Clinical scale ex vivo expansion of cord blood-derived outgrowth endothelial progenitor cells is associated with high incidence of karyotype aberrations. Exp Hematol. 2008;36:340-349.

31. Sasaki M, Abe R, Fujita $Y$, et al. Mesenchymal stem cells are recruited into wounded skin and contribute to wound repair by transdifferentiation into multiple skin cell type. J Immunol. 2008;180:2581-2587.

32. $\mathrm{Wu} Y$, Chen L, Scott PG, et al. Mesenchymal stem cells enhance wound healing through differentiation and angiogenesis. Stem Cells. 2007;25:2648-2659.

33. Badillo AT, Redden RA, Zhang L, et al. Treatment of diabetic wounds with fetal murine mesenchymal stromal cells enhances wound closure. Cell Tissue Res. 2007;329:301-311.

34. Kinnaird T, Stabile E, Burnett MS, et al. Marrow-derived stromal cells express genes encoding a broad spectrum of arteriogenic cytokines and promote in vitro and in vivo arteriogenesis through paracrine mechanisms. Circ Res. 2004;94:678-685.

35. Miura M, Miura Y, Padilla-Nash HM, et al. Accumulated chromosomal instability in murine bone marrow mesenchymal stem cells leads to malignant transformation. Stem Cells. 2006;24:1095-1103.

36. Yoshikawa $\mathrm{T}$, Mitsuno $\mathrm{H}$, Nonaka I, et al. Wound therapy by marrow mesenchymal cell transplantation. Plast Reconstr Surg. 2008;121:860-877.

37. Badiavas EV, Falanga V. Treatment of chronic wounds with bone marrow-derived cells. Arch Dermatol. 2003;139:510-516.

38. Miranville A, Heeschen C, Sengenes $C$, et al. Improvement of postnatal neovascularization by human adipose tissue-derived stem cells. Circulation. 2004;110:349-355.

39. Planat-Benard V, Silvestre JS, Cousin B, et al. Plasticity of human adipose lineage cells toward endothelial cells: physiological and therapeutic perspectives. Circulation. 2004;109:656-663.

40. Moon MH, Kim SY, Kim YJ, et al. Human adipose tissue-derived mesenchymal stem cells improve postnatal neovascularization in a mouse model of hindlimb ischemia. Cell Physiol Biochem. 2006;17:279-290.

41. Nakagami H, Maeda K, Morishita R, et al. Novel autologous cell therapy in ischemic limb disease through growth factor secretion by cultured adipose tissue-derived stromal cells. Arterioscler Thromb Vasc Biol. 2005;25:2542-2547.

42. Altman AM, Yan Y, Matthias N, et al. IFATS collection: Human adipose-derived stem cells seeded on a silk fibroin-chitosan scaffold enhance wound repair in a murine soft tissue injury model. Stem Cells. 2009;27:250-258.

43. Rubio D, Garcia-Castro J, Martin MC, et al. Spontaneous human adult stem cell transformation. Cancer Res. 2005;65:3035-3039.

44. Koponen JK, Kekarainen T, S EH, et al. Umbilical cord blood-derived progenitor cells enhance muscle regeneration in mouse hindlimb ischemia model. Mol Ther. 2007;15:2172-2177. 
45. Egana JT, Fierro FA, Kruger S, et al. Use of human mesenchymal cells to improve vascularization in a mouse model for scaffold-based dermal regeneration. Tissue Eng Part A. 2009;15:1191-1200.

46. Aranguren $\mathrm{XL}, \mathrm{McCue} J \mathrm{D}$, Hendrickx $\mathrm{B}$, et al. Multipotent adult progenitor cells sustain function of ischemic limbs in mice. J Clin Invest. 2008;118:505-514.

47. Yamashita J, Itoh $\mathrm{H}$, Hirashima $\mathrm{M}$, et al. Flk1-positive cells derived from embryonic stem cells serve as vascular progenitors. Nature. 2000;408:92-96.

48. Yamahara $\mathrm{K}$, Sone $\mathrm{M}$, Itoh $\mathrm{H}$, et al. Augmentation of neovascularization [corrected] in hindlimb ischemia by combined transplantation of human embryonic stem cells-derived endothelial and mural cells. PLoS One. 2008;3:e1666.

49. Odorico JS, Kaufman DS, Thomson JA. Multilineage differentiation from human embryonic stem cell lines. Stem Cells. 2001;19:193-204.

50. Jaffe EA, Nachman RL, Becker CG, et al. Culture of human endothelial cells derived from umbilical veins. Identification by morphologic and immunologic criteria. J Clin Invest. 1973;52:2745-2756.

51. Tonello $C$, Zavan B, Cortivo $R$, et al. In vitro reconstruction of human dermal equivalent enriched with endothelial cells. Biomaterials. 2003;24:1205-1211.

52. Hudon $\mathrm{V}$, Berthod $\mathrm{F}$, Black $\mathrm{AF}$, et al. A tissue-engineered endothelialized dermis to study the modulation of angiogenic and angiostatic molecules on capillary-like tube formation in vitro. $\mathrm{Br} \mathrm{J}$ Dermatol. 2003;148:1094-1104.

53. Black AF, Berthod $F$, L'Heureux N, et al. In vitro reconstruction of a human capillary-like network in a tissue-engineered skin equivalent. FASEB J. 1998;12:1331-1340.

54. Schechner JS, Crane SK, Wang F, et al. Engraftment of a vascularized human skin equivalent. FASEB J. 2003;17:2250-2256.

55. Zheng L, Dengler TJ, Kluger MS, et al. Cytoprotection of human umbilical vein endothelial cells against apoptosis and CTL-mediated lysis provided by caspase-resistant $\mathrm{Bcl}-2$ without alterations in growth or activation responses. J Immunol. 2000;164:4665-4671.

56. Hacein-Bey-Abina S, von Kalle C, Schmidt M, et al. A serious adverse event after successful gene therapy for X-linked severe combined immunodeficiency. N Engl J Med. 2003;348:255-256.

57. Asahara T, Murohara T, Sullivan A, et al. Isolation of putative progenitor endothelial cells for angiogenesis. Science. 1997;275:964-967.

58. Ingram DA, Caplice NM, Yoder MC. Unresolved questions, changing definitions, and novel paradigms for defining endothelial progenitor cells. Blood. 2005;106:1525-1531.

59. Luttun A, Verfaillie CM. Will the real EPC please stand up? Blood. 2007;109:1795-1796.

60. Ingram DA, Mead LE, Tanaka $\mathrm{H}$, et al. Identification of a novel hierarchy of endothelial progenitor cells using human peripheral and umbilical cord blood. Blood. 2004;104:2752-2760.

61. Awad O, Dedkov El, Jiao C, et al. Differential healing activities of CD34+ and CD14+ endothelial cell progenitors. Arterioscler Thromb Vasc Biol. 2006;26:758-764.

62. Krenning G, van Luyn MJ, Harmsen MC. Endothelial progenitor cell-based neovascularization: implications for therapy. Trends Mol Med. 2009;15:180-189.

63. Suh W, Kim KL, Kim JM, et al. Transplantation of endothelial progenitor cells accelerates dermal wound healing with increased recruitment of monocytes/macrophages and neovascularization. Stem Cells. 2005;23:1571-1578.

64. Case J, Mead LE, Bessler WK, et al. Human CD34+AC133+VEGFR-2+ cells are not endothelial progenitor cells but distinct, primitive hematopoietic progenitors. Exp Hematol. 2007;35:11091118.

65. Lin Y, Weisdorf DJ, Solovey A, et al. Origins of circulating endothelial cells and endothelial outgrowth from blood. J Clin Invest. 2000;105:71-77.

66. Yoder MC, Mead LE, Prater D, et al. Redefining endothelial progenitor cells via clonal analysis and hematopoietic stem/progenitor cell principals. Blood. 2007;109:1801-1809.

67. Shepherd BR, Enis DR, Wang F, et al. Vascularization and engraftment of a human skin substitute using circulating progenitor cell-derived endothelial cells. FASEB J. 2006;20:1739-1741.

68. Hendrickx B, Verdonck K, Van den Berge $S$, et al. Integration of blood outgrowth endothelial cells in dermal fibroblast sheets promotes full thickness wound healing. Stem Cells. 2010:In press.

69. Sieveking DP, Buckle A, Celermajer DS, et al. Strikingly different angiogenic properties of 
endothelial progenitor cell subpopulations: insights from a novel human angiogenesis assay. J Am Coll Cardiol. 2008;51:660-668.

70. Yoon $\mathrm{CH}$, Hur J, Park KW, et al. Synergistic neovascularization by mixed transplantation of early endothelial progenitor cells and late outgrowth endothelial cells: the role of angiogenic cytokines and matrix metalloproteinases. Circulation. 2005;112:1618-1627.

71. Au P, Daheron LM, Duda DG, et al. Differential in vivo potential of endothelial progenitor cells from human umbilical cord blood and adult peripheral blood to form functional long-lasting vessels. Blood. 2008;111:1302-1305.

72. Melero-Martin JM, Khan ZA, Picard A, et al. In vivo vasculogenic potential of human blood-derived endothelial progenitor cells. Blood. 2007;109:4761-4768.

73. Wu X, Rabkin-Aikawa E, Guleserian KJ, et al. Tissue-engineered microvessels on three-dimensional biodegradable scaffolds using human endothelial progenitor cells. Am J Physiol Heart Circ Physiol. 2004;287:H480-487.

74. van Beem RT, Verloop RE, Kleijer M, et al. Blood outgrowth endothelial cells from cord blood and peripheral blood: angiogenesis-related characteristics in vitro. J Thromb Haemost. 2009;7:217-226.

75. Kaushal S, Amiel GE, Guleserian KJ, et al. Functional small-diameter neovessels created using endothelial progenitor cells expanded ex vivo. Nat Med. 2001;7:1035-1040.

76. Thebaud NB, Bareille R, Remy M, et al. Human progenitor-derived endothelial cells vs. venous endothelial cells for vascular tissue engineering: an in vitro study. J Tissue Eng Regen Med.

77. Fuchs S, Ghanaati S, Orth C, et al. Contribution of outgrowth endothelial cells from human peripheral blood on in vivo vascularization of bone tissue engineered constructs based on starch polycaprolactone scaffolds. Biomaterials. 2009;30:526-534.

78. Kung EF, Wang F, Schechner JS. In vivo perfusion of human skin substitutes with microvessels formed by adult circulating endothelial progenitor cells. Dermatol Surg. 2008;34:137-146.

79. Reinisch A, Strunk D. Isolation and animal serum free expansion of human umbilical cord derived mesenchymal stromal cells (MSCs) and endothelial colony forming progenitor cells (ECFCs). J Vis Exp. 2009.

80. Mujaj S, Manton K, Upton Z, et al. Serum-Free Primary Human Fibroblast and Keratinocyte Coculture. Tissue Eng Part A.

81. Herdrich BJ, Lind RC, Liechty KW. Multipotent adult progenitor cells: their role in wound healing and the treatment of dermal wounds. Cytotherapy. 2008;10:543-550.

82. Fu X, Li H. Mesenchymal stem cells and skin wound repair and regeneration: possibilities and questions. Cell Tissue Res. 2009;335:317-321.

83. Chen L, Tredget EE, Wu PY, et al. Paracrine factors of mesenchymal stem cells recruit macrophages and endothelial lineage cells and enhance wound healing. PLoS One. 2008;3:e1886.

84. Caplan Al. Why are MSCs therapeutic? New data: new insight. J Pathol. 2009;217:318-324.

85. Nauta AJ, Fibbe WE. Immunomodulatory properties of mesenchymal stromal cells. Blood. 2007;110:3499-3506.

86. Koc ON, Day J, Nieder M, et al. Allogeneic mesenchymal stem cell infusion for treatment of metachromatic leukodystrophy (MLD) and Hurler syndrome (MPS-IH). Bone Marrow Transplant. 2002;30:215-222.

87. Bartholomew A, Sturgeon C, Siatskas M, et al. Mesenchymal stem cells suppress lymphocyte proliferation in vitro and prolong skin graft survival in vivo. Exp Hematol. 2002;30:42-48.

88. Kobayashi $M$, Spector $M$. In vitro response of the bone marrow-derived mesenchymal stem cells seeded in a type-I collagen-glycosaminoglycan scaffold for skin wound repair under the mechanical loading condition. Mol Cell Biomech. 2009;6:217-227.

89. Markowicz $M$, Koellensperger $E$, Neuss $S$, et al. Human bone marrow mesenchymal stem cells seeded on modified collagen improved dermal regeneration in vivo. Cell Transplant. 2006;15:723732.

90. Moioli EK, Clark PA, Chen M, et al. Synergistic actions of hematopoietic and mesenchymal stem/ progenitor cells in vascularizing bioengineered tissues. PLoS One. 2008;3:e3922.

91. Liu P, Deng Z, Han S, et al. Tissue-engineered skin containing mesenchymal stem cells improves burn wounds. Artif Organs. 2008;32:925-931. 
92. Vojtassak J, Danisovic L, Kubes $M$, et al. Autologous biograft and mesenchymal stem cells in treatment of the diabetic foot. Neuro Endocrinol Lett. 2006;27 Suppl 2:134-137.

93. Falanga $\mathrm{V}$, Iwamoto $\mathrm{S}$, Chartier $\mathrm{M}$, et al. Autologous bone marrow-derived cultured mesenchymal stem cells delivered in a fibrin spray accelerate healing in murine and human cutaneous wounds. Tissue Eng. 2007;13:1299-1312.

94. Schallmoser K, Bartmann C, Rohde E, et al. Human platelet lysate can replace fetal bovine serum for clinical-scale expansion of functional mesenchymal stromal cells. Transfusion. 2007;47:14361446.

95. Bernardo ME, Locatelli F, Fibbe WE. Mesenchymal stromal cells. Ann N Y Acad Sci. 2009;1176:101-117.

96. Cao Y, Sun Z, Liao L, et al. Human adipose tissue-derived stem cells differentiate into endothelial cells in vitro and improve postnatal neovascularization in vivo. Biochem Biophys Res Commun. 2005;332:370-379.

97. Zuk PA, Zhu M, Mizuno $\mathrm{H}$, et al. Multilineage cells from human adipose tissue: implications for cell-based therapies. Tissue Eng. 2001;7:211-228.

98. De Ugarte DA, Morizono K, Elbarbary A, et al. Comparison of multi-lineage cells from human adipose tissue and bone marrow. Cells Tissues Organs. 2003;174:101-109.

99. Amos PJ, Shang H, Bailey AM, et al. IFATS collection: The role of human adipose-derived stromal cells in inflammatory microvascular remodeling and evidence of a perivascular phenotype. Stem Cells. 2008;26:2682-2690.

100. Madonna R, Geng YJ, De Caterina R. Adipose tissue-derived stem cells: characterization and potential for cardiovascular repair. Arterioscler Thromb Vasc Biol. 2009;29:1723-1729.

101. Patrick CW. Breast tissue engineering. Annu Rev Biomed Eng. 2004;6:109-130.

102. Ingram DA, Mead LE, Moore DB, et al. Vessel wall-derived endothelial cells rapidly proliferate because they contain a complete hierarchy of endothelial progenitor cells. Blood. 2005;105:27832786.

103. Traktuev DO, Merfeld-Clauss S, Li J, et al. A population of multipotent CD34-positive adipose stromal cells share pericyte and mesenchymal surface markers, reside in a periendothelial location, and stabilize endothelial networks. Circ Res. 2008;102:77-85.

104. Kern S, Eichler H, Stoeve J, et al. Comparative analysis of mesenchymal stem cells from bone marrow, umbilical cord blood, or adipose tissue. Stem Cells. 2006;24:1294-1301.

105. Lee OK, Kuo TK, Chen WM, et al. Isolation of multipotent mesenchymal stem cells from umbilical cord blood. Blood. 2004;103:1669-1675.

106. Gang EJ, Jeong JA, Han S, et al. In vitro endothelial potential of human UC blood-derived mesenchymal stem cells. Cytotherapy. 2006;8:215-227.

107. Ichim TE, Solano F, Brenes R, et al. Placental mesenchymal and cord blood stem cell therapy for dilated cardiomyopathy. Reprod Biomed Online. 2008;16:898-905.

108. Kim SW, Han H, Chae GT, et al. Successful stem cell therapy using umbilical cord blood-derived multipotent stem cells for Buerger's disease and ischemic limb disease animal model. Stem Cells. 2006;24:1620-1626.

109. Conrad C, Gottgens B, Kinston S, et al. GATA transcription in a small rhodamine $123($ low)CD34(+) subpopulation of a peripheral blood-derived CD34(-)CD105(+) mesenchymal cell line. Exp Hematol. 2002;30:887-895.

110. Jiang $\mathrm{Y}$, Jahagirdar BN, Reinhardt RL, et al. Pluripotency of mesenchymal stem cells derived from adult marrow. Nature. 2002;418:41-49.

111. Aranguren $\mathrm{XL}$, Luttun $\mathrm{A}$, Clavel $\mathrm{C}$, et al. In vitro and in vivo arterial differentiation of human multipotent adult progenitor cells. Blood. 2007;109:2634-2642.

112. Reyes M, Dudek A, Jahagirdar B, et al. Origin of endothelial progenitors in human postnatal bone marrow. J Clin Invest. 2002;109:337-346.

113. Ulloa-Montoya F, Kidder BL, Pauwelyn KA, et al. Comparative transcriptome analysis of embryonic and adult stem cells with extended and limited differentiation capacity. Genome Biol. 2007;8:R163.

114. Highfill SL, Kelly RM, O'Shaughnessy MJ, et al. Multipotent adult progenitor cells can suppress graft-versus-host disease via prostaglandin E2 synthesis and only if localized to sites of allopriming. Blood. 2009;114:693-701. 
115. Luyckx A, De Somer L, Rutgeerts O, et al. Mouse MAPC-mediated immunomodulation: Cell-line dependent variation. Exp Hematol.38:1-2.

116. Shen G, Tsung HC, Wu CF, et al. Tissue engineering of blood vessels with endothelial cells differentiated from mouse embryonic stem cells. Cell Res. 2003;13:335-341.

117. Takahashi K, Yamanaka S. Induction of pluripotent stem cells from mouse embryonic and adult fibroblast cultures by defined factors. Cell. 2006;126:663-676.

118. Yu J, Vodyanik MA, Smuga-Otto K, et al. Induced pluripotent stem cell lines derived from human somatic cells. Science. 2007;318:1917-1920.

119. Choi KD, Yu J, Smuga-Otto K, et al. Hematopoietic and endothelial differentiation of human induced pluripotent stem cells. Stem Cells. 2009;27:559-567.

120. Narazaki G, Uosaki H, Teranishi M, et al. Directed and systematic differentiation of cardiovascular cells from mouse induced pluripotent stem cells. Circulation. 2008;118:498-506.

121. Taura $\mathrm{D}$, Sone $\mathrm{M}$, Homma $\mathrm{K}$, et al. Induction and isolation of vascular cells from human induced pluripotent stem cells--brief report. Arterioscler Thromb Vasc Biol. 2009;29:1100-1103.

122. Duinsbergen $D$, Salvatori $D$, Eriksson $M$, et al. Tumors originating from induced pluripotent stem cells and methods for their prevention. Ann N Y Acad Sci. 2009;1176:197-204.

123. Rolletschek A, Wobus AM. Induced human pluripotent stem cells: promises and open questions. Biol Chem. 2009;390:845-849.

124. Greenhalgh DG. The role of growth factors in wound healing. J Trauma. 1996;41:159-167.

125. Powers CJ, McLeskey SW, Wellstein A. Fibroblast growth factors, their receptors and signaling. Endocr Relat Cancer. 2000;7:165-197.

126. Raja, Sivamani K, Garcia MS, et al. Wound re-epithelialization: modulating keratinocyte migration in wound healing. Front Biosci. 2007;12:2849-2868.

127. Low QE, Drugea IA, Duffner LA, et al. Wound healing in MIP-1alpha(-/-) and MCP-1(-/-) mice. Am J Pathol. 2001;159:457-463.

128. Barrientos S, Stojadinovic O, Golinko MS, et al. Growth factors and cytokines in wound healing. Wound Repair Regen. 2008;16:585-601.

129. Conway K, Price P, Harding KG, et al. The molecular and clinical impact of hepatocyte growth factor, its receptor, activators, and inhibitors in wound healing. Wound Repair Regen. 2006;14:2-10.

130. Heldin $\mathrm{CH}$, Westermark $\mathrm{B}$. Mechanism of action and in vivo role of platelet-derived growth factor. Physiol Rev. 1999;79:1283-1316.

131. Margolis DJ, Morris LM, Papadopoulos M, et al. Phase I study of H5.020CMV.PDGF-beta to treat venous leg ulcer disease. Mol Ther. 2009;17:1822-1829.

132. Gaengel K, Genove G, Armulik A, et al. Endothelial-mural cell signaling in vascular development and angiogenesis. Arterioscler Thromb Vasc Biol. 2009;29:630-638.

133. Bao P, Kodra A, Tomic-Canic $M$, et al. The role of vascular endothelial growth factor in wound healing. J Surg Res. 2009;153:347-358.

134. Carmeliet P, Moons L, Luttun A, et al. Synergism between vascular endothelial growth factor and placental growth factor contributes to angiogenesis and plasma extravasation in pathological conditions. Nat Med. 2001;7:575-583.

135. Autiero M, Waltenberger J, Communi D, et al. Role of PIGF in the intra- and intermolecular cross talk between the VEGF receptors Flt1 and Flk1. Nat Med. 2003;9:936-943.

136. Odorisio T, Schietroma C, Zaccaria ML, et al. Mice overexpressing placenta growth factor exhibit increased vascularization and vessel permeability. J Cell Sci. 2002;115:2559-2567.

137. Ribatti D. The discovery of the placental growth factor and its role in angiogenesis: a historical review. Angiogenesis. 2008;11:215-221.

138. Hunt TK, Twomey P, Zederfeldt B, et al. Respiratory gas tensions and $\mathrm{pH}$ in healing wounds. Am J Surg. 1967;114:302-307.

139. Rodriguez PG, Felix FN, Woodley DT, et al. The role of oxygen in wound healing: a review of the literature. Dermatol Surg. 2008;34:1159-1169.

140. Sen CK. Wound healing essentials: let there be oxygen. Wound Repair Regen. 2009;17:1-18.

141. Ueno C, Hunt TK, Hopf HW. Using physiology to improve surgical wound outcomes. Plast Reconstr Surg. 2006;117:59S-71S. 
142. Silvestre JS. Vascular progenitor cells and diabetes: role in postischemic neovascularisation. Diabetes Metab. 2008;34 Suppl 1:S33-36.

143. O'Toole EA, Marinkovich MP, Peavey CL, et al. Hypoxia increases human keratinocyte motility on connective tissue. J Clin Invest. 1997;100:2881-2891.

144. Udenfriend S. Formation of hydroxyproline in collagen. Science. 1966;152:1335-1340.

145. Prockop DJ, Kivirikko KI, Tuderman L, et al. The biosynthesis of collagen and its disorders (first of two parts). N Engl J Med. 1979;301:13-23.

146. Siddiqui A, Galiano RD, Connors D, et al. Differential effects of oxygen on human dermal fibroblasts: acute versus chronic hypoxia. Wound Repair Regen. 1996;4:211-218.

147. Steinbrech DS, Longaker MT, Mehrara BJ, et al. Fibroblast response to hypoxia: the relationship between angiogenesis and matrix regulation. J Surg Res. 1999;84:127-133.

148. Yannas IV, Burke JF, Orgill DP, et al. Wound tissue can utilize a polymeric template to synthesize a functional extension of skin. Science. 1982;215:174-176.

149. Moiemen NS, Vlachou E, Staiano JJ, et al. Reconstructive surgery with Integra dermal regeneration template: histologic study, clinical evaluation, and current practice. Plast Reconstr Surg. 2006;117:160S-174S.

150. Nolte SV, Xu W, Rennekampff HO, et al. Diversity of fibroblasts--a review on implications for skin tissue engineering. Cells Tissues Organs. 2008;187:165-176.

151. Lamme EN, Van Leeuwen RT, Brandsma K, et al. Higher numbers of autologous fibroblasts in an artificial dermal substitute improve tissue regeneration and modulate scar tissue formation. J Pathol. 2000;190:595-603.

152. Wong $\mathrm{T}, \mathrm{McG}$ rath JA, Navsaria $\mathrm{H}$. The role of fibroblasts in tissue engineering and regeneration. $\mathrm{Br}$ J Dermatol. 2007;156:1149-1155.

153. Kearney JN. Clinical evaluation of skin substitutes. Burns. 2001;27:545-551.

154. MacNeil S. Progress and opportunities for tissue-engineered skin. Nature. 2007;445:874-880.

155. Erdag G, Sheridan RL. Fibroblasts improve performance of cultured composite skin substitutes on athymic mice. Burns. 2004;30:322-328.

156. Seo YK, Song KY, Kim YJ, et al. Wound healing effect of acellular artificial dermis containing extracellular matrix secreted by human skin fibroblasts. Artif Organs. 2007;31:509-520.

157. Werner S, Krieg T, Smola H. Keratinocyte-fibroblast interactions in wound healing. J Invest Dermatol. 2007;127:998-1008.

158. Waelti ER, Inaebnit SP, Rast HP, et al. Co-culture of human keratinocytes on post-mitotic human dermal fibroblast feeder cells: production of large amounts of interleukin 6. J Invest Dermatol. 1992;98:805-808.

159. Marinkovich MP, Keene DR, Rimberg CS, et al. Cellular origin of the dermal-epidermal basement membrane. Dev Dyn. 1993;197:255-267.

160. Toriseva M, Kahari VM. Proteinases in cutaneous wound healing. Cell Mol Life Sci. 2009;66:203-224.

161. Hansbrough JF, Boyce ST, Cooper ML, et al. Burn wound closure with cultured autologous keratinocytes and fibroblasts attached to a collagen-glycosaminoglycan substrate. JAMA. 1989;262:2125-2130.

162. Gilchrest BA, Karassik RL, Wilkins LM, et al. Autocrine and paracrine growth stimulation of cells derived from human skin. J Cell Physiol. 1983;117:235-240.

163. Birch M, Tomlinson A, Ferguson MW. Animal models for adult dermal wound healing. Methods Mol Med. 2005;117:223-235.

164. Gallez B, Baudelet C, Jordan BF. Assessment of tumor oxygenation by electron paramagnetic resonance: principles and applications. NMR Biomed. 2004;17:240-262.

165. Luttun A, Lupu F, Storkebaum E, et al. Lack of plasminogen activator inhibitor-1 promotes growth and abnormal matrix remodeling of advanced atherosclerotic plaques in apolipoprotein E-deficient mice. Arterioscler Thromb Vasc Biol. 2002;22:499-505.

166. Junqueira LC, Bignolas G, Brentani RR. Picrosirius staining plus polarization microscopy, a specific method for collagen detection in tissue sections. Histochem J. 1979;11:447-455.

167. Junqueira LC, Montes GS, Sanchez EM. The influence of tissue section thickness on the study of collagen by the Picrosirius-polarization method. Histochemistry. 1982;74:153-156. 
168. Lokmic Z, Darby IA, Thompson EW, et al. Time course analysis of hypoxia, granulation tissue and blood vessel growth, and remodeling in healing rat cutaneous incisional primary intention wounds. Wound Repair Regen. 2006;14:277-288.

169. Zhong H, Simons JW. Direct comparison of GAPDH, beta-actin, cyclophilin, and 28S rRNA as internal standards for quantifying RNA levels under hypoxia. Biochem Biophys Res Commun. 1999;259:523-526.

170. Nguewa PA, Agorreta J, Blanco D, et al. Identification of importin 8 (IPO8) as the most accurate reference gene for the clinicopathological analysis of lung specimens. BMC Mol Biol. 2008;9:103.

171. LaVan FB, Hunt TK. Oxygen and wound healing. Clin Plast Surg. 1990;17:463-472.

172. Varghese MC, Balin AK, Carter DM, et al. Local environment of chronic wounds under synthetic dressings. Arch Dermatol. 1986;122:52-57.

173. Cianfarani F, Zambruno G, Brogelli L, et al. Placenta growth factor in diabetic wound healing: altered expression and therapeutic potential. Am J Pathol. 2006;169:1167-1182.

174. Failla CM, Odorisio T, Cianfarani F, et al. Placenta growth factor is induced in human keratinocytes during wound healing. J Invest Dermatol. 2000;115:388-395.

175. Singer AJ, Clark RA. Cutaneous wound healing. N Engl J Med. 1999;341:738-746.

176. Bauer SM, Bauer RJ, Velazquez OC. Angiogenesis, vasculogenesis, and induction of healing in chronic wounds. Vasc Endovascular Surg. 2005;39:293-306.

177. Liu Y, Dulchavsky DS, Gao X, et al. Wound repair by bone marrow stromal cells through growth factor production. J Surg Res. 2006;136:336-341.

178. Cha J, Falanga V. Stem cells in cutaneous wound healing. Clin Dermatol. 2007;25:73-78.

179. Smadja DM, Bieche I, Silvestre JS, et al. Bone morphogenetic proteins 2 and 4 are selectively expressed by late outgrowth endothelial progenitor cells and promote neoangiogenesis. Arterioscler Thromb Vasc Biol. 2008;28:2137-2143.

180. Aranguren $\mathrm{XL}$, Verfaillie $\mathrm{CM}$, Luttun $\mathrm{A}$. Emerging hurdles in stem cell therapy for peripheral vascular disease. J Mol Med. 2009;87:3-16.

181. Ito H, Rovira, II, Bloom ML, et al. Endothelial progenitor cells as putative targets for angiostatin. Cancer Res. 1999;59:5875-5877.

182. Hill JM, Zalos G, Halcox JP, et al. Circulating endothelial progenitor cells, vascular function, and cardiovascular risk. N Engl J Med. 2003;348:593-600.

183. Vasa M, Fichtlscherer S, Adler K, et al. Increase in circulating endothelial progenitor cells by statin therapy in patients with stable coronary artery disease. Circulation. 2001;103:2885-2890.

184. Zhang SJ, Zhang H, Wei YJ, et al. Adult endothelial progenitor cells from human peripheral blood maintain monocyte/macrophage function throughout in vitro culture. Cell Res. 2006;16:577-584.

185. Urbich C, Aicher A, Heeschen C, et al. Soluble factors released by endothelial progenitor cells promote migration of endothelial cells and cardiac resident progenitor cells. J Mol Cell Cardiol. 2005;39:733-742.

186. Krenning G, van der Strate BW, Schipper M, et al. CD34+ cells augment endothelial cell differentiation of CD14+ endothelial progenitor cells in vitro. J Cell Mol Med. 2009;13:2521-2533.

187. Peichev M, Naiyer AJ, Pereira D, et al. Expression of VEGFR-2 and AC133 by circulating human CD34(+) cells identifies a population of functional endothelial precursors. Blood. 2000;95:952958.

188. Ribatti D. Hemangioblast does exist. Leuk Res. 2008;32:850-854.

189. Jaffredo T, Gautier R, Eichmann A, et al. Intraaortic hemopoietic cells are derived from endothelial cells during ontogeny. Development. 1998;125:4575-4583.

190. Marshall CJ, Thrasher AJ. The embryonic origins of human haematopoiesis. $\mathrm{Br} J$ Haematol. 2001;112:838-850.

191. Grant MB, May WS, Caballero S, et al. Adult hematopoietic stem cells provide functional hemangioblast activity during retinal neovascularization. Nat Med. 2002;8:607-612.

192. Cogle CR, Wainman DA, Jorgensen ML, et al. Adult human hematopoietic cells provide functional hemangioblast activity. Blood. 2004;103:133-135.

193. Timmermans F, Plum J, Yoder MC, et al. Endothelial progenitor cells: identity defined? J Cell Mol Med. 2009;13:87-102. 
194. Oppliger Leibundgut E, Horn MP, Brunold C, et al. Hematopoietic and endothelial progenitor cell trafficking in patients with myeloproliferative diseases. Haematologica. 2006;91:1465-1472.

195. Nagano M, Yamashita T, Hamada $\mathrm{H}$, et al. Identification of functional endothelial progenitor cells suitable for the treatment of ischemic tissue using human umbilical cord blood. Blood. 2007;110:151-160.

196. Sieminski AL, Hebbel RP, Gooch KJ. Improved microvascular network in vitro by human blood outgrowth endothelial cells relative to vessel-derived endothelial cells. Tissue Eng. 2005;11:13321345.

197. Verfaillie CM. Hematopoietic stem cells for transplantation. Nat Immunol. 2002;3:314-317.

198. Ziegler BL, Valtieri M, Porada GA, et al. KDR receptor: a key marker defining hematopoietic stem cells. Science. 1999;285:1553-1558.

199. Veleva AN, Cooper SL, Patterson C. Selection and initial characterization of novel peptide ligands that bind specifically to human blood outgrowth endothelial cells. Biotechnol Bioeng. 2007;98:306-312.

200. Velazquez OC. Angiogenesis and vasculogenesis: inducing the growth of new blood vessels and wound healing by stimulation of bone marrow-derived progenitor cell mobilization and homing. $J$ Vasc Surg. 2007;45 Suppl A:A39-47.

201. Kairuz E, Upton Z, Dawson RA, et al. Hyperbaric oxygen stimulates epidermal reconstruction in human skin equivalents. Wound Repair Regen. 2007;15:266-274.

202. Kan C, Abe M, Yamanaka M, et al. Hypoxia-induced increase of matrix metalloproteinase-1 synthesis is not restored by reoxygenation in a three-dimensional culture of human dermal fibroblasts. J Dermatol Sci. 2003;32:75-82.

203. Kim KL, Shin IS, Kim JM, et al. Interaction between Tie receptors modulates angiogenic activity of angiopoietin2 in endothelial progenitor cells. Cardiovasc Res. 2006;72:394-402.

204. Bompais H, Chagraoui J, Canron X, et al. Human endothelial cells derived from circulating progenitors display specific functional properties compared with mature vessel wall endothelial cells. Blood. 2004;103:2577-2584.

205. Brown LF, Yeo KT, Berse B, et al. Expression of vascular permeability factor (vascular endothelial growth factor) by epidermal keratinocytes during wound healing. J Exp Med. 1992;176:1375-1379.

206. Carlson MA, Longaker MT. The fibroblast-populated collagen matrix as a model of wound healing: a review of the evidence. Wound Repair Regen. 2004;12:134-147.

207. Pierce GF, Vande Berg J, Rudolph R, et al. Platelet-derived growth factor-BB and transforming growth factor beta 1 selectively modulate glycosaminoglycans, collagen, and myofibroblasts in excisional wounds. Am J Pathol. 1991;138:629-646.

208. Lee JA, Conejero JA, Mason JM, et al. Lentiviral transfection with the PDGF-B gene improves diabetic wound healing. Plast Reconstr Surg. 2005;116:532-538.

209. Kyriakides TR, Wulsin D, Skokos EA, et al. Mice that lack matrix metalloproteinase- 9 display delayed wound healing associated with delayed reepithelization and disordered collagen fibrillogenesis. Matrix Biol. 2009;28:65-73.

210. Soo C, Shaw WW, Zhang X, et al. Differential expression of matrix metalloproteinases and their tissue-derived inhibitors in cutaneous wound repair. Plast Reconstr Surg. 2000;105:638-647.

211. Mauch C. Regulation of connective tissue turnover by cell-matrix interactions. Arch Dermatol Res. 1998;290 Suppl:S30-36.

212. Davidson JM. Wound repair. J Hand Ther. 1998;11:80-94.

213. Senter LH, Legrand EK, Laemmerhirt KE, et al. Assessment of full-thickness wounds in the genetically diabetic mouse for suitability as a wound healing model. Wound Repair Regen. 1995;3:351-358.

214. Gerharz M, Baranowsky A, Siebolts U, et al. Morphometric analysis of murine skin wound healing: standardization of experimental procedures and impact of an advanced multitissue array technique. Wound Repair Regen. 2007;15:105-112.

215. Michaels Jt, Churgin SS, Blechman KM, et $\mathrm{al}$. $\mathrm{db} / \mathrm{db}$ mice exhibit severe wound-healing impairments compared with other murine diabetic strains in a silicone-splinted excisional wound model. Wound Repair Regen. 2007;15:665-670. 
216. Van Winkle W, Jr. Wound contraction. Surg Gynecol Obstet. 1967;125:131-142.

217. Harrison CA, MacNeil S. The mechanism of skin graft contraction: an update on current research and potential future therapies. Burns. 2008;34:153-163.

218. Lamme EN, van Leeuwen RT, Mekkes JR, et al. Allogeneic fibroblasts in dermal substitutes induce inflammation and scar formation. Wound Repair Regen. 2002;10:152-160.

219. Akasaka Y, Ono I, Tominaga A, et al. Basic fibroblast growth factor in an artificial dermis promotes apoptosis and inhibits expression of alpha-smooth muscle actin, leading to reduction of wound contraction. Wound Repair Regen. 2007;15:378-389.

220. Kandyba EE, Hodgins MB, Martin PE. A murine living skin equivalent amenable to live-cell imaging: analysis of the roles of connexins in the epidermis. J Invest Dermatol. 2008;128:1039-1049.

221. Gurtner GC, Werner S, Barrandon Y, et al. Wound repair and regeneration. Nature. 2008;453:314321.

222. Stroncek JD, Grant BS, Brown MA, et al. Comparison of endothelial cell phenotypic markers of late-outgrowth endothelial progenitor cells isolated from patients with coronary artery disease and healthy volunteers. Tissue Eng Part A. 2009;15:3473-3486.

223. Kolbe M, Dohle E, Katerla D, et al. Enrichment of Outgrowth Endothelial Cells in High and Low Colony-Forming Cultures from Peripheral Blood Progenitors. Tissue Eng Part C Methods. 2010.

224. Reinisch A, Hofmann NA, Obenauf AC, et al. Humanized large-scale expanded endothelial colonyforming cells function in vitro and in vivo. Blood. 2009;113:6716-6725.

225. Mujaj S, Manton K, Upton Z, et al. Serum-Free Primary Human Fibroblast and Keratinocyte Coculture. Tissue Eng Part A. 2010.

226. Gill M, Dias $S$, Hattori $K$, et al. Vascular trauma induces rapid but transient mobilization of VEGFR2(+)AC133(+) endothelial precursor cells. Circ Res. 2001;88:167-174.

227. Shintani S, Murohara T, Ikeda H, et al. Mobilization of endothelial progenitor cells in patients with acute myocardial infarction. Circulation. 2001;103:2776-2779.

228. Heiss C, Keymel S, Niesler U, et al. Impaired progenitor cell activity in age-related endothelial dysfunction. J Am Coll Cardiol. 2005;45:1441-1448.

229. Heeschen C, Lehmann R, Honold J, et al. Profoundly reduced neovascularization capacity of bone marrow mononuclear cells derived from patients with chronic ischemic heart disease. Circulation. 2004;109:1615-1622.

230. Assmus B, Fischer-Rasokat U, Honold J, et al. Transcoronary transplantation of functionally competent BMCs is associated with a decrease in natriuretic peptide serum levels and improved survival of patients with chronic postinfarction heart failure: results of the TOPCARE-CHD Registry. Circ Res. 2007;100:1234-1241.

231. Sugihara S, Yamamoto $Y$, Matsuura T, et al. Age-related BM-MNC dysfunction hampers neovascularization. Mech Ageing Dev. 2007;128:511-516.

232. Massa $M$, Campanelli $R$, Bonetti $E$, et al. Rapid and large increase of the frequency of circulating endothelial colony-forming cells (ECFCs) generating late outgrowth endothelial cells in patients with acute myocardial infarction. Exp Hematol. 2009;37:8-9.

233. Huang L, Hou D, Thompson MA, et al. Acute myocardial infarction in swine rapidly and selectively releases highly proliferative endothelial colony forming cells (ECFCs) into circulation. Cell Transplant. 2007;16:887-897.

234. Guven H, Shepherd RM, Bach RG, et al. The number of endothelial progenitor cell colonies in the blood is increased in patients with angiographically significant coronary artery disease. J Am Coll Cardiol. 2006;48:1579-1587.

235. Tan K, Lessieur E, Cutler A, et al. Impaired function of circulating CD34(+) CD45(-) cells in patients with proliferative diabetic retinopathy. Exp Eye Res.

236. Fox A, Smythe J, Fisher N, et al. Mobilization of endothelial progenitor cells into the circulation in burned patients. Br J Surg. 2008;95:244-251.

237. Groger A, Piatkowski A, Grieb G, et al. The mobilisation of mononuclear cells and endothelial progenitor cells after burn injury in a porcine model. Burns. 2009.

238. Piatkowski A, Groger A, Pantel $M$, et al. The extent of thermal injury affects fractions of mononuclear cells. Burns. 2009;35:256-263. 
239. Larrivee B, Niessen K, Pollet I, et al. Minimal contribution of marrow-derived endothelial precursors to tumor vasculature. J Immunol. 2005;175:2890-2899.

240. Gothert JR, Gustin SE, van Eekelen JA, et al. Genetically tagging endothelial cells in vivo: bone marrow-derived cells do not contribute to tumor endothelium. Blood. 2004;104:1769-1777.

241. Patenaude A, Parker J, Karsan A. Involvement of endothelial progenitor cells in tumor vascularization. Microvasc Res. 2010.

242. Thill M, Strunnikova NV, Berna MJ, et al. Late outgrowth endothelial progenitor cells in patients with age-related macular degeneration. Invest Ophthalmol Vis Sci. 2008;49:2696-2708.

243. Wood FM, Kolybaba ML, Allen P. The use of cultured epithelial autograft in the treatment of major burn injuries: a critical review of the literature. Burns. 2006;32:395-401.

244. Vermeulen P, Dickens S, Degezelle K, et al. A plasma-based biomatrix mixed with endothelial progenitor cells and keratinocytes promotes matrix formation, angiogenesis, and reepithelialization in full-thickness wounds. Tissue Eng Part A. 2009;15:1533-1542.

245. Brucker MJ, Gruskin E, Farrell CL, et al. Differential expression of platelet-derived growth factor receptor-beta in an aging model of wound repair. Wound Repair Regen. 1996;4:219-223.

246. Morimoto N, Takemoto S, Kawazoe T, et al. In vivo culturing of a bilayered dermal substitute with adipo-stromal cells. J Surg Res. 2008;146:246-253.

247. Coleman SR. Long-term survival of fat transplants: controlled demonstrations. Aesthetic Plast Surg. 1995;19:421-425.

248. Maruyama K, Asai J, li M, et al. Decreased macrophage number and activation lead to reduced lymphatic vessel formation and contribute to impaired diabetic wound healing. Am J Pathol. 2007;170:1178-1191.

249. Wong AK, Schonmeyr B, Singh P, et al. Histologic analysis of angiogenesis and lymphangiogenesis in acellular human dermis. Plast Reconstr Surg. 2008;121:1144-1152. 
But in science the credit goes to the man who convinces the world, not to the man to whom the idea first occurs.

(Sir Francis Darwin; Eugenics Review 6: I (1914)) 

The child is the father of the man.

(William Wordsworth)

Curriculum vitae 



\section{Contact information}

Official adress: Bayauxlaan 44, 8300 Knokke, Belgium

Mobile Phone: +32 475332078

Email address: benoit_hendrickx@yahoo.fr

\section{Personal information}

Date of birth: July $5^{\text {th }}, 1979$

Place of birth: Knokke, Belgium

Nationality: Belgian

\section{Education}

High school 1991-1997: St Barbara college, Ghent, Belgium, Latin and Greek, magna cum laude.

University: Catholic University of Leuven (KULeuven), Belgium, 1997-2004: medical degree, summa cum laude.

Medical specialisation: plastic, reconstructive and aesthetic surgery, 2004-2011.

\section{$\underline{\text { Peer reviewed publications }}$}

Hendrickx B., Vranckx J.J., Luttun A.

Cell-based vascularization strategies for skin tissue engineering. Tissue Eng Part B. 2010, under revision.

Hendrickx B., Verdonck K., Van den Berge S., Dickens S., Eriksson E., Vranckx J.J., Luttun A.

Integration of Blood Outgrowth Endothelial Cells (BOEC) in dermal fibroblast sheets promotes full thickness wound healing.

Stem Cells, 2010, in press.

Dickens S, Van den Berge S, Hendrickx B, Verdonck K, Luttun A, Vranckx JJ. Nonviral gene therapy strategies for keratinocytes, fibroblasts and endothelial progenitor cells for ex vivo gene transfer to skin wounds. Tissue Eng Part C, 2010, in press.

Vermeulen P., Dickens S., Degezelle K., Van den Berge S., Hendrickx B.,Vranckx JJ. A Plasma-Based Biomatrix Mixed with Endothelial Progenitor Cells and Keratinocytes 
Promotes Matrix Formation, Angiogenesis, and Reepithelialization in Wounds.

Tissue Eng Part A. 2009 Jul;15(7):1533-42.

Dickens S., Vermeulen P., Hendrickx B., Van den berge S., Vranckx JJ.

Regulable $V_{E G F_{165}}$ overexpression by ex vivo expanded keratinocyte cultures promotes matrix formation, angiogenesis and healing in porcine full thickness wounds Tissue Eng Part A. 2008;14(1):19-27,

Aranguren X., McCue J.*, Hendrickx B.*, Zhu X., Du F., Chen E., Pelacho B., Peñuelas I., Abizanda G., Uriz M., Frommer SA, Ross J., Schroeder B., Seaborn M., Adney JR., Hagenbrock J., Harris NH., Zhang Y., Zhang X., Nelson-Holte M., Jiang Y., Billiau A., Chen W., Prósper F., Verfaillie C., Luttun A.

Multipotent adult progenitor cells sustain function of ischemic limbs by stimulating vessel and muscle regeneration.

J Clin Invest, 2008 Feb;118(2):505-14 (* : both authors contributed equally)

\section{Proceedings.}

Vranckx J., Dickens S., Vandenberge S., Verdonck K., Hendrickx B., Luttun A. Characterisation of mesenchymal progenitor cells from processed lipoaspirates Plast. Reconstr. Surg. 124, 679 A., 2009

Hendrickx B., Verdonck K., Van den Berge S., Dickens S., Vranckx J., Luttun A. Human blood outgrowth endothelial cells improve dermal and epidermal wound healing both through reoxygenation and growth factor release.

Plast. Reconstr. Surg. 124, 679 A., 2009

Hendrickx B., Verdonck K.,Dickens S., Van den Berge S., Vranckx JJ.,Luttun A Human blood outgrowth endothelial cells induce dermal matrix organization and epidermal recovery through increased oxygen delivery and trophic factor production. Plast.Reconstr. Surg. 2009, 123 S,58

Verdonck K.,Hendrickx B.,Dickens S., Van den Berge S., Vranckx JJ.,Luttun A Human blood outgrowth endothelial cells combined with human dermal fibroblasts sheets improve wound vascularization and reeptihelialization in a diabetic wound model.

Plast.Reconstr. Surg. 2009, 123 S,82

Dickens S., Vermeulen P., Hendrickx B., Van den Berge S., Vranckx J.J.

Application of an Autologous Mixture of Platelet Rich Plasma, Endothelial Progenitor Cells and Keratinocytes Promotes Matrix organisation, Neo-vascularisation and 
Reepithelialisation in Porcine Full Thickness

Wounds.Tissue Eng Part A (2008) 14 (5):A 700

Van den Berge S., Dickens S., Hendrickx B., Vermeulen P., Vranckx J.J.

The Millefeuille Principle: a New Approach to Tissue-engineered Skin Reconstruction. Tissue Eng Part A (2008) 14 (5): A787-788

Hendrickx B., Van den Berge S., Dickens S., Luttun A., Vranckx J.J.

Enhanced Vascularisation Induced by Endothelial Progenitor Cells (EPCs) Improves Matrix Organisation in Wound Healing.

Tissue Eng Part A (2008) 14 (5):A 848-849

Dickens S., Vermeulen P., Hendrickx B., Van den Berge S., Vranckx J.J.

A biomatrix of autologous Platelet Rich Plasma gel mixed with endothelial progenitor cells and keratinocytes promotes matrix formation, angiogenesis and reepithelialisation in porcine full-thickness wounds.

Plast Reconstr Surg (2008) June 121 (6): S 19

Hendrickx B., Van den Berge S., Dickens S., Luttun A., Vranckx J.J.

Peripheral blood-derived endothelial progenitor cells increase vascularisation in vivo in a 3D dermal substitute

Plast Reconstr Surg (2008) June 121 (6): S 59

Van den Berge S., Dickens S., Hendrickx B., Vermeulen P., Vranckx J.J.

The Millefeuille principle: A new approach to tissue-engineered skin reconstruction.

Plast Reconstr Surg (2008) June 121 (6): S 115

Dickens S., Vermeulen P., Van den Berge S., Hendrickx B., Vranckx J.J. VEGF165 overexpression and membrane type 1 matrix metalloproteinase regulates endothelial cells attraction and polarization for neo-vascularization in porcine wounds. Tissue Eng.13 (7): 1775-1776, 2007

Dickens S., Vermeulen P., Van den Berge S., Hendrickx B., Vranckx J.J. Differentiation capacity of processed lipoaspirates before and after cryopreservation. Tissue Eng.13 (7): 1674-1675, 2007

Van den Berge S., Hendrickx B., Dickens S., Vermeulen P., Vranckx J.J. Prelamination of keratinocytes, fibroblasts, adipocytes and EPC to create an entirely autologous full thickness and vascularised skin substitute: Are we there yet?

Tissue Eng. 13 (7): 1746, 2007 (L'Oreal best paper award TERMIS European Tissue Engineering \& Regenerative Medicine Society Congress London 2007 + Best paper award BVPS Belgian Soc. Plastic Surgery, Leuven, 11/2007) 
Hendrickx B., Dickens S., Vermeulen P., Van den Berge S., Vranckx J.J. Ex vivo expanded endothelial progenitor cells (EPC) for the vascularisation of dermal substitutes.

Tissue Eng. 13 (7): 1692, 2007

Dickens S.,Vermeulen P., Van den Berge S., Hendrickx B.,Vranckx JJ.

In vivo regulable VEGF165 overexpression by ex vivo expanded keratinocyte cell cultures, promotes neovacularization and healing in porcine full thickness wounds.

Plast.Reconstr.Surg.S.,120,515, 2007 

Le vent se lève! . . il faut tenter de vivre! L'air immense ouvre et referme mon livre, La vague en poudre ose jaillir des rocs! Envolez-vous, pages tout éblouies! 

Illustrations:

NV Dream Team, Loonbeek

Print and layout:

\section{4. cassochrome}

Waregem, www.csc.be

\section{C2010 by Benoit Hendrickx}

Alle rechten voorbehouden. Niets uit deze uitgave mag vermenigvuldigd en/of openbaar gemaakt worden door middel van druk, fotokopie, microfilm, elektronisch of op welke andere wijze ook zonder voorafgaande schriftelijke toestemming van de uitgever.

All rights reserved. No part of this publication may be reproduced in any form by print, photo print, microfilm, or any other means without written permission of the publisher. 
